\title{
COVID-19: THREE PHASES OF THE PANDEMIC Dynamics of cases, deaths and tests related to SARS-CoV-2 A systematic analysis of 213 countries and territories
}

\author{
Mikhail Teppone \\ Medical Director, Nano City Holdings Berhad, No. 1, Jalan Sungai Jeluh 32/192, \\ Shah Alam, 40460, Selangor, Malaysia. \\ ORCID: 0000-0002-5366-3188; Email: mikhail.teppone@ gmail.com
}

\begin{abstract}
Mary Jo Takach, No Cure for that Cold?
"The common cold is like the weather - everybody talks about it but no one can do much about it ... A new group of viruses has also been isolated. These are called 'human coronaviruses' and they also cause typical colds... Dr. James Spray estimates that there are at least 200 cold viruses ... The U.S. National Institutes of Health (NIH) closed down its Board of Vaccine Development last year, deciding it was a waste of time and money". [This World (San Francisco, CA), 1972, Oct 8, Sun, N 41: 28].
\end{abstract}

\begin{abstract}
Background

Since the previous study dealing with the case fatality ratio and infection fatality ratio caused by COVID-19, the author has received many comments that prompted the question: "Why did an optimistic prognosis fail?" To answer this question, a more detailed and expanded analysis was carried out in a new study.
\end{abstract}

\section{Objective}

To evaluate the dynamics of monthly numbers of cases, deaths, tests and CFR worldwide during three phases of the COVID-19 pandemic.

\section{Material and Methods}

Twenty three sets of databases, dated the 22nd of each month from January 2020 to November 2021, for 213 countries were collected from the Worldometer website. The number of cases, deaths, tests, CFR, IFR, etc. were counted for various periods of time for each of the 213 countries, then results related to different periods of time were compared.

\section{Results}

The analysis of the main epidemiological parameters led to the division of three phases of the global pandemic evolution. The first phase (23.01.20-22.07.20), the second phase (23.07.2022.01.21) and the third phase (23.01.21-22.07.21) were different in terms of the number of tests performed, new cases, and mortality due to COVID-19. By the end of the second phase, the worldwide statistics indicated the imminent end of the pandemic, but the third phase was characterized by a sudden rise in the number of new cases and deaths that could not be explained rationally. The most dramatic evolution of the epidemic curve occurred in the countries where doctors had successfully battled COVID-19 during the first two phases of the pandemic.

\section{Conclusions}

Despite the decrease in overall death numbers during the latest months analyzed, additional study is necessary to identify the cause for the increase in the number of new cases and deaths during the third phase of the pandemic.

Only complete information regarding the positive and negative impact of medical and non-medical methods of diagnostics and prophylaxis of COVID-19 can help to organize effective measures to end the current pandemic and prevent a similar one from occurring in the future.

Presumably, there are several causes of the negative evolution of the current pandemic, including the overreliance on PCR tests, application of non-specialized premises for quarantine and treatment, decrease in herd and individual immunity, inadequate change of therapeutic protocols, and ignoring prophylactic treatment.

It can be suggested that the use of immunemodulatory drugs, for example, thymus extract or thymic peptides, in groups of people with compromised immunity is necessary, and prophylactic and therapeutic protocols should be changed from the 'standard' types to 'personalized' ones. 


\title{
COVID-19: Three Phases of the Pandemic Dynamics of cases, deaths and tests related to SARS-CoV-2 A systematic analysis of 213 countries and territories
}

\author{
Mikhail Teppone
}

\section{Background}

Since the previous study dealing with the case fatality ratio and infection fatality ratio caused by COVID- $19,{ }^{1}$ the author has received many comments that prompted the question: "Why did an optimistic prognosis fail?" To answer this question, a more detailed and expanded analysis was carried out in a new study.

\section{Introduction}

1.1. Initial and current state of the COVID-19 pandemic narrative

On December 31, 2019, the WHO's China Country Office was alerted to cases of pneumonia of unknown cause detected in Wuhan City, Hubei Province of China. ${ }^{2}$ On January 3, 2020 , the first complete genome of the novel coronavirus (2019-nCoVs) was identified. ${ }^{3}$ On February 11, 2020, a new disease was named "the coronavirus disease 2019" or CoViD-19. ${ }^{4}$ Further studies revealed that SARS-CoV-2 was circulating in various countries, including Spain, ${ }^{5}$ Italy, ${ }^{6}$ India, ${ }^{7}$ France, ${ }^{8}$ USA, ${ }^{9}$ etc. before the outbreak of the epidemic in China. ${ }^{10-11}$

During the initial stage of the COVID-19 pandemic two well-known discoveries, namely: "Unique inserts in the 2019-nCoV spike protein" and "Reduction and functional exhaustion of T-Cells" in COVID-19 patients, ${ }^{12-13}$ were published. These discoveries demonstrated structural and functional similarities between two viruses and prompted a common sense question about the origin of SARS-CoV-2. ${ }^{14-15}$ Questions about the origins of the virus resurfaced in December 2020 when production of an Australian vaccine was discontinued as healthy vaccinated people became tested positive for HIV. ${ }^{16}$

Other issues related to the epidemic curve that had anomalous evolution include:

(1) New patterns:

In April 2020, an expert in epidemiology, Prof. Vladimir Nikiforov mentioned: "if the virus followed the 'classical pattern', the epidemic would have ended within three months, but now we are faced with something new". ${ }^{17}$

(2) Data adjustments:

During the first half of the pandemic there were many cases of local number adjustments that affected the worldwide statistics related to COVID-19. ${ }^{18}$ (Fig. 1)

On April 26, 2020, a cumulative report of Palestine was reduced by 153 cases; on May 25, 2020, a report of Spain was reduced by 1915 deaths; on June 3, 2020, a report of France was reduced by 37,895 cases; on June 20, 2020, a report of Mayotte was reduced by 787 cases; on August 13, 2020, a report of the United Kingdom was reduced by 29,726 cases and by 5,319 deaths. ${ }^{18}$ (Fig. 2 ) (a)

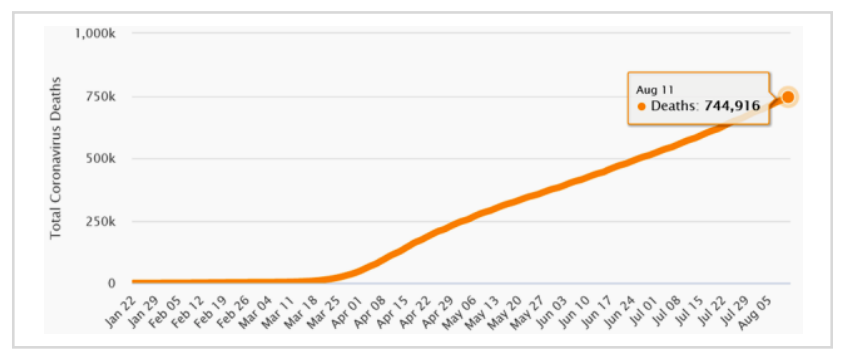

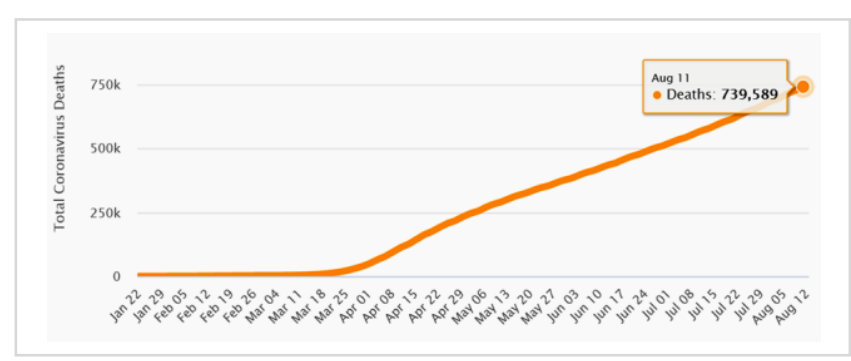

(b)

Figure 1. Worldometer: Adjustment of the worldwide cumulative number of deaths. ${ }^{18}$ These are two screenshots dated (a) August 12, 2020, 07:27 GMT; and (b) August 13, 2020, 09:18 GMT. The total number of deaths decreased suddenly from 744,916 to 739,589 cases. 
(a)

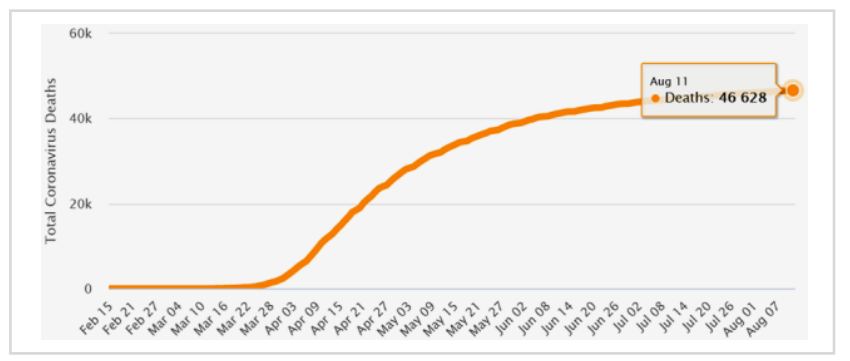

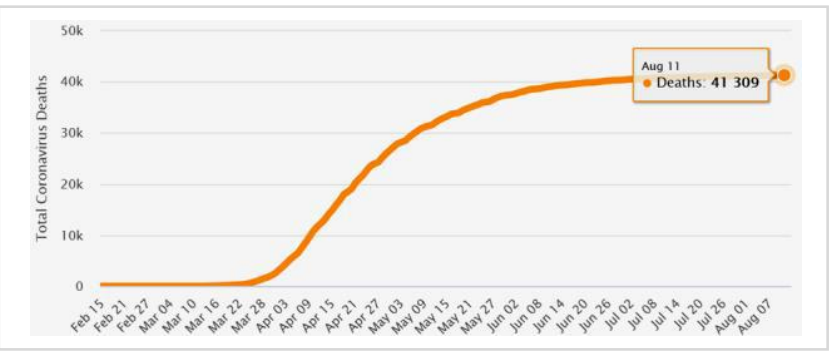

(b)

Figure 2. Worldometer: Adjustment of cumulative number of deaths in the United Kingdom. ${ }^{18}$ These are two screenshots dated (a) August 12, 2020, 07:34 GMT; and (b) August 13, 2020, 08:19 GMT.

(a)

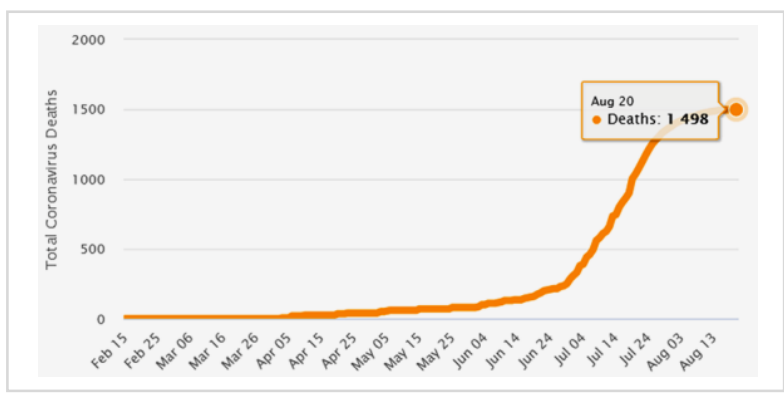

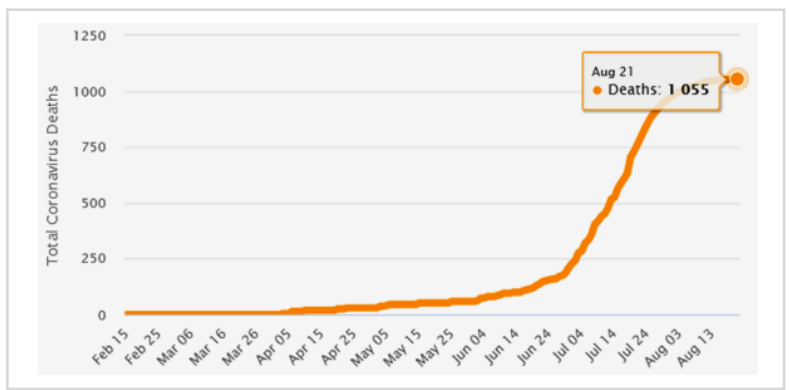

On August 14, 2020, a report of Peru increased by 3,935 new deaths; on August 21, 2020, the number of deaths in Kyrgyzstan, decreased by 443 cases (Fig. 3); on September 24, 2020, a record of Liberia, decreased by 133 cases, ${ }^{18}$ etc. Similar adjustments took place during the later period of the pandemic: on July 2, 2021, it was reported, "Santa Clara County's COVID-19 death toll drops by $505 ",{ }^{20}$ and so on .

\section{(3) A synchronization-like phenomena:}

The first example of synchronization was a weekly mortality cycle which was noticed in June $2020,{ }^{21}$ later this anomalous cycle of daily death became obvious and steady. ${ }^{22}$ A comparison of the percentage of fatal cases on different days of the week for a period of 100 weeks (26.01.2025.12.21) revealed almost identical distribution as described in a previous study. ${ }^{22}$ (Fig. 4).

There is another example of synchronization related to the daily new cases of COVID-19. During 1.5 years of the pandemic the highest number of daily new cases in the United States and the United Kingdom were recorded on the same day, on January 8, 2021; together they accounted for $44 \%$ of the total number of new cases worldwide. ${ }^{18}$

\section{(4) A Strange evolution of the pandemic:}

In mid December 2021, a well-known expert in infectious diseases, Dr. Anthony Fauci, said: "it's 'unprecedented' how long

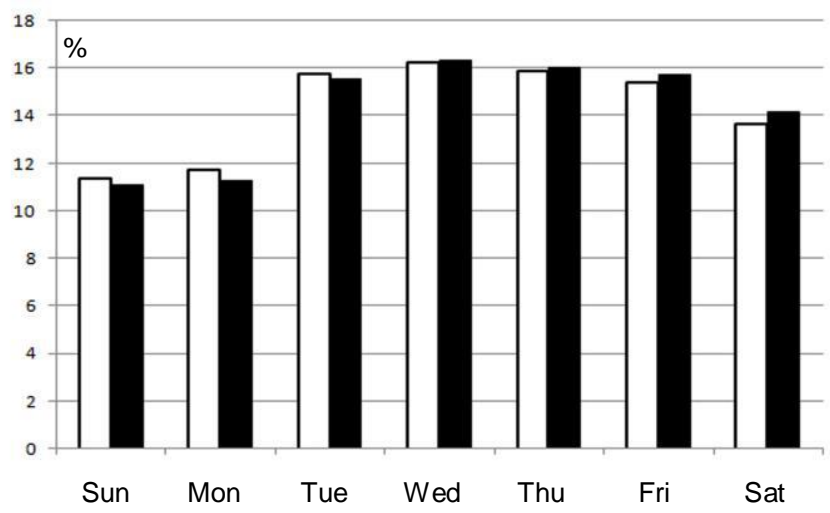

Figure 4. Global mortality due to COVID-19 on various days of the week: white columns - period of 100 weeks (26.01.20-25.12.21); black columns - period of 40 weeks (01.03.20-05.12.20). The vertical axis shows percentages; the horizontal axis shows days of the week.

the COVID-19 pandemic has lasted globally, with many countries enduring multiple major waves of infections since it was declared in March 2020". ${ }^{23}$ So, a pertinent question that pops up is: why, despite unprecedented control measures to prevent the spread of a new virus, including worldwide quarantines, isolation, movement control order, curfew, social distancing, wearing of masks and mass vaccinations, the epidemic curve still has a 'wave-like' or 'propagated' shape instead of going down? Were preventive measures effective, or simply useless or harmful? 
1.2. Infectious disease $-\mathrm{a}$ battle between the human body's defense and viruses or bacteria

History of the battle against viruses and bacteria goes back at least several thousand years. Ancient physicians already knew about external pathogens which could cause acute febrile diseases. They also knew that an evolution of any clinical case depended on the health status of the patient before the onset of the disease, so they talked about "body defense". ${ }^{24}$ At the beginning of modern microbiology the importance of body resistance was confirmed by a Prof. Max von Pettenkofer, who swallowed the entire contents of a tube filled with germs of cholera, but nothing happened to him. So he claimed: "The important thing is the disposition of the individual!" 25

Despite a variety of external pathogens, the human body has a limited number of defense mechanisms, which is accompanied by a few clinical syndromes, consisting of common symptoms, such as fatigue, chills or hot feeling, headache, cough, shortness of breath, nausea, vomiting, diarrhea, skin rashes or discoloration of the skin, etc.

In ancient times the mechanism of the onset of fever was differentiated into two main groups based on the presence of thirst, sweating, chills, or feelings of heat; and the choice of individual treatment was determined by the type of fever. According to the modern view on fever, which commonly accompanies infectious diseases, one can define only two mechanisms leading to an increase in temperature: one is an increase in heat production and another, a decrease in heat transfer, or their combination. ${ }^{26}$ Thus ancient and modern explanations of fever are quite similar, and two types of antipyretic medicines are necessary and sufficient to manage any case of excessive fever. Similarly, 2-3 mechanisms can be identified that underlie each of the remaining symptoms of any acute viral disease, so, a small group of commonly used drugs would be sufficient to manage any infectious diseases, including old and new ones.

After the discovery of bacteria and viruses as a cause of infectious diseases the main emphasis was changed from supporting the body resistance to the fighting against pathogens. It was successful in the majority of bacterial infection cases, but it was almost useless when disease was caused by a virus.

Therefore, if there is no etiotropic treatment, then there is no need to identify a new viral disease. All pharmaceutical and non-pharmaceutical therapeutic modalities would be addressed to the well-known protective mechanisms of the human body, and treatment should be based on the leading syndromes and symptoms, using the principle called off label therapy.
1.3. The classical foundation of medicine is wisdom, which is evergreen

Multiplication tables, the Pythogorean theorem, Archimedes' law, ideas of inertia and atomic structure of matter appeared several thousand years ago. In the course of history ancient knowledge developed and improved until it turned into higher Mathematics and quantum Physics, however, the multiplication table, Archimedes' law and other basic knowledge have not lost their value in our time.

Similarly, ancient medicine also had its own canon, preserved within the framework of traditional Chinese medicine. The most important law of that canon was postulate: to strengthen or reinforce that which is deficient, and drain or sedate that which is excessive. ${ }^{27}$ Over the centuries, it has taken on new forms, and was introduced in the theory of asthenic and sthenic diseases by Dr. John Brown. ${ }^{28}$ At the beginning of the 20th century, two physiologists presented this postulate in the form of theories of parabiosis ${ }^{29}$ and dominant. ${ }^{30}$ In the 1930s, Hans Selye discovered a dynamic interaction between excess and deficiency, and described General Adaptation Syndrome theory, which distinguished the alarm phase (= excess, sthenic disease, dominant) and exhaustion phase (= deficiency, asthenic disease, parabiosis). ${ }^{31-32}$

At the beginning of organotherapy $y^{33-34}$ doctors used extracts of animal organs to treat various age-related problems, nowadays called frailty. ${ }^{35-36}$ Later a modern branch of organotherapy, taking the form of hormonotherapy, became a powerful tool to treat various diseases caused by hormonal insufficiency. ${ }^{37-38}$ They followed the first part of the ancient postulate: to strengthen or reinforce that which is deficient. When antibiotics were discovered, physicians got a tool to inhibit bacterial growth. ${ }^{39}$ Application of antibiotics was an example of following the second ancient postulate: drain or sedate that which is excessive. But further development of medicine did not follow the basic canon.

Nowadays despite the fact that deficiency patterns are the causes of the majority of chronic diseases, especially among elderly people, antagonists, blockers, or inhibitors, such as $\alpha$-blockers, $\beta$-blockers, calcium channel blockers, ACE inhibitors, PDF-5 inhibitors, and $\mathrm{H} 2$ antagonists are used for therapy. Before prescribing sedative therapy patients are not tested whether the corresponding target is in an excited state or not. So, a rational medical sense is ignored and patients have to take medication for all their life.

The same problem has arisen with the treatment of COVID-19. The main pathologic target was T-cell immunedeficiency, ${ }^{13,40-41}$ nevertheless a lot of attention was paid to the cytokine storm which was a consequence, but not a primary cause. According to basic medical law, treatment should be focused more at restoring T-cell immunity, ${ }^{42}$ and less against increased activity of certain components of the immune system. 
1.4. Treatment of patients suffering from acute infectious diseases

About 1800 years ago, Dr. Zhang Zhongjing summarized the results of research from previous generations and developed a theory of acute infectious diseases, which explained therapy based on leading clinical symptoms and syndromes. ${ }^{43}$ According to this theory, there could be only 6 phases, and certain phases could have 2-3 variants. Thus, the whole variety of clinical syndromes related to infectious diseases was limited to 10-12 variants, each having specific treatment and prevention. (Fig. 5.b)

\begin{tabular}{|c|c|c|c|}
\hline $\begin{array}{l}\text { (a) Phases of } \\
\text { Defense System Affection }\end{array}$ & \multicolumn{2}{|c|}{ (b) Six Phases of Acute Infectious Diseases } & $\begin{array}{l}\text { (c) General Adapta } \\
\text { Syndrome by H. Se }\end{array}$ \\
\hline Activation of defense & Tai Yang & - Common cold symptoms & \multirow{4}{*}{ Alarm Phase } \\
\hline Unstable phase & Shao Yang & - Unstable phase & \\
\hline Highest activity of defense & Yang Ming & - Progressive fever & \\
\hline \multirow{3}{*}{ Exhaustion of defense } & Tai Yin & - Beginning of exhaustion & \\
\hline & 5. Shao Yin & \multirow{2}{*}{$\begin{array}{l}\text { - Hemorrhagic syndrome, } \\
\text { and other complications }\end{array}$} & \multirow[t]{2}{*}{ Exhaustion Phase } \\
\hline & 6. Jue Yin & & \\
\hline
\end{tabular}

Figure 5. A comparison between various theories which describe phase evolution of acute infectious diseases:

(a) Four phases of diseases caused by external physical or biological pathogens called "excessive heat". ${ }^{44}$

(b) Six phases of diseases caused by various external physical, chemical or biological pathogens. ${ }^{43}$

(c) Two phases of diseases according to the general adaptation syndrome discovered by Hans Selye. ${ }^{31-32,45}$

There are some examples of treatment of the initial phases of infectious diseases: in the case of initial fever with general cold feelings without sweating - Herba Ephedrae was recommended; if there is initial fever with general hot feelings - Folium Mori Albae or Herba Menthae Haplocalycis should be used; if there is initial fever with intensive sweating or tension in the muscles - Ramulus Cinnamomi Cassiae was recommended; in the case of fever with alternating cold and hot feelings - Radix Bupleuri, was used, etc. ${ }^{43}$ (Fig. 5.b). A change in symptoms pointed to a change in the phase of the disease and required an adjustment of therapy. If a patient has a severe fever with hemorrhagic symptoms, skin rashes, kidney and liver impairment, delirium, etc. Radix of Isatis tinctoria should be applied. ${ }^{44,46}$ (Fig. 5.a)

It would be useful for modern pathophysiology to distinguish between various types of the fever and choose antipyretic medicines (paracetamol, ibuprofen, etc) based on the pharmacodynamic of these popular drugs, but not empirically, as they are usually used. ${ }^{47}$

During later centuries, protocols of infectious disease treatment were updated according to the new scientific discoveries of that time. Excepting deadly epidemic diseases (plague, smallpox, or cholera), therapy of other infectious diseases was effective and successful. Theoretically, modern medicine having a long history in the past and advanced pharmaceutical science nowadays must be able to treat any problem more effectively than our predecessors, but the helplessness of the modern medical system during the current pandemic was beyond common sense, ${ }^{48}$ and raised a question about the quality of medical education of the distinguished leaders and their followers.

\subsection{Treatment of COVID-19 at initial phase of pandemic}

At the beginning of the pandemic, WHO encouraged doctors to use well-known medicines as off-label treatment of a new disease since there were no approved drugs yet for the treatment of COVID-19. ${ }^{49}$ The majority of knowledgeable and experienced doctors who received high quality medical education treated patients suffering from COVID-19 with great success. They recommended using anticoagulants, such as dipyridamole $e^{50}$ or heparine, ${ }^{51}$ antiviral and anti-inflammatory drugs, including ivermectin, ${ }^{52-53}$ colchicine, ${ }^{54-55}$ methylene blue, ${ }^{56-57}$ chloroquine and hydroxychloroquine, ${ }^{58-60}$ immunemodulators, such as thymic extracts, ${ }^{61}$ thymic peptides, ${ }^{62}$ solution of Formaldehyde, ${ }^{63}$ melatonin ${ }^{64}$ and common adjuvants. ${ }^{65}$ A group of physicians, who had identified the similarity between COVID-19 and toxic damage to red blood cells, recommended to use therapeutic protocol which was effective in cases of acute intoxication. ${ }^{66}$ Other experts recommended an inhalation with ethanol vapor ${ }^{67-68}$ and helium-oxygen mixture ${ }^{69}$ since those methods had already been applied to similar cases before. ${ }^{70-72}$ Plant derived medicines, including extracts of Artemisia, Isatis or Colchicum as well as green and black tea, and various complex prescriptions were also used either for prophylaxis or for combined therapy. ${ }^{73-78}$ 
During the early days of the COVID-19 epidemic, doctors in Russia used their own treatment protocols, that resulted in very low mortality, and even raised questions and skepticism from the international medical community. ${ }^{79-80}$ For example, in April-June 2020, in a hospital attached to the Moscow State University, 420 out of 424 indoor patients suffering from COVID-19 were successfully treated with routine medication. Effectiveness of the therapy was around $100 \%{ }^{81}$

As basic medicines these doctors used Colchicine, Dipyridamole, Bromhexine, and Spironolactone; additional application of certain anticoagulants and corticosteroids depended on a particular case. ${ }^{82}$ Thus, common medical knowledge and experience were enough to treat the infectious disease caused by the new virus.

Every doctor knows that effective therapy of any patient requires individual approach due to the natural difference between even two similar cases, especially if a patient suffers from COVID-19. ${ }^{83}$ Following standard protocols without dose adjustment and individual correction of used medicines in certain clinical trials resulted in decreasing or even losing effectiveness of the drugs that had been used by other doctors earlier on. ${ }^{84}$ Nevertheless knowledgeable doctors continued their successful and effective treatment. ${ }^{65,85-86}$ The therapeutic effects of the medicines mentioned above have been proven in further clinical trials and the results were published in peer-reviewed journals. ${ }^{87}$

After recent discussions on therapeutic protocols taking place between various experts, Dr. Peter A. McCullough recommended to his colleagues to treat COVID-19 patients according to their own knowledge and experience. ${ }^{88}$ One can only deduce there is no common sense for doctors to follow the protocol of an expert or a country where mortality was high, otherwise they will gain the same high mortality among their patients.

\subsection{Clinical trials}

Early in the 18th century, homeopathic doctors, who studied pathogenesis of new remedies, introduced extensive and multi-centered clinical trials to the medical public. They needed to differentiate the primary and secondary symptoms, and to separate important symptoms from non-important ones, and so on. According to the demand of homeopathic pharmacy, there was a rationale for using large groups of people. Nevertheless extensive trials were criticized by Dr. Rudolf Virchow, the father of modern Pathology. He insisted that despite certain similarities in pathology discovered in different patients with a similar disease, each patient has his/her individual disease, so instead of using statistics collected from large groups of patients, doctors should pay more attention to detailed analysis of every particular case. ${ }^{89}$

As far as acute infectious diseases are concerned, their pathological condition is not stable, but has several phases.
Each of the phases requires the use of different medicines and patient care. It would be illogical to look for the treatment of COVID-19 in general, but each phase of the disease requires an appropriate group of medicines. Then a doctor should choose one or two medicines taking into account the main symptoms of a certain patient. Multiple attempts to find a unique medicine against 'COVID-19' have failed. That means treatment of COVID-19 or any further new acute viral infectious diseases should be managed by means of routine drugs applied as off label therapy.

When COVID-19 was announced as a new disease, ${ }^{4}$ healthcare worldwide was challenged to conduct new clinical trials to find medicines that were safe and effective in treating COVID-19 and comorbidities. After Dr. T. A. Ghebreyesus expressed an opinion about the pandemic, ${ }^{48}$ all patients suspected of being infected with SARS-CoV-2 were automatically made participants of clinical trials which were the most extensive in the history of mankind.

Since all the pathogenic mechanisms encountered in COVID-19 were already well-known before April-May, 2020, the treatment of COVID-19 should not have been difficult.

Moreover, since some routine medicines had already been used successfully, the main goal of further clinical trials was to design the most effective and adjustable protocols, but not to reject the effects of the used medicines. That is why it is crucial that ongoing clinical trials should focus more on adjusting protocols to enhance the efficacy of the tested medicines, rather than adhering to some standard approach. Adhering to such rigid protocols might render the treatment of COVID-19 ineffective, not due to the ineffectiveness of the medicine per se but due to the inappropriate protocols applied. The trials also tested the ability of doctors to form homogeneous groups, taking into account the leading pathogenic mechanisms, presented among the patients in the group of study and the main therapeutic action of the studied medicine. Unfortunately, many ongoing clinical trials have ended up demonstrating insufficient knowledge and experience of the physicians conducting the research.

For experienced physicians with a solid background, clinical trials were not necessary. Since they knew the pathogenesis of COVID-19 and pharmacodynamic of the medicines used, in their clinics efficacy of therapy must be around $100 \% .^{65,82,85,86}$ But results of clinical trials were very important and useful for beginners, since standard protocols help them to reduce the number of adverse reactions of their treatment.

\subsection{Paradoxes of Clinical trials}

There were some facts that would be worth paying attention to, since they could indicate possible causes of high mortality at the initial phase of the COVID-19 pandemic. 
In January-April, 2020, mortality among CoViD-19 patients who were treated with invasive mechanical ventilation (IMV) was higher than $80 \%$, including, $81 \%,{ }^{90} 88.1 \%,{ }^{91}$ $92 \%,{ }^{92}$ and even $97 \% .^{93}$ According to a review by G. Bellani, et al. published in 2016, the highest mortality among the severest cases of patients with Acute Respiratory Distress Syndrome (ARDS) of various origin, who were treated with IMV, was around $50 \% .^{94}$

After comparing the results of IMV application among COVID-19 patients with the results presented in the review on IMV (2016), one may conclude that IMV had no therapeutic value among patients with ARDS caused by SARS-CoV-2. The lack of a therapeutic effect of IMV was explained by systemic endotheliitis and coagulopathy which led to micro and macro-thromboses in various organs including the lungs. ${ }^{95}$ Nevertheless, IMV is still in use to treat COVID-19 patients with ARDS.

From the outset of the COVID-19 pandemic, it was known that there would be a high risk group, comprising mainly of aged people with compromised immunity and comorbidities. The main parameter that could point to the risk of severe cases was lymphopenia. ${ }^{93}$ Prognostically unfavorable signs of COVID-19 were: a decrease in the number of lymphocytes in general, a decrease in subpopulations of T-lymphocytes (CD4+, CD8+) and, as a consequence, a dysfunction of B-lymphocytes and dysregulation of their production of $\mathrm{Ig}-\mathrm{M}$ and $\mathrm{Ig}-\mathrm{G}$. The number of T-lymphocytes, including CD4+ and CD8+, was especially reduced among patients requiring treatment in the intensive care unit. ${ }^{13}$ The severity of the case and outcome of COVID-19 largely depended on a patient's age, that correlated with a decrease in T-cells, due to the thymus atrophy. ${ }^{40,96}$ The risk of COVID-19 hospitalization rises exponentially with age, inversely proportional to T-cell production. ${ }^{41}$ In COVID patients, thymus enlargement was frequent and associated with increased T-lymphocytes production that appears to be a beneficial adaptation to virus-induced lymphopenia. The loss of thymic reactivation might contribute to a worse prognosis. ${ }^{97}$ Despite great importance of immunological dysregulation caused by T-cell deficiency, there were only a few studies with application of thymus derived medicines, ${ }^{42,61,98}$ although the immunemodulating and protective effect of thymus extract has already been known for more than two hundred years. ${ }^{99}$

On June 16, 2020, Professor Peter Horby said, that dexamethasone "is the only drug so far that has been shown to reduce mortality - and it reduces it significantly". ${ }^{100}$ It reduced deaths by one-third in patients receiving invasive mechanical ventilation, by one-fifth in patients receiving oxygen without invasive mechanical ventilation, but did not reduce mortality in patients not receiving respiratory support at randomization. ${ }^{101}$ The later conclusion on the efficacy of corticosteroids was pessimistic: "There is no evidence that corticosteroids are safe and effective on the treatment of severe acute respiratory infection when COVID-19 disease is suspected". ${ }^{102}$ The key point of these controversial claims was a wrong approach to use corticosteroids on patients with COVID-19. The corticosteroids should be recommended as a replacement therapy to the patients with bacterial or viral infectious disease being in the phase of exhaustion according to the general adaptation syndrome described by Hans Selye. ${ }^{31-32,45}$ (Fig. 5.c) Thus, blood tests on cortisol and aldosterone must be obligatory routine analyses before prescription of corticosteroids therapy, especially in the case of COVID-19.

\subsection{Case fatality ratio and infection fatality ratio}

There are two most important characteristics of infectious diseases: the first is a case fatality ratio (CFR) and the second, an infection fatality ratio (IFR). Case fatality ratio is the proportion between the number of patients who died from COVID-19 and the number of confirmed cases of COVID19 , while infection fatality ratio is the proportion between the number of patients who died from COVID-19 and the number of estimated cases infected with SARS-CoV-19. ${ }^{103}$

To identify the total number of infection prevalence, tests were carried out for the presence of the viral genome Polymerase chain reaction (PCR), or for specific antibodies against SARS-CoV-2 virus (IgM and IgG). Due to the fact that PCR provided positive results for a limited time after infection, and specific antibodies were produced and circulated in the blood of an infected person from several months up to a year, ${ }^{104-105}$ the percentage of seroprevalence would always be lower than the real one, and, therefore, IFR from COVID-19 would be always overestimated.

In a study published by J. Ioannidis (2020), at the end of October 2020, the number of infected people worldwide reached $10 \%{ }^{106}$ Similar proportion of infected people in October 2020 was calculated for Belgium, Brazil, and the United States. ${ }^{107}$ In December 2020, the number of infected people in the United States was estimated at 50 million, or around $15 \%{ }^{108}$

On January 29, 2021, the Mayor of Moscow, Sergei Sobyanin announced that "half of Moscow's 12 million residents have had Covid-19" and recovered. ${ }^{109}$ That estimation was based on a trial where antibodies to the SARS-CoV-2 virus were found in more than half of the blood samples taken randomly from a thousand healthy residents of Moscow. ${ }^{110}$

Thus, one may conclude that since the beginning of the pandemic, major populations of large cities have already been infected with SARS-CoV-2 and have some amount of circulated antibodies or have memory about this virus stored in the T-cells. ${ }^{111-113}$ 


\subsection{Databases were collected from Worldometer website}

Information on cumulative numbers of the total cases and deaths due to COVID-19 is available at the Worldometer website from January $21,2020 .{ }^{18}$ (Fig. 6) On January 23, 2020, a controversial article on RT-PCR tests was published, ${ }^{114}$ and a historical session of the World Economic Forum devoted to Wuhan Coronavirus took place in Davos. ${ }^{115}$ Despite the fact that there was no cause for alarm yet, ${ }^{116}$ January 23, 2020 was chosen as the first day of the current study."

To provide an overall and detailed analysis of the COVID-19 pandemic, one year and a half was divided into three phases: (23.01.20-22.07.20), (23.07.20-22.01.21) and (23.01.2122.07.21). Twenty three sets of databases, dated the $22 \mathrm{nd}$ of each month from January 2020 to November 2021, were collected. Raw data included more than 20,000 figures in total. Only simple calculations using MS Excel easily understandable by any doctor have been used.

The databases related to each month for every country were calculated by subtracting the previous month's data from the analyzed month's data. For example, in China on 22.02.20 there were 76,923 cases, and 2,441 deaths, and on 22.01.20 there were 571 cases and 17 deaths. Subtracting the second from the first, one gets that from 23.01.20 to 22.02.20 there were 76,352 cases and 2,424 deaths, and so on. The same method was used to count the database related to each phase for every country. Since only 213 countries $^{\dagger}$ were affected by COVID-19 during the first phase, these 213 countries were analyzed during the current study.

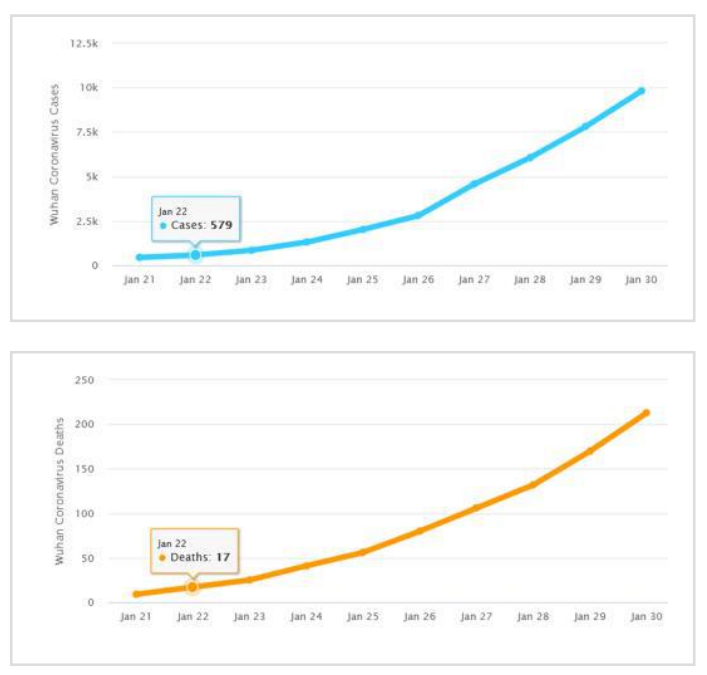

Figure 6. Cumulative numbers of the total cases of COVID-19, and the total deaths due to COVID-19 started on January 21, 2020; daily counts of both parameters have been available since January 22, 2020. [A part of the screenshot of the Worldometer website dated January 31, 2020, 21:35 GM].

\footnotetext{
* On January 23, 2020, Dr. Peter Salama, an expert in epidemiology, the former director of WHO's Health Emergencies Program, who organized a successful battle against the Ebola virus in the D.R.C., died suddenly. ${ }^{117}$

† Here and below 'Countries' means 'Countries and Territories'.
}

\section{One and a half years of the pandemic: Case fatality ratio and infection fatality ratio}

\section{Objective}

To evaluate CFR and IFR in 213 countries during one and a half years of COVID-19 pandemic.

2.1. Calculation of CFR among COVID-19 patients in 213 countries

\section{Material and Methods}

To calculate the CFR and IFR worldwide, the databases of 220 countries dated as July 22, 2021, 23:49 GMT, were collected at the Worldometer website. In these countries there were 193,349,043 confirmed cases of COVID-19; $4,150,541$ deaths due to COVID-19; and a total population of $7,838,783,871$ people.

Since in the first phase of COVID-19 pandemic (23.01.2022.07.20) only 213 countries were affected, so databases of only these 213 countries were used for this study. Seven countries, including Marshall Islands, Micronesia, Saint Helena, Samoa, Solomon Islands, Vanuatu, and Wallis and Futuna, with 479 confirmed cases, 8 deaths, and population of 1,412,031 people were excluded from the study. In 213 countries there were 193,348,564 cases and 4,150,526 deaths.

A case fatality ratio was calculated by dividing the number of deaths by the number of confirmed cases.

\section{Results}

The overall case fatality ratio for 213 countries, counted by dividing the number of deaths $(n=4,150,526)$ by the number of confirmed cases $(n=193,348,564)$, was $2.147 \%$. The overall case fatality ratio for 220 countries was $2.147 \%$ too.

\subsection{Calculation of CFR among COVID-19 patients in 175} countries

\section{Material and Methods}

To increase the homogeneity of the main group of study, 38 countries with death numbers of fewer than 50 were excluded from further analysis. Thus, the main group of study decreased to 175 countries, with a total population of $7,734,426,580$ people. These countries had 193,207,132 confirmed cases and 4,149,944 fatal cases. For each country, the CFR was calculated by dividing the number of deaths by the number of confirmed cases.

\section{Results}

The overall case fatality ratio for 175 countries was $2.148 \%$. In this group the CFR ranged from $0.267 \%$ in Qatar to $19.597 \%$ in Yemen, and the average value of CFR was $2.146 \pm 1.965 \%$. Based on the calculated CFR values, all countries were divided into 16 groups as shown in Fig. 7.

The first group ( $\mathrm{n}=7)$ where CFR was less than $0.500 \%$, included Qatar $(0.267 \%)$, Maldives $(0.285 \%)$, UAE $(0.286 \%)$, Cyprus (0.418\%), Seychelles (0.490\%), Mongolia (0.495\%), and Vietnam $(0.498 \%)$. 


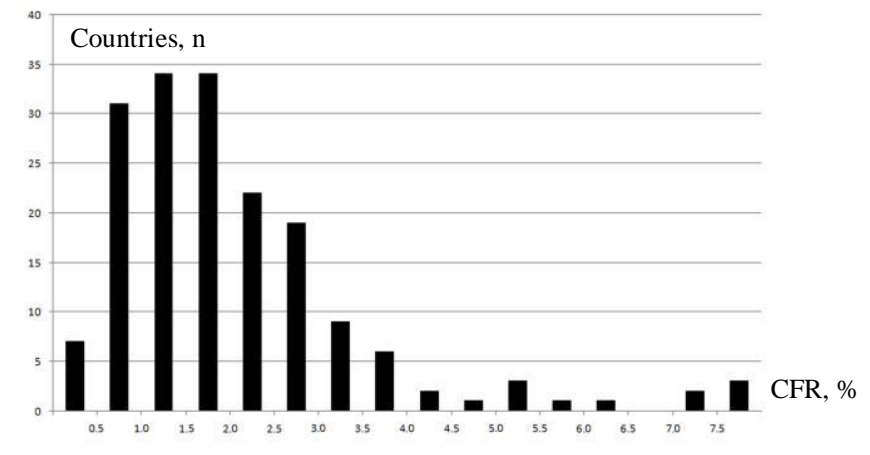

Figure 7. Distribution of 175 countries into 16 groups according to a CFR value 16 groups are: 1) CFR $<0.5 \%, \mathrm{n}=7$; 2) $0.5-1.0 \%, \mathrm{n}=31$; 3) $1.0-1.5 \%, \mathrm{n}=34$; 4) $1.5-2.0 \%$, $\mathrm{n}=34$; 5) $2.0-2.5 \%, \mathrm{n}=22$; 6) $2.5-3.0 \%, \mathrm{n}=19$; 7) $3.0-3.5 \%, \mathrm{n}=9$; 8) $3.5-4.0 \%, \mathrm{n}=6$; 9) $4.0-4.5 \%, \mathrm{n}=2$; 10) $4.5-5.0 \%, \mathrm{n}=1$; 11) $5.0-5.5 \%, \mathrm{n}=3$; 12) $5.5-6.0 \%, \mathrm{n}=1$; 13) $6.0-6.5 \%, \mathrm{n}=1$; 14) $6.5-7.0 \%, \mathrm{n}=0$; 15) 7.0-7.5\%, $\mathrm{n}=2$; 16) $\mathrm{CFR}>7.5 \%, \mathrm{n}=3$.

The groups \# 9-16, where CFR exceeded $4.00 \%$, included 13 countries: Bulgaria (4.296\%), Afghanistan (4.432\%), Bosnia and Herzegovina (4.710\%), China (5.017\%), Taiwan (5.042\%), Somalia (5.151\%), Egypt $(5.801 \%)$, Ecuador (6.415\%), Syria (7.370\%), Sudan (7.475\%), Mexico (8.807\%), Peru $(9.316 \%)$, and Yemen $(19.597 \%)$

\section{Conclusion}

The calculations done in this section showed that in 38 out of 175 countries, CFR was less than $1.00 \%$, in 68 countries CFR varied between $1.00 \%$ and $2.00 \%$, and in 69 countries CFR was more than 2.00\%. In 7 out of 175 countries, CFR was less than $0.50 \%$.

2.3. Calculation of CFR among patients in 38 countries excluded from the main study

\section{Background}

As mentioned above, 38 countries were excluded from the main group of study.

\section{Material and Methods}

The group of countries excluded from the main study consisted of 8 countries without fatal cases related to COVID-19, and 30 countries where the number of fatal cases was from 1 to 49 . In 30 countries with a total population of 102,945,260, there were 140,853 cases of COVID-19 and 582 deaths caused by COVID-19. For each country, a CFR was calculated.

\section{Results}

In 18 out of 30 countries CFR was less than $1.00 \%$ (including 10 with CFR $<0.50 \%$ ), in 8 countries CFR was between $1.00 \%$ and $2.00 \%$, and in the remaining 4 countries, CFR was more than $2.00 \%$. Since there were no fatal cases due to COVID-19 in 8 countries, the CFR was less than $1.00 \%$ and less than $0.50 \%$.

\section{Conclusion}

If the previous calculations done in section 2.2. were to be taken into account, then in 64 out of 213 countries, CFR was less than $1.00 \%$; in 76 countries CFR varied between 1.00 and 2.00\%; and in 73 countries, CFR was more than $2.00 \%$. In 25 out of 213 countries, CFR was less than $0.50 \%$.
2.4. Calculation of IFR among COVID-19 patients of 136 countries

\section{Background}

Before estimation of an infection fatality ratio, it was assumed that each person was tested only once, and the distribution of infected people among the entire population was equal. Therefore, the number of infected people was expected to increase in direct proportion to the increase in the number of new tests performed. The total number of infected people (IP) was derived from the number of total confirmed cases (C) divided by the total number of tests performed $(\mathrm{T})$ and multiplied by the total population $(\mathrm{P})$. Then, IFR was calculated by dividing the number of deaths due to COVID-19 (D) by the estimated number of people infected with the SARS-CoV-2 virus.

In the previous study ${ }^{1}$ to estimate the number of infected people, a formula $\{\mathrm{IP}=\mathrm{C} \cdot \mathrm{P} / \mathrm{T}\}$ was used, but it was assumed that results of IFR $\{$ IFR=D/IP $\}$ would be overestimated. Further comparison of the results calculated using this formula, with the results estimated in other studies ${ }^{106-108}$ revealed the consistency of the results with a difference of around 1.8 fold; so, a corrected formula was $\{\mathrm{IP}=(\mathrm{C} \cdot \mathrm{P} / \mathrm{T}) \bullet 1.8\}$. The final adjusted formula used in the current study was $\mathrm{IFR}=[(\mathrm{D} \cdot \mathrm{T}) /(\mathrm{C} \cdot \mathrm{P})] / 1.8$.

\section{Material and Methods}

After collecting the databases, countries with fewer than 50 reported cases of deaths, countries without information on the number of tests on SARS-CoV-2, and countries where the number of tests performed exceeded the total population, were excluded from the IFR study group.

The main group consisted of 136 countries with a total population of $6,864,034,602$ people, $121,373,035$ confirmed COVID-19 cases, 2,768,774 fatal cases related to COVID19 and 1,370,764,127 COVID-19 tests. To calculate the number of infected people, a formula $\{\mathrm{IP}=(\mathrm{C} \cdot \mathrm{P} / \mathrm{T}) \cdot 1.8\}$ was used. To calculate infectious fatality ratio for each country a formula $\{$ IFR $=[(\mathrm{D} \bullet \mathrm{T}) /(\mathrm{C} \cdot \mathrm{P})] / 1.8\}$ was used.

\section{Results}

Since 121,373,035 COVID-19 cases were detected after $1,370,764,127$ tests, it can be expected that if the number of tests would reach the total population $(6,864,034,602)$, the number of infected people would increase up to $1,093,985,210$. Thus, the overall IFR for 136 countries would be $[(2,768,774$ $1,370,764,127) /(121,373,035 \cdot 6,864,034,602)] / 1.8=0.253 \%$.

Among 136 countries analyzed, the IFR ranged from $0.003 \%$ in the Democratic Republic of Congo (the minimal value) to $2.340 \%$ in Peru (the maximal value).

Based on the estimated IFR values, all the countries analyzed were divided into 16 groups, as illustrated in Fig. 8.

The first and largest group with the lowest value of IFR $(<0.10 \%)$ included 52 countries. Some of the countries had quite large populations, for example, Pakistan (225,392,516; $0.088 \%)$, Nigeria $(211,492,907 ; 0.008 \%)$, Bangladesh $(166,414,749 ; 0.040 \%)$, Ethiopia $(117,947,327 ; 0.022 \%)$, 
Egypt (104,359,775; 0.095\%); Vietnam (98,259,748; 0.033\%), etc. But other countries in this group had small populations, for example, Seychelles $(98,988 ; 0.059 \%)$, French Polynesia (282,617; 0.039\%), Réunion (902,035; 0.049\%), Equatorial Guinea $(1,451,181 ; 0.090 \%)$, etc.

The groups \# 11-16 with high values of IFR $(>1.00 \%)$ included 8 countries: Slovakia (1.001\%), Canada (1.030\%), Germany (1.065\%), Chile (1.134\%), Bulgaria (1.207\%), Hungary (1.343\%), Australia (1.425\%), and Peru (2.340\%).

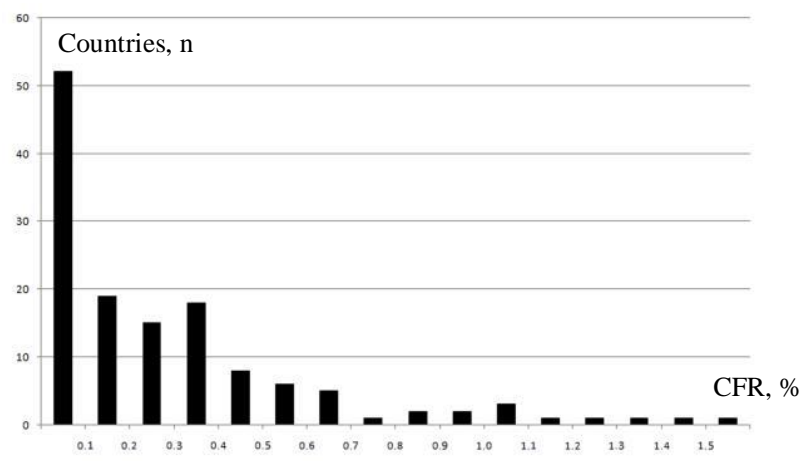

Figure 8. Distribution of 136 countries into 16 groups according to a IFR value 16 groups are: 1) IFR $<0.10 \%, \mathrm{n}=52$; 2) $0.10-0.20 \%, \mathrm{n}=19$; 3) $0.20-0.30 \%, \mathrm{n}=15$; 4) $0.30-0.40 \%, \mathrm{n}=18$; 5) $0.40-0.50 \%, \mathrm{n}=8$; 6) $0.50-0.60 \%, \mathrm{n}=6$; 7) $0.60-0.70 \%, \mathrm{n}=5$; 8) $0.70-0.80 \%, \mathrm{n}=1$; 9) $0.80-0.90 \%, \mathrm{n}=2$; 10) $0.90-1.00 \%, \mathrm{n}=2$; 11) $1.00-1.10 \%, \mathrm{n}=3$; 12) $1.10-1.20 \%, \mathrm{n}=1$; 13) $1.20-1.30 \%, \mathrm{n}=1$; 14) $1.30-1.40 \%, \mathrm{n}=1$; 15) $1.40-1.50 \%$, $\mathrm{n}=1 ; 16)$ IFR $>1.50 \%, \mathrm{n}=1$.

\section{Conclusion}

The calculations done in this section showed that in 128 out of 136 countries, the IFR was below $1.00 \%$, in 7 countries IFR was between 1.00 and $2.00 \%$, and only in 1 country IFR were above $2.00 \%$. In 112 out of 136 countries IFR was less than $0.50 \%$.

2.5. Estimation of IFR in the 77 countries excluded from the main study

\section{Background}

As mentioned above, some countries were excluded from the main group of study.

\section{Material and Methods}

To estimate IFR for 52 countries, including 5 countries without information on the number of tests, and 47 countries where the number of tests performed exceeded the total population, a ratio between average CFR and average IFR in the main group of countries was calculated.

The main group $(\mathrm{n}=136)$ was divided into 4 subgroups: (1st) CFR was less than $1.00 \%, \mathrm{~N}=24$; (2nd) CFR was between 1.00 and $2.00 \%, \mathrm{~N}=50$; (3rd) $\mathrm{CFR}$ was between 2.00 and $3.00 \%, \mathrm{~N}=35$; and (4th) CFR was higher than $3.00 \%, \mathrm{~N}=27$. For each of these subgroups a ratio or a coefficient between average CFR and average IFR was counted: (1st) $\quad$ CFR/IFR=4.369; (2nd) $\quad \mathrm{CFR} / \mathrm{IFR}=5.991$; (3rd) $\mathrm{CFR} / \mathrm{IFR}=7.565$; (4th) $\mathrm{CFR} / \mathrm{IFR}=11.586$. These four coefficients were used to calculate IFR in the group of 52 countries mentioned above.

In the group of countries $(n=17)$ where the number of tests performed was higher than " 0 " but less than the population, and the number of deaths was less than 50, IFR was counted using the formula IFR $=[(\mathrm{D} \bullet \mathrm{T}) /(\mathrm{C} \bullet \mathrm{P})] / 1.8$, which was used in section 2.4.

\section{Results}

In 47 countries without information on the number of tests performed and 5 countries where the number of tests performed exceeded the total population ( 52 countries in total), the estimated IFR was less than $1.00 \%$, including 51 countries, where IFR was less than $0.50 \%$.

In all countries where the number of death was less than $50(\mathrm{n}=17)$, IFR was less than $1.00 \%$; and in 14 out of 17 countries, IFR was less than $0.50 \%$.

In 8 countries without deaths, IFR was " 0 ", so it was less than $1.00 \%$ and less than $0.50 \%$.

\section{Conclusion}

The calculations done in the section 2.4 and 2.5 revealed that in 205 out of 213 countries, IFR was less than $1.00 \%$; in 7 countries IFR was between $1.00 \%$ and $2.00 \%$; and only in 1 country IFR was more than $2.00 \%$. In 185 out of 213 countries IFR was less than $0.50 \%$.

Taking into account the results of a study conducted in January, 2021, when $50 \%$ of Moscow's city population had already antibodies against SARS-CoV-2, ${ }^{109-110}$ one may assume that in July, 2021, the percentage of seroprevalence could be even higher and IFR could be lower than estimated in the current study.

2.6. Dynamics of the main cumulative data during 22 months of the COVID-19 pandemic

\section{Background}

The current pandemic curve has a wave-like form with a gradual increase and decrease of daily, weekly, and monthly numbers related to cases and deaths.

\section{Material and Methods}

Twenty three sets of databases, which were dated the 22nd of each month from January 2020 to November 2021, were collected. The number of total COVID-19 cases, deaths due to COVID-19, tests performed, and population were presented in Table 1. CFR, IFR as well as number of cases per 1 million $(\mathrm{C} / \mathrm{M})$ and death per 1 million $(\mathrm{D} / \mathrm{M})$ were counted for each date (Table 1). Dynamics of CFR and IFR were illustrated in Fig. 9.

\section{Results}

During 22 months of the pandemic there was an increase in the total number of cases, deaths, and tests on COVID-19 as well as population worldwide. Comparisons between numbers related to the pandemic collected on January 22, 2021 (12 months, or 1 year) and July 22, 2021 (18 months, or 1.5 years), revealed that during the six months, parameters of the pandemic were almost doubled compared to the 
M. Teppone. COVID-19: Three Phases of the Pandemic

similar cumulative parameters during the previous one year. The number of COVID-19 cases and deaths increased by 1.96 fold, and the number of tests increased by 2.13 fold.
The cumulative CFR was highest in April and May, 2020, followed by a decreasing trend, but the estimated cumulative IFR increased gradually (Fig. 9).

Table 1. Dynamics of the main cumulative data during 22 months of the COVID-19 pandemic

\begin{tabular}{|r|r|r|r|r|r|r|r|r|r|}
\hline$\#$ & Date & Cases & Deaths & Tests & Population & CFR & IFR & C/M & D/M \\
\hline & & & & & & & & \\
\hline 0 & 22.01 .20 & 579 & 17 & - & - & 2.936 & - & - & - \\
\hline 1 & 22.02 .20 & 78,001 & 2,457 & - & - & 3.150 & - & - & - \\
\hline 2 & 22.03 .20 & 334,886 & 14,603 & - & - & 4.361 & - & - & - \\
\hline 3 & 22.04 .20 & $2,632,559$ & 183,879 & $23,282,447$ & - & 6.985 & - & - & - \\
\hline 4 & 22.05 .20 & $5,296,813$ & 339,374 & $67,673,680$ & $7,749,928,184$ & 6.407 & 0.031 & 683 & 44 \\
\hline 5 & 22.06 .20 & $9,176,001$ & 473,406 & $130,810,378$ & $7,756,390,179$ & 5.159 & 0.048 & 1,183 & 61 \\
\hline $\mathbf{6}$ & $\mathbf{2 2 . 0 7 . 2 0}$ & $\mathbf{1 5 , 3 6 2 , 7 4 5}$ & $\mathbf{6 2 5 , 3 9 5}$ & $\mathbf{3 0 2 , 3 7 4 , 5 4 4}$ & $\mathbf{7 , 7 6 2 , 5 3 0 , 9 2 4}$ & $\mathbf{4 . 0 7 1}$ & $\mathbf{0 . 0 8 8}$ & $\mathbf{1 , 9 7 9}$ & $\mathbf{8 1}$ \\
\hline 7 & 22.08 .20 & $23,358,160$ & 807,665 & $409,774,283$ & $7,768,876,378$ & 3.458 & 0.101 & 3,007 & 104 \\
\hline 8 & 22.09 .20 & $31,750,352$ & 974,050 & $609,767,516$ & $7,775,221,824$ & 3.068 & 0.134 & 4,084 & 125 \\
\hline 9 & 22.10 .20 & $41,959,098$ & $1,142,057$ & $759,449,532$ & $7,781,362,578$ & 2.722 & 0.148 & 5,392 & 147 \\
\hline 10 & 22.11 .20 & $58,947,048$ & $1,392,963$ & $955,296,514$ & $7,787,708,023$ & 2.363 & 0.161 & 7,569 & 179 \\
\hline 11 & 22.12 .20 & $78,280,842$ & $1,721,802$ & $1,164,332,290$ & $7,793,848,775$ & 2.200 & 0.183 & 10,044 & 221 \\
\hline $\mathbf{1 2}$ & $\mathbf{2 2 . 0 1 . 2 1}$ & $\mathbf{9 8 , 6 6 9 , 5 9 3}$ & $\mathbf{2 , 1 1 3 , 7 5 0}$ & $\mathbf{1 , 3 7 5 , 8 8 7 , 5 0 9}$ & $\mathbf{7 , 8 0 0 , 1 9 4 , 2 2 5}$ & $\mathbf{2 . 1 4 2}$ & $\mathbf{0 . 2 1 0}$ & $\mathbf{1 2 , 6 5 0}$ & $\mathbf{2 7 1}$ \\
\hline 13 & 22.02 .21 & $112,239,378$ & $2,484,426$ & $1,589,416,906$ & $7,806,539,667$ & 2.214 & 0.250 & 14,378 & 318 \\
\hline 14 & 22.03 .21 & $124,265,956$ & $2,734,688$ & $1,805,314,644$ & $7,812,271,038$ & 2.201 & 0.283 & 15,907 & 350 \\
\hline 15 & 22.04 .21 & $145,297,992$ & $3,083,902$ & $2,087,974,472$ & $7,818,616,492$ & 2.122 & 0.315 & 18,584 & 394 \\
\hline 16 & 22.05 .21 & $167,027,095$ & $3,467,994$ & $2,378,274,484$ & $7,825,090,334$ & 2.076 & 0.350 & 21,345 & 443 \\
\hline 17 & 22.06 .21 & $179,871,406$ & $3,896,149$ & $2,660,800,034$ & $7,831,231,088$ & 2.166 & 0.409 & 22,968 & 498 \\
\hline $\mathbf{1 8}$ & $\mathbf{2 2 . 0 7 . 2 1}$ & $\mathbf{1 9 3 , 3 4 8 , 5 6 4}$ & $\mathbf{4 , 1 5 0 , 5 3 3}$ & $\mathbf{2 , 9 2 6 , 4 4 3 , 2 5 4}$ & $\mathbf{7 , 8 3 7 , 3 7 1 , 8 4 0}$ & $\mathbf{2 . 1 4 7}$ & $\mathbf{0 . 4 4 5}$ & $\mathbf{2 4 , 6 7 0}$ & $\mathbf{5 3 0}$ \\
\hline 19 & 22.08 .21 & $212,552,947$ & $4,443,846$ & $3,218,070,808$ & $7,843,921,989$ & 2.010 & 0.477 & 27,098 & 567 \\
\hline 20 & 22.09 .21 & $230,824,305$ & $4,731,461$ & $3,598,394,533$ & $7,850,062,735$ & 2.050 & 0.522 & 29,404 & 603 \\
\hline 21 & 22.10 .21 & $243,676,239$ & $4,952,263$ & $3,889,118,661$ & $7,856,203,486$ & 2.032 & 0.559 & 31,017 & 630 \\
\hline 22 & 22.11 .21 & $258,262,254$ & $5,172,861$ & $4,212,580,383$ & $7,862,548,934$ & 2.003 & 0.596 & 32,847 & 658 \\
\hline
\end{tabular}

\section{Conclusion}

During the last 6 months of the analyzed 1.5 years of the pandemic, the number of COVID-19 cases, deaths and tests was dramatically increasing. To provide a more detailed analysis of this negative trend, 1.5 years was divided into 3 phases: the 1st phase (23.01.20-22.07.20), the 2nd phase (23.07.20-22.01.21), and the 3rd phase (23.01.21-22.07.21), which are analyzed in the next section.

\section{Three phases of the COVID-19 pandemic in 213 countries}

\section{Background}

During six months of the 3rd phase (23.01.21-22.07.21) the number of cases, deaths and tests was almost equal to the similar ones reported during the previous one year (23.01.20-22.01.21).

\section{Objective}

To analyze and compare the dynamics of cases, deaths and tests during three phases of the pandemic.

\section{Material and Methods}

Analysis of the three phases of the COVID-19 pandemic was divided into two parts. The overall analysis in 213 countries was carried out in the first part, and a separate analysis of each country, - in the second part.

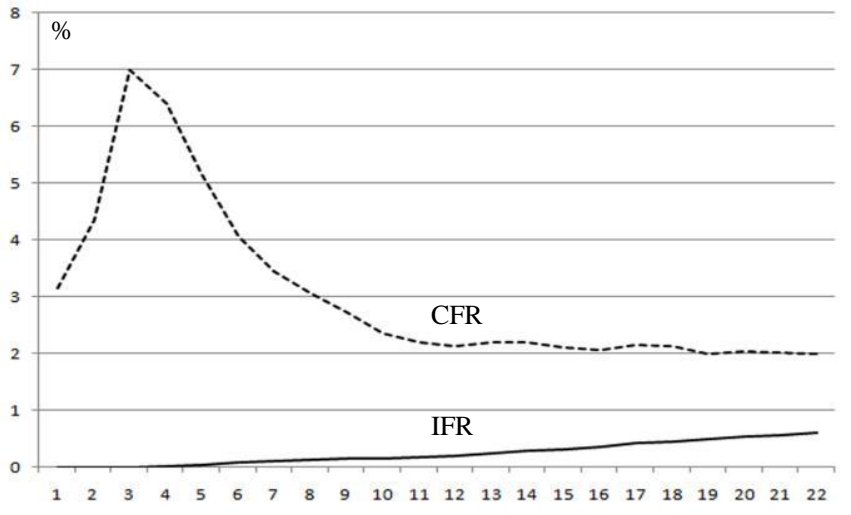

Figure 9. Dynamics of CFR and IFR during 22 months of the COVID-19 pandemic

3.1. Overall analysis of the three phases of the COVID19 pandemic in 213 countries

\section{Material and Methods}

Four databases, dated 22.01.20, 22.07.20, 22.01.21 and 22.07.21 were collected from the Worldometer website. The number of cases, deaths, and tests related to each phase for each of the 213 countries was calculated by subtracting the previous phase's data from the analyzed phase's data. For example, on 22.01.21 there were 98,669,593 cases, 2,113,750 deaths, and 1,375,887,509 tests; and on 22.07.21 there were 
193,348,564 cases, 4,150,533 deaths, and 2,926,443,254 tests. Subtracting the first numbers (dated 22.01.21) from the second (dated 22.07.21), one concludes that during 6 months, from 23.01.21 to 22.07.21 there were 94,678,971 new cases, 2,036,783 new deaths, and 1,550,555,745 new tests, etc. CFR for each phase was calculated.

Ratios between cases, deaths and tests recorded during the 1st, 2nd and 3rd phases in relation to the similar parameters recorded during the whole 1.5 years were also counted. Additionally, a calculation of ratios between cases, deaths and tests recorded during 12 months of the first year of the pandemic in relation to the similar parameters recorded during the whole 1.5 years was also carried out. (Table 2).

\section{Results}

According to the calculations done, the 3rd phase was characterized by a dramatic increase for all parameters of the pandemic, including cases, deaths, and tests. The most intensive growing parameter was tests conducted to reveal new suspicious cases of COVID-19.

The case fatality ratio was the highest in the 1st phase, then decreased in the 2 nd phase and again increased in the 3rd phase.

Table 2. Number of cases, deaths and tests related to 6 months of various phases, and also the same numbers recorded during the first 12 months (phases I+II, 1 year) and the whole period of 18 months (phases I+II+III, 1.5 years).

\begin{tabular}{|r|r|r|r|r|r|r|r|r|}
\hline Phase, \# & Date & Cases & \% & Deaths & \% & Tests & \% & CFR,\% \\
\hline I & $23.01 .20-22.07 .20$ & $15,362,166$ & 7.94 & 625,378 & 15.07 & $302,374,544$ & 10.33 & 4.071 \\
\hline II & $23.07 .20-22.01 .21$ & $83,306,848$ & 43.09 & $1,488,355$ & 35.86 & $1,073,512,965$ & 36.68 & 1.787 \\
\hline III & $23.01 .21-22.07 .21$ & $94,678,971$ & 48.97 & $2,036,783$ & 49.07 & $1,550,555,745$ & 52.99 & 2.151 \\
\hline I+II+III & $\mathbf{2 3 . 0 1 . 2 0 - 2 2 . 0 7 . 2 1}$ & $\mathbf{1 9 3 , 3 4 8 , 5 6 4}$ & $\mathbf{1 0 0 . 0}$ & $\mathbf{4 , 1 5 0 , 5 3 3}$ & $\mathbf{1 0 0 . 0}$ & $\mathbf{2 , 9 2 6 , 4 4 3 , 2 5 4}$ & $\mathbf{1 0 0 . 0}$ & $\mathbf{2 . 1 4 7}$ \\
\hline & & & & & & & & \\
\hline I+II & $23.01 .20-22.01 .21$ & $98,669,014$ & 51.03 & $2,113,733$ & 50.93 & $1,375,887,509$ & 47.01 & 2.142 \\
\hline III & $23.01 .21-22.07 .21$ & $94,678,971$ & 48.97 & $2,036,783$ & 49.07 & $1,550,555,745$ & 52.99 & 2.151 \\
\hline I+II+III & $\mathbf{2 3 . 0 1 . 2 0 - 2 2 . 0 7 . 2 1}$ & $\mathbf{1 9 3 , 3 4 8 , 5 6 4}$ & $\mathbf{1 0 0 . 0}$ & $\mathbf{4 , 1 5 0 , 5 3 3}$ & $\mathbf{1 0 0 . 0}$ & $\mathbf{2 , 9 2 6 , 4 4 3 , 2 5 4}$ & $\mathbf{1 0 0 . 0}$ & $\mathbf{2 . 1 4 7}$ \\
\hline
\end{tabular}

3.2. Analysis of the three phases of the COVID-19 pandemic for each of the 213 countries

\section{Material and Methods}

Four databases for each country, dated 22.01.20, 22.07.20, 22.01.21 and 22.07.21 were collected from the Worldometer website.

The number of cases, deaths, and tests related to each phase for every country was calculated by subtracting the previous phase's data from the analyzed phase's data. For example, in Malaysia, on 22.07.20 there were 123 deaths; on 22.01.21 there were 660 deaths, and on 22.07.21 there were 7,574 deaths in total. (Fig. 10). Subtracting 660 from 7,574 , and 123 from 660, one concludes that during 6 months, from 23.01.21 to 22.07.21 there were 6,914 new deaths, and from 23.07.20 to 22.01.21, there were 537 deaths. A CFR was calculated for each country for every phase.

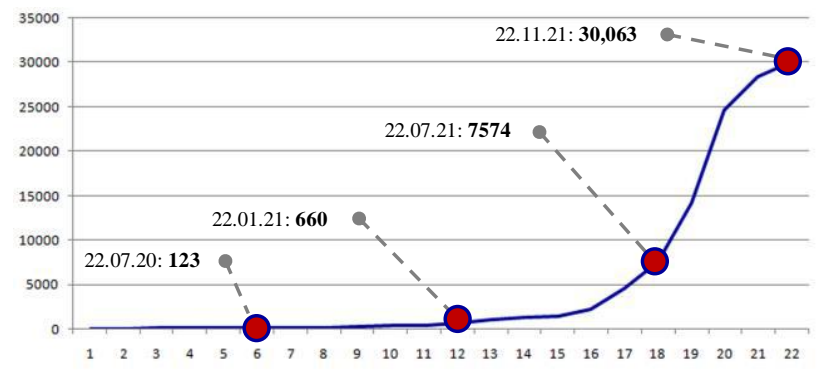

Figure 10. Dynamics of cumulative number of deaths in Malaysia. The vertical axis shows number of deaths; the horizontal axis shows number of a month.
Then a comparison between the number of cases, deaths, and tests recorded during the 3rd phase of the pandemic (23.01.21-22.07.21) and the number of similar parameters recorded during 1.5 years (23.01.20-22.07.21) was carried out for each country.

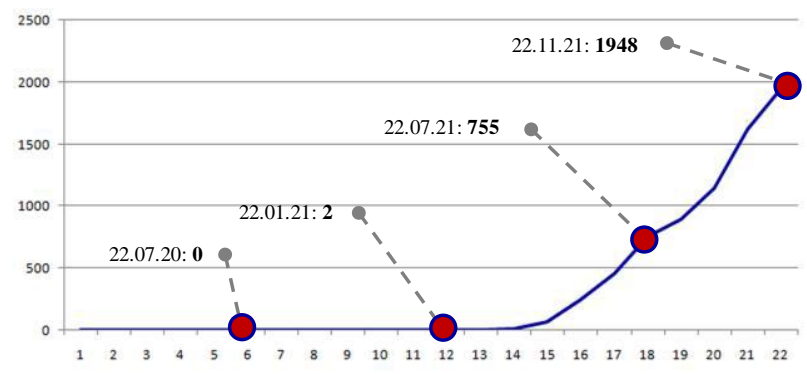

Figure 11. Dynamics of cumulative number of deaths in Mongolia. The vertical axis shows number of deaths; the horizontal axis shows number of a month.

For example, in Mongolia, at the end of the 2nd phase or one year of the pandemic (22.01.21), there were 2 deaths only; but at the end of the 3rd phase or 1.5 years of the pandemic (22.07.21), there were 755 deaths in total. (Fig. 11). After subtracting the first figure from the second, one can conclude that during 6 months of the 3rd phase of the pandemic there were 753 new deaths in Mongolia. If the a number of deaths for the 3rd phase ( $\mathrm{n}=753)$ is divided by the number of deaths for 1.5 years of the pandemic $(n=755)$, it can be concluded that during the 1.5 years of the pandemic, $99.74 \%$ of deaths due to COVID-19 in Mongolia took place during the 3rd phase of the COVID-19 pandemic. 
M. Teppone. COVID-19: Three Phases of the Pandemic

Table 3. (a) Distribution of countries according to CFR, and (b) average CFR during each phase of the COVID-19 pandemic

\begin{tabular}{|c|c|c|c|c|c|c|c|c|}
\hline \multicolumn{7}{|c|}{ (a) } & \multirow{3}{*}{\multicolumn{2}{|c|}{$\begin{array}{c}\text { (b) } \\
\text { Average CFR, \% } \\
\text { in countries with fatal cases }\end{array}$}} \\
\hline & & & & CFR, & & & & \\
\hline \multirow{2}{*}{ Phase } & \multirow{2}{*}{$\mathrm{N}$} & \multirow{2}{*}{$>2.0$} & \multirow{2}{*}{$1.0-2.0$} & \multirow{2}{*}{$<1.0$} & \multicolumn{2}{|c|}{ Including } & & \\
\hline & & & & & $<0.50$ & 0.00 & Average CFR & Countries, $\mathrm{N}$ \\
\hline I & 213 & 110 & 39 & 64 & 41 & 28 & $3.597 \pm 3.732$ & 185 \\
\hline II & 213 & 61 & 61 & 91 & 49 & 19 & $1.863 \pm 2.616$ & 194 \\
\hline III & 213 & 68 & 72 & 73 & 37 & 16 & $2.025 \pm 2.098$ & 197 \\
\hline
\end{tabular}

\section{Results}

Based on the CFR calculated for each phase, the 213 countries were divided into 3 groups (Table 3/a). A group of countries where CFR was less than $1.00 \%$ included countries with CFR less than $0.50 \%$ and with CFR $=0.00 \%$. An average CFR for each phase was calculated for countries $(\mathrm{N})$ where fatal cases were recorded (Table $3 / \mathrm{b}$ ).

Based on the comparison between numbers related to the 3rd phase and the whole period of 1.5 years, all the countries were divided into 6 groups (Table 4). If the ratio between numbers recorded during the 3rd phase and the numbers recorded during the whole 1.5 years of the pandemic is higher than $33.33 \%$, it means the number of cases, or deaths or tests recorded during the $3 \mathrm{rd}$ phase was higher than the average number for each of the three phases. If this ratio is higher than $50.00 \%$, it means that the vast majority of cases, or deaths or tests took place during the 3rd phase of the pandemic. The higher the percentage, the more cases, deaths or tests took place during the 3 rd phase.

Table 4. Distribution of countries into six groups where more than one third of cases, deaths and tests took place during the 3rd phase of the COVID-19 pandemic

\begin{tabular}{|c|c|c|c|c|c|c|c|}
\hline & \multicolumn{6}{|c|}{$\begin{array}{l}\text { Six groups of countries according to the ratio between the number of cases, deaths and tests } \\
\text { recorded in the 3rd phase and the similar numbers recorded during } 1.5 \text { years. }\end{array}$} & \multirow{2}{*}{$\begin{array}{c}\text { Total number of } \\
\text { countries (\%) } \\
\text { where ratio was } \\
\text { more than } 33.33 \%\end{array}$} \\
\hline & $33.33-50 \%$ & $50-60 \%$ & $60-70 \%$ & $70-80 \%$ & $80-90 \%$ & $90-100 \%$ & \\
\hline Cases & 71 & 43 & 29 & 15 & 8 & 14 & $\mathbf{1 8 0}(84.51 \%)$ \\
\hline Deaths & 50 & 43 & 19 & 14 & 14 & 17 & $157(73.71 \%)$ \\
\hline Tests & 52 & 67 & 34 & 19 & 9 & 12 & $193(90.61 \%)$ \\
\hline
\end{tabular}

A list of the countries where the vast majority (80-100\%) of COVID-19 cases or deaths, or tests took place during the 3rd phase of the pandemic is presented in small font below.

Cases [80-90 \%, n=8]: Anguilla, Antigua and Barbuda, Isle of Man, Malaysia, Maldives, Mauritius, Saint Lucia, and Sri Lanka; [90-100\%, $\mathrm{n}=14]$ : British Virgin Islands, Cambodia, Cuba, Fiji, Laos, Mongolia, Papua New Guinea, Saint Kitts and Nevis, Seychelles, Taiwan, Thailand, Timor-Leste, Uruguay, and Vietnam.

Deaths [80-90 \%, n=14]: Antigua and Barbuda, Barbados, Caribbean Netherlands, Curaçao, Eritrea, Namibia, Paraguay, Réunion, Saint Lucia, Somalia, St. Vincent Grenadines, Trinidad and Tobago, Uganda, Zambia; [90-100 \%, n=17]: Botswana, British Virgin Islands, Cambodia, Cuba, Laos, Malaysia, Mongolia, Fiji, Papua New Guinea, Saint Kitts and Nevis; Seychelles, Sri Lanka, Taiwan, Thailand, Timor-Leste, Uruguay, and Vietnam.

Tests: [80-90\%, n=9]; Cyprus, Vietnam, Yemen, Turks and Caicos, Thailand, Denmark, Czechia, Timor-Leste, British Virgin Islands; [90-100 \%, n=12]: Algeria, Austria, Burkina, Cameroon, Chad, DRC, Faso, Fiji, Sierra Leone, Somalia, Sudan, Syria; Taiwan.

\section{Conclusion}

Calculations done in this section have revealed that in most countries, the main number of cases, deaths and tests were recorded during the $3 \mathrm{rd}$ phase of the pandemic.

\section{Twenty Two Months of the COVID-19 pandemic: Dynamics of cases, deaths, tests and CFR}

\section{Objective}

To evaluate dynamics of monthly number of cases, deaths, and tests worldwide during 22 months of the COVID-19 pandemic, and to identify countries with the most dramatic tendency.

4.1. Twenty two months of the COVID-19 pandemic: Overall cases, deaths, tests and CFR worldwide

\section{Objective}

To evaluate dynamics of monthly numbers of cases, deaths, tests and CFR worldwide during 22 months of the COVID-19 pandemic

\section{Material and Methods}

Twenty three sets of databases, dated the 22nd of each month from January 2020 to November 2021, for 213 countries were collected. The databases related to each month for every country were calculated by subtracting the previous month's data from the analyzed month's data. The 
number of cases, deaths, tests as well as monthly ratios between cases and tests $(\mathrm{C} / \mathrm{T})$, deaths and tests $(\mathrm{D} / \mathrm{T}), \mathrm{CFR}$, cases per 1 million $(\mathrm{C} / \mathrm{M})$ and deaths per 1 million $(\mathrm{D} / \mathrm{M})$ for all 213 countries together were counted and presented in Table 5. Monthly number of tests, cases, deaths illustrated in Figures 12-14.

Table 5. Monthly cases, deaths, and tests during 22 months of the COVID-19 pandemic worldwide. There are also ratios between number of cases and tests $(\mathrm{C} / \mathrm{T})$, number of deaths and tests $(\mathrm{D} / \mathrm{T})$, as well as CFR. The highest numbers in the column are highlighted in bold.

\begin{tabular}{|c|c|c|c|c|c|c|c|c|c|}
\hline M,\# & Date & Cases & Deaths & Tests & CFR & $\mathrm{C} / \mathrm{T}$ & $\mathrm{D} / \mathrm{T}$ & $\mathrm{C} / \mathrm{M}$ & D/M \\
\hline 0 & before 22.01 .20 & 579 & 17 & - & 2.936 & - & - & - & - \\
\hline 1 & $23.01 .20-22.02 .20$ & 77,422 & 2,440 & - & 3.152 & - & - & - & - \\
\hline 2 & $23.02 .20-22.03 .20$ & 256,885 & 12,146 & - & 4.728 & - & - & - & - \\
\hline 3 & $23.03 .20-22.04 .20$ & $2,297,673$ & 169,276 & $23,282,447$ & 7.367 & 9.869 & 0.727 & - & - \\
\hline 4 & $23.04 .20-22.05 .20$ & $2,664,254$ & 155,495 & $44,391,233$ & 5.836 & 6.002 & 0.350 & 344 & 20 \\
\hline 5 & $23.05 .20-22.06 .20$ & $3,879,188$ & 134,032 & $63,136,698$ & 3.455 & 6.144 & 0.212 & 500 & 17 \\
\hline 6 & $23.06 .20-22.07 .20$ & $6,186,744$ & 151,989 & $171,564,166$ & 2.457 & 3.606 & 0.089 & 797 & 20 \\
\hline 7 & $23.07 .20-22.08 .20$ & $7,995,415$ & 182,270 & $107,399,739$ & 2.280 & 7.445 & 0.170 & 1,029 & 23 \\
\hline 8 & $23.08 .20-22.09 .20$ & $8,392,192$ & 166,385 & $199,993,233$ & 1.983 & 4.196 & 0.083 & 1,079 & 21 \\
\hline 9 & $23.09 .20-22.10 .20$ & $10,208,746$ & 168,007 & $149,682,016$ & 1.646 & 6.820 & 0.112 & 1,312 & 22 \\
\hline 10 & $23.10 .20-22.11 .20$ & $16,987,950$ & 250,906 & $195,846,982$ & 1.477 & 8.674 & 0.128 & 2,181 & 32 \\
\hline 11 & $23.11 .20-22.12 .20$ & $19,333,794$ & 328,839 & $209,035,776$ & 1.701 & 9.249 & 0.157 & 2,481 & 42 \\
\hline 12 & $23.12 .20-22.01 .21$ & $20,388,751$ & 391,948 & $211,555,219$ & 1.922 & 9.638 & 0.185 & 2,614 & 50 \\
\hline 13 & $23.01 .21-22.02 .21$ & $13,569,785$ & 370,676 & $213,529,397$ & 2.732 & 6.355 & 0.174 & 1,738 & 47 \\
\hline 14 & $23.02 .21-22.03 .21$ & $12,026,578$ & 250,262 & $215,897,738$ & 2.081 & 5.571 & 0.116 & 1,539 & 32 \\
\hline 15 & $23.03 .21-22.04 .21$ & $21,032,036$ & 349,214 & $282,659,828$ & 1.660 & 7.441 & 0.124 & 2,690 & 45 \\
\hline 16 & $23.04 .21-22.05 .21$ & $21,729,103$ & 384,092 & $290,300,012$ & 1.768 & 7.485 & 0.132 & 2,777 & 49 \\
\hline 17 & $23.05 .21-22.06 .21$ & $12,844,311$ & 428,155 & $282,525,550$ & 3.333 & 4.546 & 0.152 & 1,640 & 55 \\
\hline 18 & $23.06 .21-22.07 .21$ & $13,477,158$ & 254,384 & $265,643,220$ & 1.888 & 5.073 & 0.096 & 1,720 & 32 \\
\hline 19 & $23.07 .21-22.08 .21$ & $19,204,383$ & 293,313 & $291,627,554$ & 1.527 & 6.585 & 0.101 & 2,448 & 37 \\
\hline 20 & $23.08 .21-22.09 .21$ & $18,271,358$ & 287,615 & $380,323,725$ & 1.574 & 4.804 & 0.076 & 2,328 & 37 \\
\hline 21 & $23.09 .21-22.10 .21$ & $12,851,934$ & 220,802 & $290,724,128$ & 1.718 & 4.421 & 0.076 & 1,636 & 28 \\
\hline 22 & $23.10 .21-22.11 .21$ & $14,586,015$ & 220,598 & $323,461,722$ & 1.512 & 4.509 & 0.068 & 1,855 & 28 \\
\hline
\end{tabular}

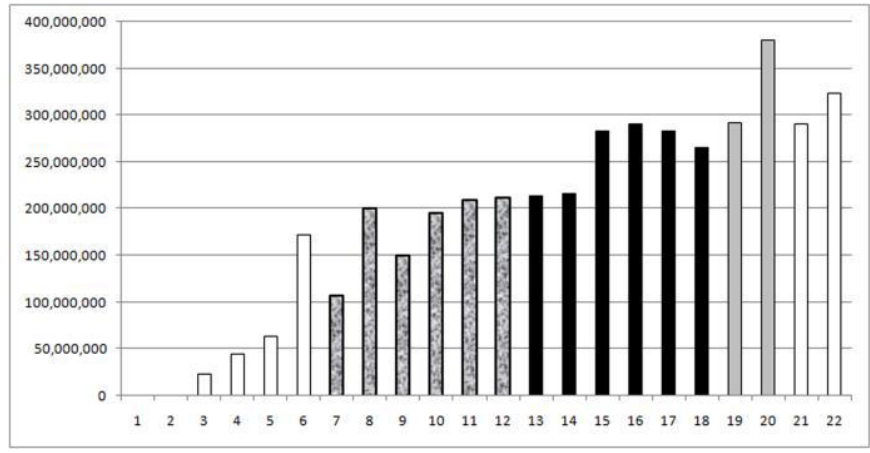

Figure 12. Monthly number of tests. The vertical axis shows number of tests; the horizontal axis shows number of a month. The 1 st phase includes months \# 1-6 (white columns); the 2nd phase includes months \# 7-12 (grey-white columns); the 3rd phase includes months \# 13-18 (black columns); months \# 19-20th (grey columns); months \# 21-22nd (white columns).

\section{Results}

During 22 months of the pandemic, the monthly number of tests increased almost gradually from $23,282,447$ in the 3rd month, up to $380,323,725$ in the 20th month (Fig. 12). The monthly number of cases varied from 77,422 in the first month up to $21,729,103$ in the 16 th month; there are three peaks, in the 11-12th, 15-16th and 19-20th months (Fig. 13). The monthly number of deaths varied from 2,440 in the

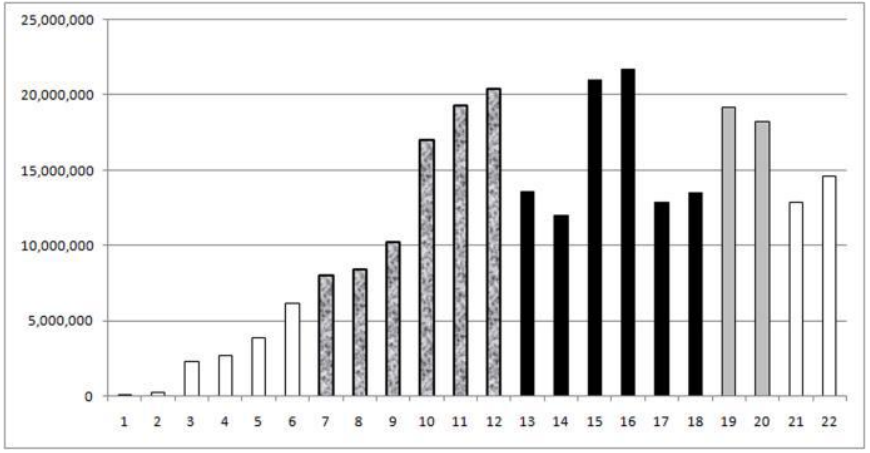

Figure 13. Monthly number of cases. The vertical axis shows number of cases; the horizontal axis shows number of a month. The 1 st phase includes months \# 1-6 (white columns); the 2nd phase includes months \# 7-12 (grey-white columns); the 3rd phase includes months \# 13-18 (black columns); months \# 19-20th (grey columns); months \# 21-22nd (white columns).

first month up to 428,155 in the 17 th month; there are two peaks, in the 12th month and in the 17th month (Fig. 14).

The highest monthly CFR (7.367) and the highest monthly ratio between cases and tests (9.869), as well as deaths and tests (0.727) were in the 3rd month (23.03.20-22.04.20) of the pandemic. Since March 11, 2020 the highest weekly CFR (8.507\%) was estimated for the week April 12-18, 2020, and the highest daily CFR $(9.514 \%)$ was estimated for April 17, 2020. ${ }^{1}$ 


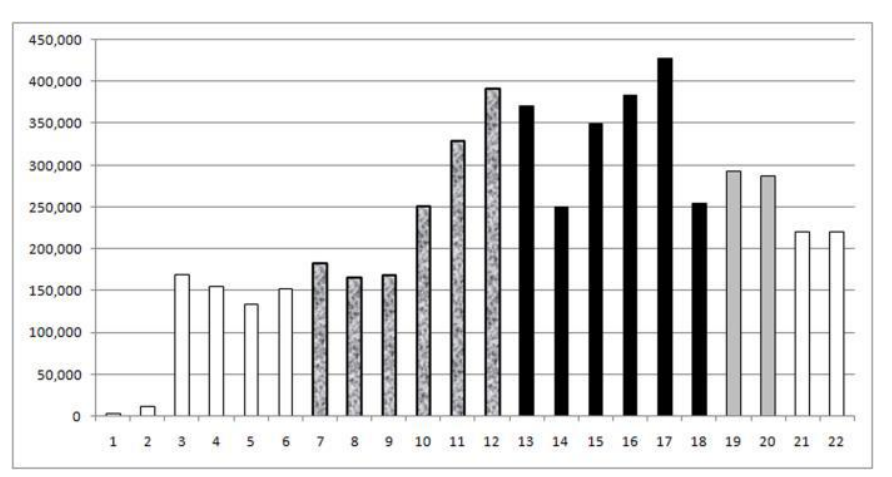

Figure 14. Monthly number of deaths. The vertical axis shows number of deaths; the horizontal axis shows number of a month. The 1st phase includes months \# 1-6 (white columns); the 2nd phase includes months \# 7-12 (greywhite columns); the 3rd phase includes months \# 13-18 (black columns); months \# 19-20th (grey columns); months \# 21-22nd (white columns).

4.2. Evolution of the COVID-19 pandemic before and after the end of the 3rd Phase

\section{Background}

During 1.5 years of the pandemic, in the majority of the countries analyzed, number of COVID-19 cases, deaths and tests were highest during the 3rd phase.

\section{Objective}

To analyze the evolution of COVID-19 pandemic before and after the end of the $3 \mathrm{rd}$ phase

\section{Material and Methods}

Three databases for each country, dated 22.05.21, 22.07.21, and 22.09.21 were collected from the Worldometer website. Then, for each country, the cases, deaths and tests were calculated for 2 periods of time: (1st) 23.05.21-22.07.21 and (2nd) 23.07.21-22.09.21.

The trend of the pandemic was analyzed by dividing the numbers recorded during the 2 nd period by the numbers recorded during the 1 st period, accordingly. If the ratio is more than 1, i.e. more than $100 \%$, it means that after the end of the 3rd phase, there is still an upward trend in the number of COVID-19 cases, deaths, or tests in a certain country.
For example, in the United Kingdom, there were 127,716 total deaths on $22.05 .21 ; 128,980$ on 22.07 .21 , and 135,621 - on 22.09.21. (Fig. 15) Hence, there were 6,641 new deaths recorded during the 2 nd period (23.07.21-22.09.21) and 1,264 new deaths recorded during the 1 st period of time (23.05.21-22.07.21). Dividing 6,641 by 1,264 resulted in 5.225. That means, the number of deaths during the second period was more than five times higher than the number of deaths during the 1 st period. Thus, in the United Kingdom there was a trend pointing to a dramatic increase in the number of deaths, etc.

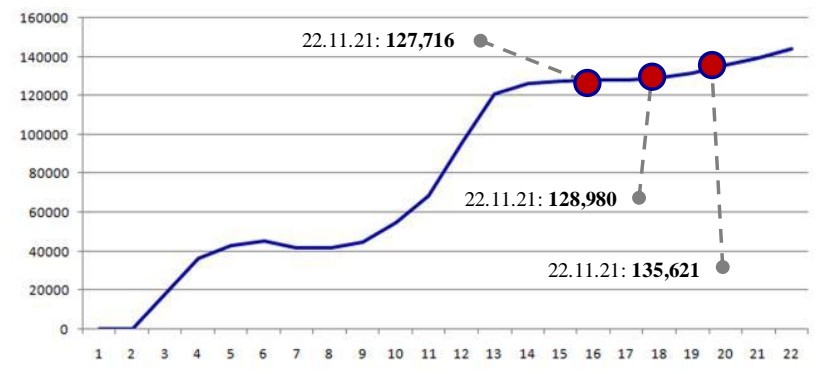

Figure 15. Dynamics of cumulative number of deaths in the United Kingdom. The vertical axis shows number of deaths; the horizontal axis shows number of a month.

\section{Results}

A comparison of the main parameters of the pandemic between the 2 nd and 1 st period of time for each country revealed that in the majority of them, there was an upward trend pointing to an increase in cases $(\mathrm{n}=158 ; 74.178 \%)$, deaths $(n=133 ; 62.441 \%)$ and tests $(n=125 ; 58.685 \%)$. Table 6 .

\section{Conclusion}

A group of countries with a dramatic increase in COVID-19 cases, deaths, and tests during the 2nd period of time (23.07.21-22.09.21), in comparison with the 1st period 23.05.21-22.07.21), was revealed. In some of countries the difference between analyzed parameters exceeded 5-10 times, or even more. In three of them (Guadeloupe, Israel, Vietnam) there was a dramatic increase in all parameters including cases, deaths and tests.

Table 6. Results of a comparison between the number of cases, deaths and tests recorded in the databases of 213 countries during the 2nd (23.07.21-22.09.21) and the 1st (23.05.21-22.07.21) period of time.

\begin{tabular}{|c|c|c|c|c|c|c|c|}
\hline \multirow[t]{2}{*}{$\#$} & \multirow[t]{2}{*}{ Decrease / Increase } & \multicolumn{2}{|c|}{ Cases } & \multicolumn{2}{|c|}{ Deaths } & \multicolumn{2}{|c|}{ Tests } \\
\hline & & $\mathrm{N}$ & $\%$ & $\mathrm{~N}$ & $\%$ & $\mathrm{~N}$ & $\%$ \\
\hline 1 & Decrease $(<100 \%)$ & 53 & 24.88 & 65 & 30.52 & 69 & 32.39 \\
\hline 2 & No change & 2 & 0.94 & 15 & 7.04 & 19 & 8.92 \\
\hline 3 & Increase $(>100 \%)$ & 158 & 74.18 & 133 & 62.44 & 125 & 58.69 \\
\hline & including: & & & & & & \\
\hline & from 0 to $1+n$ & 4 & 01.88 & 16 & 07.51 & 3 & 01.41 \\
\hline & $+100-200 \%$ & 46 & 21.60 & 38 & 17.84 & 91 & 42.72 \\
\hline & $+200-500 \%$ & 54 & 25.35 & 46 & 21.60 & 24 & 11.27 \\
\hline & $+>500 \%$ & 54 & 25.35 & 33 & 15.49 & 7 & 03.29 \\
\hline & Total & 213 & 100 & 213 & 100 & 213 & 100 \\
\hline
\end{tabular}


A list of countries with a dramatic increase in COVID-19 cases, deaths, and tests between 23.07.21 and 22.09.21, is presented in small font below:

Increase in Cases [500-1000\%; n=29]: Yemen, Austria, Estonia, Guinea-Bissau, Japan, USA, Ethiopia, Mauritius, Equatorial Guinea, Martinique, Laos, Burundi, Palestine, Morocco, Togo, Turks and Caicos, Moldova, Barbados, New Zealand, Eswatini, Somalia, Nigeria, Jamaica, Singapore, Greenland, Vietnam, Saint Lucia, Bulgaria, Sao Tome and Principe; [1000-2000\%; n=8]: Bosnia and Herzegovina, Aruba, Montserrat, Romania, Iceland, Montenegro, Serbia, Azerbaijan; [>2000\%; n=16]: Israel, Australia, San Marino, Guadeloupe, CAR, North Macedonia, Bermuda, Albania, Anguilla, French Polynesia, Antigua and Barbuda, Benin, Brunei, Dominica, New Caledonia, Grenada.

Increase in Deaths [by 500-1000\%; n=17] Togo, the United Kingdom, North Macedonia, Kazakhstan, Timor-Leste, Libya, Benin, Belize, Curaçao, Singapore, Saint Lucia, Eswatini, Nigeria, Azerbaijan, Gambia, Guinea-Bissau, Ghana; [1000-2000\%; n=8] Bermuda, Albania, Ivory Coast, Barbados, Morocco, Malta, Burundi, Israel; [>2000\%; n=8] Mauritius, Somalia, Aruba, Guadeloupe, Vietnam, Australia, Martinique, French Polynesia.

Increase in Tests [by 300-500\%; $\mathrm{n}=5$ ] Israel, Vietnam, South Sudan, Falkland Islands, Guadeloupe; [>500\%; n=7] Saint Pierre Miquelon, Brunei, Bhutan, Dominica, Timor-Leste, Thailand, Réunion.

4.3. Comparison of the average monthly number of cases, deaths and tests in each of the 213 countries related to the months \# 21-22 (23.09.21-22.11.21) and to the previous two months \# 19-20 (23.07.21-22.09.21).

\section{Objective}

To evaluate the dynamics of the monthly number of cases, deaths and tests in each of the 213 countries during the months \# 19-22 of the COVID-19 pandemic, and to identify countries with a negative trend.

\section{Material and Methods}

The average number of monthly cases, deaths and tests were counted for two months \# 21-22 (23.09.21-22.11.21) and for the previous two months \# 19-20 (23.07.21-22.09.21). Then a comparison of these parameters was done by dividing the numbers related to the months \# 21-22 by the numbers related to the previous two months \# 19-20. If the ratio was more than 1, i.e. more than $100 \%$, it means that in a certain country, there was a trend pointing to an increase in COVID-19 cases, deaths, or tests. If the ratio was less than one $(<100 \%)$, it means that the parameters of the pandemic had a downward trend - to decrease. Results are presented in Table 7.

\section{Results}

Despite the majority of countries analyzed showing lower average monthly number of cases, deaths, and tests in the last two months (\# 21-22), compared with the same parameters recorded during the previous two months (\# 1920 ), there was a group of countries where the average monthly cases and deaths during the latest months were at least 5 times higher than during the previous two months; and the monthly number of tests during the latest months was at least 2 times higher than during the previous two months. The following list in small font included only countries with a total population of more than $3,000,000$ people.

Increase in Cases [>500\%; $\mathrm{n}=11$ ] Cameroon (526\%), Croatia (536\%), Romania (713\%), Ukraine (844\%), Singapore (973\%), Papua New Guinea (1033\%), Slovakia (1643\%), Czechia (2037\%), Hungary (2066\%), Poland (2537\%), Tanzania (2897\%).

Increase in Deaths [ $>500 \% ; \mathrm{n}=19]$ Egypt (504\%), Austria (546\%), Moldova (565\%), Croatia (625\%), Niger (643\%), Congo (987\%), Cameroon (1058\%), Laos (1064\%), Ukraine (1115\%), Romania (1214\%), Burkina Faso (1271\%), New Zealand (1300\%), Papua New Guinea (1370\%), Czechia (1744\%), Poland (1817\%), Singapore (1856\%), Tanzania (2334\%), Slovakia (2418\%), Hungary (2463\%).

Increase in Tests [>200\%; $\mathrm{n}=8]$ Slovenia (213\%), Israel (219\%), Greece (219\%), Ukraine (226\%), Hungary (235\%), Germany (256\%), Brazil (260\%), Thailand (533\%).

\section{Conclusion}

A comparison of the data related to the months \# 21-22 and to the previous two months \# 19-20 revealed a trend showing a decrease in the number of cases, deaths and tests. Nevertheless, there emerged a group of countries where the main parameters of the pandemic still had a tendency to increase.

Table 7. Results of a comparison between the average monthly number of cases, deaths and tests recorded during two months \# 21-22 (23.09.21-22.11.21) and during the previous two months \# 19-20 (23.07.21-22.09.21).

\begin{tabular}{|c|c|c|c|c|c|c|c|}
\hline \multirow[t]{2}{*}{$\#$} & \multirow[t]{2}{*}{ Decrease / Increase } & \multicolumn{2}{|c|}{ Cases } & \multicolumn{2}{|c|}{ Deaths } & \multicolumn{2}{|c|}{ Tests } \\
\hline & & $\mathrm{N}$ & $\%$ & $\mathrm{~N}$ & $\%$ & $\mathrm{~N}$ & $\%$ \\
\hline 1 & Decrease $(<100 \%)$ & 129 & 60.56 & 108 & 50.70 & 124 & 58.22 \\
\hline 2 & No change & 2 & 0.94 & 10 & 4.70 & 25 & 11.74 \\
\hline 3 & Increase $(>100 \%)$ & 82 & 38.50 & 95 & 44.60 & 64 & 30.04 \\
\hline & including: & & & & & & \\
\hline & from 0 to $1+n$ & 0 & 00.00 & 5 & 02.35 & 3 & 01.41 \\
\hline & $+100-200 \%$ & 32 & 15.03 & 29 & 13.62 & 51 & 23.94 \\
\hline & $+200-500 \%$ & 35 & 16.43 & 33 & 15.49 & 8 & 03.75 \\
\hline & $+>500 \%$ & 15 & 07.04 & 28 & 13.14 & 2 & 00.94 \\
\hline & Total & 213 & 100 & 213 & 100 & 213 & 100 \\
\hline
\end{tabular}


4.4. Comparison of the average monthly number of cases, deaths and tests in each of the 213 countries related to the latest month analyzed \# 22 (23.10.21-22.11.21) and the previous month \# 21 (23.09.21-22.10.21)

\section{Objective}

To evaluate the dynamics of the monthly number of cases, deaths and tests in each of the 213 countries during the months \# 21-22, and to identify countries with a negative tendency.

\section{Material and Methods}

The number of monthly cases, deaths and tests for the months \# 22 (23.10.21- 22.11.21) and \# 21 (23.09.21-22.10.21) was counted in the same manner as in the previous sections. A comparison between two months was done by dividing the numbers related to month \# 22nd by the numbers related to the month \# 21 st. If the ratio is more than 1, i.e. more than $100 \%$, there is still an upward trend in the number of COVID-19 cases, deaths, or tests in a certain country. If the ratio is less than one $(<100 \%)$, it means parameters of the pandemic had a tendency to decrease. Results are presented in Table 8.

\section{Results}

A comparison of the data related to the month \# 22 with the data related to the previous month (\# 21) revealed a trend showing a decrease in number of cases, deaths and tests. Nevertheless, there are groups of countries where the monthly numbers of cases and deaths during the month \# 22 was at least 5 times higher than during the previous month \# 21; and the monthly number of tests during the month \# 22 was at least 2 times higher than during the previous month \# 21. The following list in small font included only countries with a total population of more than $3,000,000$ people.

Increase in Cases [ $>500 \% ; \mathrm{n}=3$ ] Poland (638\%), Czechia (803\%), Hungary $(733 \%)$.

Increase in Deaths [>500\%; $\mathrm{n}=5$ Poland (535\%), Hungary (768\%), Niger (800\%), Czechia (1075), New Zealand (1200\%).

Increase in Tests [>200\%; $\mathrm{n}=7$ ] Nigeria (204\%), Iran $(211 \%)$, Hungary (220\%), Haiti (250\%), Argentina (236\%), Germany (290\%), Denmark (308\%).

\section{Conclusion}

The study done in this section has revealed that during the months \# 21-22 in the majority of countries analyzed, the number of new COVID-19 cases, deaths and tests had shown a tendency to decrease. This is an objective basis for optimism and inspires hope for an end to the pandemic.

Table 8. Results of a comparison between the monthly number of cases, deaths and tests recorded during the month \# 22 (23.10.21-22.11.21) and the previous month \# 21 (23.09.21-22.10.21)

\begin{tabular}{|c|c|c|c|c|c|c|c|}
\hline \multirow[t]{2}{*}{ \# } & \multirow[t]{2}{*}{ Decrease / Increase } & \multicolumn{2}{|c|}{ Cases } & \multicolumn{2}{|c|}{ Deaths } & \multicolumn{2}{|c|}{ Tests } \\
\hline & & $\mathrm{N}$ & $\%$ & $\mathrm{~N}$ & $\%$ & $\mathrm{~N}$ & $\%$ \\
\hline 1 & Decrease $(<100 \%)$ & 118 & 55.40 & 117 & 54.93 & 96 & 45.07 \\
\hline 2 & No change & 6 & 2.82 & 16 & 7.51 & 40 & 18.78 \\
\hline 3 & Increase $(>100 \%)$ & 89 & 41.78 & 80 & 37.56 & 77 & 36.15 \\
\hline & including: & & & & & & \\
\hline & from 0 to $1+n$ & 0 & 00 & 10 & 04.69 & 9 & 04.23 \\
\hline & $+100-200 \%$ & 48 & 22.53 & 49 & 23.01 & 57 & 26.76 \\
\hline & $+200-500 \%$ & 35 & 16.43 & 16 & 07.51 & 10 & 04.69 \\
\hline & $+>500 \%$ & 6 & 02.82 & 5 & 02.35 & 1 & 00.47 \\
\hline & Total & 213 & 100 & 213 & 100 & 213 & 100 \\
\hline
\end{tabular}

\section{Discussion}

An analysis of the main epidemiological parameters worldwide has resulted in distinguishing three phases of the pandemic worldwide: these phases are different in terms of the number of new tests, cases and deaths, and they have their own features in each country.

The first phase (23.01.20-22.07.20) began with new cases and first victims of COVID-19 identified outside China. During the first phase, diagnostic tests to detect SARS-CoV-2 were used mainly on people with symptoms and their immediate contacts. Clinical trials of potentially effective drugs were in the initial phase, and invasive mechanical ventilation, which had no therapeutic effect on patients with COVID-19, was used very actively. Since protocols of treatment were not developed yet, and the number of confirmed cases was small, the CFR value was the highest in the history of the pandemic.
During the second phase (23.07.20-22.01.21) clinical trials were completed and doctors received effective protocols of treatment. ${ }^{65,82,85}$ Despite the emergence of new variants of the virus, mechanisms of the disease development remained unchanged and were not associated with a more severe course of the disease. ${ }^{118-119}$ In most countries the mortality rate was very low. By the end of the second phase, worldwide statistics indicated the imminent end of the pandemic. ${ }^{1}$

During the third phase (23.01.21-22.07.21) of the pandemic, in various countries, mass vaccination was introduced to protect people against SARS-CoV-2. Coincidentally, a sudden rise in the number of new cases and deaths happened, and it could not be explained rationally. The highest number of monthly deaths was recorded between May 23, and June 22, 2021. The most dramatic evolution of the epidemic curve occurred in the countries where doctors had successfully battled COVID-19 during the first year of the pandemic [see 
appendix: Cambodia, Cuba, Laos, Malaysia, Mongolia, the Seychelles, Singapore, Shi Lanka, Taiwan, Tanzania, Thailand, Uruguay, Vietnam, etc.]. The further evolution of the pandemic was an undulating continuation of the third phase.

A group of countries where more than $90 \%$ of deaths were recorded during the third phase included Botswana, British Virgin Islands, Cambodia, Cuba, Laos, Malaysia, Mongolia, Fiji, Papua New Guinea, Saint Kitts and Nevis; Seychelles, Sri Lanka, Taiwan, Thailand, Timor-Leste, Uruguay, and Vietnam.

After the end of the 3rd phase, during the next two months (\#19-20) in the majority of countries analyzed, the number of deaths continued to increase. Dramatic increases in deaths during these months took place in the following countries: Albania, Aruba, Australia, Azerbaijan, Barbados, Belize, Benin, Bermuda, Burundi, Curaçao, Eswatini, French Polynesia, Gambia, Ghana, Guadeloupe, Guinea-Bissau, Ivory Coast, Israel, Kazakhstan, Libya, Malta, Martinique, Mauritius, Morocco, Nigeria, North Macedonia, Singapore, Saint Lucia, Somalia, Timor-Leste, Togo, the United Kingdom, and Vietnam.

In the following countries the number of deaths continued to increase even during the latest month analyzed (\# 22): Burkina Faso, Cameroon, Congo, Djibouti, Gabon, Hungary, Laos, Latvia, Lesotho, Papua New Guinea, Poland, Romania, Singapore, Slovakia, South Sudan, Tanzania, Ukraine, etc.

\section{Conclusions}

Two years have passed since the Wuhan Municipal Health Commission announced a pneumonia epidemic. Despite the positive dynamics during October-November 2021, the current pandemic is not over yet, and additional research is necessary to identify the cause of the increase in the number of new cases and deaths observed during the third phase of the pandemic.

6.1. After simulating a forecast done by Neil M. Ferguson and his team (Imperial College London) in March 2020, ${ }^{120}$ many countries introduced social distancing, quarantines and lockdowns. Despite objections to Mr. Ferguson's calculations from his own colleagues, ${ }^{121}$ and the United Kingdom's removal of COVID-19 from the category of high consequence infectious disease, ${ }^{122}$ quarantine measures were continued. As far as medical prophylactic measure in the form of global vaccination program is concerned, it had already been proposed before the new disease got its name. ${ }^{115,123}$

There are plenty of studies which revealed that in certain cases, various prophylactic measures used to prevent the spread of SARS-CoV-2 and other viruses and bacteria, could have negative effects on the human body, ${ }^{124-225}$ have low efficacy or may even be useless in terms of prevention of diseases. ${ }^{226-253}$

Since the main target for SARS-CoV-2 are people with weak immunity, ${ }^{13,40-42}$ and prolonged mental stress affects both the entire body, ${ }^{124-126,254}$ and the immune system in particular, ${ }^{255-259}$ a new study is needed to answer the question, if medical and non-medical measures used to prevent the spread of SARSCoV-2 could affect natural immunity. This question is especially relevant for countries which had a dramatic increase in cases and deaths during the third phase of the pandemic. An affirmative answer to this question is highly probable since certain types of medical prophylactic products can reprogram immune system response, ${ }^{163}$ and without a new dose of a booster immunity of the body declines after 3-6 months. ${ }^{252}$ Moreover, there has been a tendency towards an increase in herpes zoster cases, ${ }^{260-270}$ and "the link between compromised immunity and herpes zoster has been recognized for more than half a century". ${ }^{271-272}$

Since the list of criteria for exclusion from clinical trials with anti-SARS-CoV-2 vaccines included people who had received immune-modifying drugs, ${ }^{273}$ due to early immunologic response to vaccination, ${ }^{274}$ and people who have natural durable specific immunity after recovery from COVID-19, ${ }^{275-284}$ these two groups of people should be analyzed separately, and at least four groups of studies are necessary, including:

1) unvaccinated people who have not received immunomodulatory drugs;

2) unvaccinated people who have received immunomodulatory drugs;

3) unvaccinated people who recovered from COVID-19 spontaneously or after treatment;

4) vaccinated people who received one, two or more doses of vaccine and boosters.

6.2. In July 2021 it was announced that after December 31, 2021, CDC would withdraw the request to the U.S. Food and Drug Administration for Emergency Use Authorization of the CDC 2019-Novel Coronavirus (2019-nCoV) Real-Time RTPCR Diagnostic Panel. ${ }^{285}$

Previously, some experts had already rejected the reliability and validity of the RT-PCR test to be used for screening. ${ }^{286-289}$ That decision has been done to avoid negative epidemic consequences of the false positive results which could be caused by contamination of the environment ${ }^{290-294}$ or test kits, ${ }^{288,295-301}$ by the limitations of the diagnostic method itself, ${ }^{302}$ and errors of the software used, ${ }^{303}$ as well as by application of a cycle threshold of 25-30 or higher. ${ }^{304-306}$

A number of false positive results could be dramatically increased if the RT-PCR test is used to conduct large-volume screening at the area of low prevalence of SARS-CoV-2. ${ }^{307-309}$ Thus, mass-screening with RT-PCR test could create a false epidemic without a real basis. ${ }^{310}$

At the time when Dr. Tedros A. Ghebreyesus assumed the outbreak of the pandemic, ${ }^{48}$ objective data for such a decision was not available yet. Therefore, no official documents were issued and published. Five days later, Dr. Ghebreyesus explained that WHO did not know how many people were infected, and invited all countries to fill up this informative gap, by suggesting: "We have a simple message for all countries: test, test, test". ${ }^{311}$ Mass testing resulted in sudden outbreaks of COVID-19 in many countries and this fact could not be explained rationally based on the natural evolution of infectious diseases. ${ }^{312}$

Since the recent study by S. Shah, A. Stang, et al (2021) revealed that application of mass screening with RT-PCR test had no value to predict severe cases or deaths, ${ }^{289,313}$ an additional study is required to answer the question - if screening with RT-PCR test can increase the number of deaths, especially in countries where quarantine facilities do not provide isolated rooms for each person suspected to be infected. ${ }^{314-316}$ 
6.3. One can assume that the application of non-specialized premises for quarantine and treatment of people suffering from infectious diseases can lead to unpredictable consequences. For example, the conversion of a new general municipal hospital (\#40) in Moscow City into a specialized hospital for COVID-19 patients without reconstructions according to the hygienic requirements for infectious hospitals resulted in the steady increase in hospital mortality. (Fig. 16) Three fourths of the patients died due to sepsis caused by $K$. Pneumoniae, $A$. Baumannii, P. Aeruginosa, E. Coli, S. Aureus, fungus, etc. ${ }^{317}$
Since these data were presented by the head physician of the modern and well equipped hospital, one can assume that mass mortality from nosocomial infection was a common occurrence in COVID-19 hospitals worldwide. ${ }^{318-322}$

Therefore, a thorough investigation of the causes of death is necessary to distinguish between deaths from COVID-19 and deaths from other causes. Many statistical errors caused by imperfect diagnostics and registration are likely would be found. ${ }^{250,323-325}$

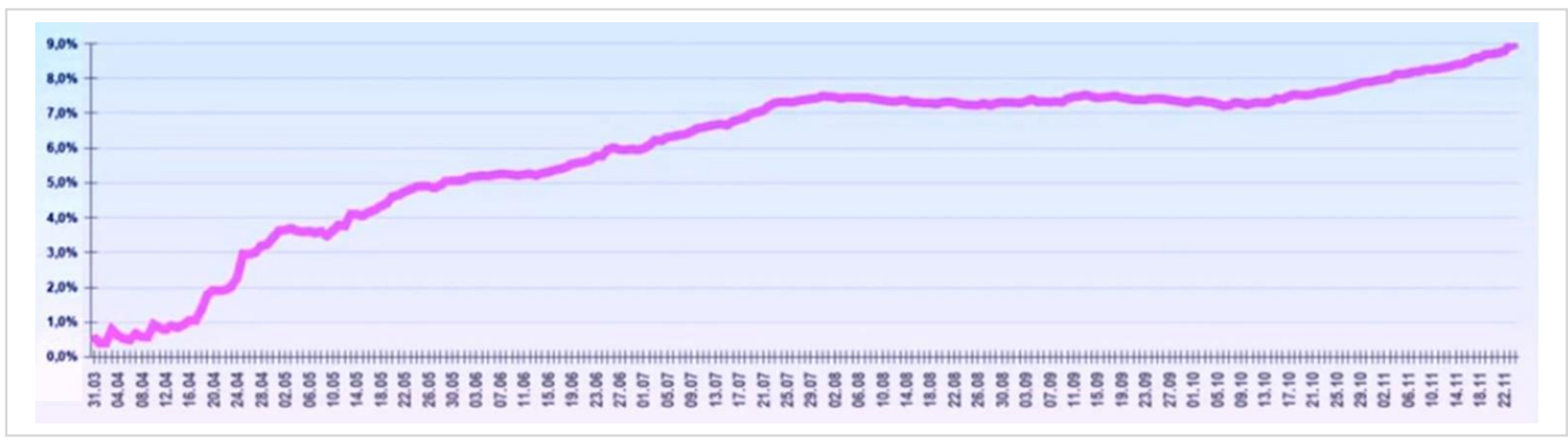

Figure 16. A steady increase in mortality in the leading anti-COVID-19 hospital in Moscow City. ${ }^{317}$

6.4. A comparison of different therapeutic methods and protocols used during the current pandemic should be done to identify the most effective ones. ${ }^{65,82,85,86,326-329}$ An equally important task is to analyze information on the preventive effects of certain drugs, food supplements, vitamins and microelements. ${ }^{330-347}$ This analysis should be carried out by experts in the appropriate field who have already demonstrated low mortality using their therapeutic protocols, but not by an outside reviewer who has no practical experience with analyzed remedies and who selects and rejects publications using an unprofessional view of the reviewed remedy or method. Otherwise, we can get negative results which we have already been warned by I. Prigogine et al., (1984): "what for generations had been a source of joy and amazement withers at its touch" (in this quote 'it' - means the spirit of science). ${ }^{348}$ Global negative consequences of unprofessional review of the topic can be demonstrated by the example of the use of hydroxychloroquine and chloroquine, where reviewers "were unable to confirm a benefit" of these effective drugs. ${ }^{84}$

Thus, only complete information regarding the positive and negative impact ${ }^{349}$ of medical and non-medical methods of diagnostics and prophylaxis of COVID-19 can help to organize effective measures to end the current pandemic and prevent a similar one from occurring in the future.

Presumably, there are several causes of the negative evolution of the current pandemic including (1) overreliance on PCR tests, (2) application of non-specialized premises for quarantine and treatment, (3) following therapeutic protocols used in countries with high number of deaths, (4) decrease in individual and herd immunity and (5) ignoring prophylactic treatment.
It can be suggested that the use of immunomodulatory drugs (for example, thymus extract or thymic peptides) should be included in the treatment of people with compromised T-cell immunity. Prophylactic as well as therapeutic protocols should also be changed from the 'standard' to 'personalized' ones.

Appendix includes illustrations for the following countries: Australia, Azerbaijan, Belarus, Cambodia, Cuba, Czechia, Denmark, Finland, Germany, Hungary, India, Indonesia, Israel, Italy, Japan, Kazakhstan, Laos, Malaysia, Mongolia, Morocco, Namibia, Norway, Paraguay, Russia, Poland, the Seychelles, Singapore, South Korea, Spain, Sri Lanka, Sweden, Taiwan, Tanzania, Thailand, Ukraine, the United Kingdom, the United States, Uruguay, Vietnam, Zimbabwe.

\section{Disclosure Statement}

The author declares there are no conflicts of interest in the submitted manuscript. This research did not receive any specific grant from funding agencies in the public, commercial, or notfor-profit sectors. 


\section{References}

Remark: A list of the references includes some articles or manuscripts, which have not been peer reviewed yet, or were published and then retracted. They are not recommended to doctors who have not enough knowledge and experience to evaluate the quality of a study.

1. Teppone M. One Year of COVID-19 Pandemic: Case Fatality Ratio and Infection Fatality Ratio. A Systematic Analysis of 219 Countries and Territories. Preprints 2021; 2021070185 (doi: 10.20944/ preprints202107.0185.v1).

2. Pneumonia of unknown cause - China, 5 Jan, 2020. [cited 2021 Dec 30]. Available from: https://www.who.int/csr/don/05-january2020-pneumonia-of-unkown-cause-china/en/

3. Tan WJ, Zhao XA, Ma XJ, et al. Notes from the Field: A Novel Coronavirus Genome Identified in a Cluster of Pneumonia Cases Wuhan, China 2019-2020. - China CDC Weekly 2020; Jan 21, 2(4): 61-62; DOI: $10.46234 / \mathrm{ccdcw} 2020.017$

4. Novel Coronavirus (2019-nCoV). Situation Report, 22. - WHO: 11 February 2020. [cited 2021 Dec 30]. Available from: https://apps. who.int/iris/handle/10665/330991

5. COVID-19 was in Spain a year before breakout. - EurActive, Jun 29, 2020. [cited 2021 Dec 30]. Available from: https://www.euractiv. com/section/all/short_news/covid-19-was-in-spain-a-year-before-breakout/

6. Apolone G, Montomoli E, Manenti A, et al. Unexpected detection of SARS-CoV-2 antibodies in the prepandemic period in Italy. - Tumori. 2020 Nov 11:300891620974755. doi: 10.1177/0300891620974755.

7. Shen LB, He FN, Zhang Z, The Early Cryptic Transmission and Evolution of SARS-CoV-2 in Human Hosts. - SSRN Electronic Journal, 2020, Jan; DOI: 10.2139/ssrn.3724275

8. Carrat F, Figoni J, Henny J, et al. Evidence of early circulation of SARS-CoV-2 in France: findings from the population-based "CONSTANCES" cohort. Eur J Epidemiol. 2021; Feb; 36(2): 219222. doi: 10.1007/s10654-020-00716-2.

9. Basavaraju SV, Patton ME, Grimm K, et al. Serologic Testing of US Blood Donations to Identify Severe Acute Respiratory Syndrome Coronavirus 2 (SARS-CoV-2)-Reactive Antibodies: December 2019. January 2020. Clin Infect Dis. 2021; Jun 15; 72(12): e1004-e1009. doi: $10.1093 / \mathrm{cid} / \mathrm{ciaa} 1785$.

10. US scientists report earliest known COVID-19 case a solid proof; next stage should be focused especially on the US: Chinese epidemiologist. - Global Times, Jun 16, 2021. [cited 2021 Dec 30] https://www.globaltimes.cn/page/202106/1226339.shtml

11. Manning J, Zaidi I, Lon C, et al. Pre-pandemic SARS-CoV-2 serological reactivity in rural malaria-experienced Cambodians. - medRxiv 2021.09.27.21264000; doi: https://doi.org/10.1101/2021.09.27.21264000

12. Pradhan P, Pandey AK, Mishra A, et al. Uncanny similarity of unique inserts in the 2019-nCoV spike protein to HIV-1 gp120 and Gag. bioRxiv, 2020, Jan 31; doi:10.1101/2020.01.30.927871. [withdrawn on 2020, Feb 2]

13. Diao B, Wang CH, Tan YJ, et al. Reduction and Functional Exhaustion of T-Cells in Patients with Coronavirus Disease 2019 (COVID-19). - Front Immunol, 2020; May 1, 11: 827; medRxiv, 2020, Feb 20.

14. Urmantseva A. The Case of Virologists: New facts about the laboratory origin of the source of COVID-19. - Izvestia, Mar 23, 2020. [Russian] [cited 2021 Dec 30]. Available from: https://iz.ru/990058/annaurmantceva/delo-virusologov-novye-fakty-o-laboratornom-proiskhozhdenii -istochnika-covid-19

15. Holmes EC, Goldstein SA, Rasmussen AL, et al. The origins of SARS-CoV-2: A critical review. Cell. 2021;184(19):4848-4856. doi:10.1016/j.cell.2021.08.017

16. Covid: Australian vaccine abandoned over false HIV response. - BBC News, 2020, Dec 11. [cited 2021 Dec 30] Available from: https://www.bbc.com/news/world-australia-55269381
17. Infectionists of the Russian Federation and China: the strangeness of the virus is completely incomprehensible, "we are faced with something new". - NewsRu, 2020, Apr 20. [cited 2021 Dec 30]. Available from: https://www.newsru.com/russia/20apr2020/strange_virus.html

18. Worldometers web site [cited on various dates from 29.01.20 to 31.12.21]; Available from: [https://web.archive.org/web/*/https:// www.worldometers.info/coronavirus/, etc.

19. Chinese mainland reports 82,692 overall confirmed COVID-19 cases as Wuhan revises figures: official. - Xinhua, April 17, 2020. [cited 2021 Dec 30]. Available from: http://en.people.cn/n3/2020/0417/ c90000-9681219.html

20. Santa Clara County's COVID-19 Death Toll Drops by 505 After Data Change. NBC Bay City News, 2021, July 2. [cited 2021 Dec 30]. Available from: https://www.nbcbayarea.com/news/local/ santa-clara-countys-covid-19-death-toll-drops-by-505-after-datachange/2585739/

21. The weekly cycle of deaths from coronavirus in the world. YandexZen, Jun 2, 2020. [cited 2021 Dec 30]. Available from: https://zen.yandex.ru/media/id/5e246015433ecc00b9398413/182nedelnyi-cikl-smertnosti-ot-koronavirusa-v-mire-5ed387e90840737 a544a944a

22. Teppone M. [The weekly cycle of mortality among patients with COVID-19]. Probl Sotsialnoi Gig Zdravookhranenniiai Istor Med. 2021; Jan; 29(1): 14-24. [Russian]. doi: 10.32687/0869-866X2021-29-1-14-24.

23. Paas-Lang C. Almost 2 years later, Anthony Fauci didn't think COVID-19 pandemic would have lasted this long. - CBC News, December 12, 2021. [cited 2021 Dec 30]. Available from: https://www. cbc.ca/news/politics/anthony-fauci-pademic-rbl-1.6282521

24. The Circulation of Wei-energy [Wei Qi Xing]. Ch. 76. - In: Yellow Emperor's Canon Internal Medicine, translated and edited by L. S. Wu, Q. Wu, - Beijing: China Science \& Technology Press, 1997: 799-803

25. de Kruif, P. Koch: The Death Fighter. - In: Kruif de, P. Microbe hunters. - New York: Harcourt, etc., 1926: 143-144.

26. Grosman SC. Alterations in Temperature Regulation. - In: Grosman SC, Porth CM. Porth's Pathophysiology: Concepts of Altered Health States. 9th ed. - Philadelphia, Baltimore, New York, etc.: Wolters Kluwer; Lippincott Williams \& Wilkins, 2014: 216-229.

27. Acupuncture: A Comprehensive Text. Ed. Shanghai Zhong yi xue yuan. Translated in English and edited by O'Connor J, Bensky D. - Chicago: Eastland Press, 1981, p. 550.

28. Brown J. Sthenic and asthenic diseases, and diatheses. - In: Brown J, editor. Elements of medicine. - London: J. Johnson; 1795, V 1, p. 49-53.

29. Vvedensky NE. Excitation, Inhibition and Narcosis. - St. Petersburg, Stasulevich Press, 1901 [Russian].

30. Uktomsky AA. Dominant as a Working Principle of Nerve Centers. - Rus. Fiziol. Zhurn, 1923, 6, 31-45. [Russian]

31. Selye H. A Syndrome produced by Diverse Nocuous Agents. Nature, 1936, July 4, V. 138, N 3479: 32; https://doi.org/10.1038/138032a0

32. Tan SY, Yip A. Hans Selye (1907-1982): Founder of the stress theory. Singapore Med J. 2018;59(4):170-171. doi:10.11622/smedj. 2018043

33. Brown-Séquard CÉ. The effect produced on man by subcutaneous injections of a liquid obtained from the testicles of animals. Lancet, 1889; July 20, 134 (3438): 105-107. DOI: https://doi.org/10.1016/ S0140-6736(00)64118-1

34. Kahane M. [On Organotherapy]. Centralblatt für die gesammte Therapie (Wien), 1893, Heft 11: 641-648, 705-711 [German].

35. Scientific Basis of Organotherapy, editorial. JAMA, 1900; XXXV(23): 1483-1484. doi:10.1001/jama.1900.02460490041004

36. Lerch O. Organotherapy. - In: Rational therapy. - Troy, NY: The Southworth Company, 1919, p. 351-405. 
37. Sheppard JB. Organotherapy. J Natl Med Assoc. 1923 Jan;15 (1): 31-33.

38. Langdon-Brown W. Organotherapy. - Br Med J, 1938, Oct 15, 2(4058): 773-776. doi: https://doi.org/10.1136/bmj.2.4058.773

39. Fleming A. On the Antibacterial Action of Cultures of a Penicillium, with Special Reference to their Use in the Isolation of B. influenzæ. - Br J Exp Pathol. 1929; 10(3): 226-236.

40. Mueller AL, McNamara MS, Sinclair DA. Why does COVID19 disproportionately affect older people? Aging (Albany NY). 2020 May 29;12(10):9959-9981. doi: 10.18632/aging.103344. Epub 2020 May 29.

41. Palmer S, Cunniffe N, Donnelly R. Risk of COVID-19 hospitalization rises exponentially with age, inversely proportional to T-cell production. - medRxiv, 2020, Aug 31. medRxiv 2020.08.25. 20181487; doi: https://doi.org/10.1101/2020.08.25.20181487; [New: doi: 10.1098/rsif.2020.0982].

42. Khavinson VK, Kuznik BI, Trofimova SV, et al. Results and Prospects of Using Activator of Hematopoietic Stem Cell Differentiation in Complex Therapy for Patients with COVID-19. - Stem Cell Rev Rep. 2021 Feb;17(1):285-290. doi: 10.1007/s12015-020-10087-6.

43. Zhang ZJ. Shang Han Lun: Treatise on Febrile Diseases Caused by Cold. - Beijing: New World Press; 1986.

44. Liu GH. Warm diseases: A clinical guide. - Seattle: Eastland Press, 2001.

45. Panin L. Biochemical Mechanisms of the Stress. - Novosibirsk: Nauka (Science), 1983 [Russian]

46. Isatidis Folium and Radix (Da Qing Ye / Ban Lan Gen). - In: Bensky D, Clavey SC, Stoger E. Materia Medica (3rd ed). - Seattle: Eastland Press; 2004, p. 156-160.

47. Wong T, Stang AS, Ganshorn $\mathrm{H}$, et al. Combined and alternating paracetamol and ibuprofen therapy for febrile children. Evid Based Child Health. 2014; 9(3): 675-729. doi: 10.1002/ebch.1978.

48. WHO Director-General's opening remarks at the media briefing on COVID-19. - March 11, 2020. [cited 2021 Dec 30]. Available from: https://www.who.int/director-general/speeches/detail/who-directorgeneral-s-opening-remarks-at-the-media-briefing-on-covid-19---11march-2020

49. Off-label use of medicines for COVID-19: Scientific brief. March 31, 2020. [cited 2021 Dec 30]. Available from: https://www.who. $\mathrm{int} /$ news-room/commentaries/detail/off-label-use-of-medicines-forcovid-19

50. Liu XY, Li Z, Liu S, et al. Therapeutic effects of dipyridamole on COVID-19 patients with coagulation dysfunction. - medRxiv 2020, Feb 27, 20027557; doi: https://doi.org/10.1101/2020.02.27.20027557

51. Tang N, Bai H, Chen X, Gong J, Li D, Sun Z. Anticoagulant treatment is associated with decreased mortality in severe coronavirus disease 2019 patients with coagulopathy. J Thromb Haemost. 2020; May;18(5): 1094-1099. doi: 10.1111/jth.14817. Epub 2020 Apr 27.

52. Heidary F, Gharebaghi R. Ivermectin: a systematic review from antiviral effects to COVID-19 complementary regimen. J Antibiot, 2020; 73, 593-602. https://doi.org/10.1038/s41429-020-0336-Z

53. Rajter JC, Sherman MS, Fatteh N, et al. ICON (Ivermectin in COVID Nineteen) study: Use of Ivermectin is Associated with Lower Mortality in Hospitalized Patients with COVID19. medRxiv 2020.06 .06.20124461; doi: https://doi.org/10.1101/2020.06.06.20124461

54. Deftereos SG, Siasos G, Giannopoulos G, et al. The Greek study in the effects of colchicine in COVID-19 complications prevention (GRECCO-19 study): Rationale and study design. Hellenic J Cardiol. 2020 Jan-Feb;61(1):42-45. doi: 10.1016/j.hjc.2020.03.002.

55. Montealegre-Gómez G, Garavito E, Gómez-López A, et al. Colchicine: A potential therapeutic tool against COVID-19. Experience of 5 patients [Colchicina: una herramienta terapéutica potencial frente a COVID-19. Experiencia en 5 pacientes]. Reumatol Clin. 2021; 17(7): 371-375. [Spanish] doi:10.1016/j.reuma.2020.05.001
56. Schwartz L, Henry M, Summa M, Vierling C. [Open Trial Testing Methylene Blue in Covid-19]. - Guerir du Cancer, France, 2020, Mar 29. [French] [cited 2021 Dec 30]. Available from: https://guerir -ducancer.fr/essai-ouvert-testant-le-bleu-de-methylene-dans-le-covid-19/

57. Jin C, Yu B, Zhang J, et al. Methylene blue photochemical treatment as a reliable SARS-CoV-2 plasma virus inactivation method for blood safety and convalescent plasma therapy for COVID-19. BMC Infectious Diseases. 2021 Apr;21(1):357. DOI: 10.1186/s12879-02105993-0.

58. Antimalarial drug confirmed effective on COVID-19. - Xinhua, Feb 17, 2020. [cited 2021 Dec 30]. Available from: http://www. xinhuanet.com/english/2020-02/17/c_138792545.htm

59. Gao J, Tian Z, Yang X. Breakthrough: Chloroquine phosphate has shown apparent efficacy in treatment of COVID-19 associated pneumonia in clinical studies. Biosci Trends. 2020; Mar 16; 14(1): 72-73. doi:10.5582/bst.2020.01047.

60. Kapoor KM, Kapoor A. Role of Chloroquine and Hydroxychloroquine in the Treatment of COVID-19 Infection. A Systematic Literature Review. - medRxiv 2020.03.24.20042366; doi: https://doi. org/10.1101/2020.03.24.20042366

61. Lukyanov SA, Kuznik BI, Shapovalov KG, Khavinson VK, Smolyakov YN, et al. Thymalin as a Potential Alternative in the Treatment of Severe Acute Respiratory Infection Associated with SARSCoV-2. - Int J Immun. Immunother. 2020; Aug, 7(2): 055, DOI: $10.23937 / 2378-3672 / 1410055$

62. Liu YP, Pan Y, Hu ZH. Thymosin Alpha 1 Reduces the Mortality of Severe Coronavirus 2019 by Restoration of Lymphocytopenia and Reversion of Exhausted T Cells. - Clin. Infect. Dis. 2020; May 22; ciaa630. doi: 10.1093/cid/ciaa630

63. Laskavyy VV, Shurdov M.A. Agent for the treatment of coronaviral, retroviral infections and hepatitis C. - Priority to RU2020112322A on March 26, 2020; Application granted on December 15, 2020. [Russian] https://patentimages.storage. googleapis.com/36/10/5d/5d91fbf38d44ca/RU2738719C1.pdf

64. Zhang R, Wang X, Ni L, et al. COVID-19: Melatonin as a potential adjuvant treatment. Life Sci. 2020; 250: 117583. doi: 10.1016/j.lfs.2020.117583 / Published online 2020 Mar 23

65. Derwand R, Scholz M, Zelenko V. COVID-19 outpatients: early risk-stratified treatment with zinc plus low-dose hydroxychloroquine and azithromycin: a retrospective case series study. Int $\mathbf{J}$ Antimicrob Agents. 2020; 56(6): 106214. doi:10.1016/j.ijantimicag.2020.106214

66. Lodyagin AN, Batotsyrenov BV, Shikalova IA, Voznyuk IA. Acidosis and toxic hemolysis - goals of pathogenetic treatment of polyorgan pathology in Covid-19. - Bull Rehab Med. 2020; 97 (3): 25-30. [Russian] https://doi.org/10.38025/ 2078-1962-2020-97-3-25-30

67. Shintake T. Possibility of Disinfection of SARS-CoV-2 (COVID19) in Human Respiratory Tract by Controlled Ethanol Vapor Inhalation. Okinawa Institute of Science and Technology Graduate University, 2020, Mar 13. https://arxiv.org/ftp/arxiv/papers/2003/2003.12444.pdf

68. Cao Y. Suggestion Using Alcohol Vaporization or Nebulization Inhalation Therapy for Pneumonitis Caused by Coronavirus. - Preprint from SSRN, 2020, Feb 28; DOI: 10.2139/ssrn.3545744 PPR: PPR303804 [Retracted]

69. Shogenova LV, Petrikov SS, Zhuravel SV, et al. Thermal Helium-Oxygen Mixture as Part of a Treatment Protocol for Patients with COVID-19. - Ann Rus Acad Med Sci, 2020, 75(5S): 353-362. [Russian] doi:10.15690/vramn1412

70. Gootnick A, Lipson Hi, Turbin J. Inhalation of ethyl alcohol for pulmonary edema. N Engl J Med. 1951; Nov 29; 245(22):842-3. doi: 10.1056/NEJM195111292452202.

71. Noda N, Watanabe M, Yamada F, Fujimoto S. [Virucidal activity of alcohols. Virucidal efficiency of alcohols against viruses in liquid phase]. Kansenshogaku Zasshi. 1981 May; 55(5): 355-66. [Japanese] doi: 10.11150/kansenshogakuzasshi1970.55.355. 
72. Valli G, Paoletti P, Savi D, et al. Clinical use of Heliox in asthma and COPD. Monaldi Arch Chest Dis. 2007 Sep;67(3):159-64. doi: 10.4081/monaldi.2007.488.

73. Tan CK, Herbal medicines being used on the coronavirus frontline, but mainly in China. NIKKEI Asia, May 8, 2020. [cited 2021 Dec 30]. Available from: https://asia.nikkei.com/Business/Pharmaceuticals/ Traditional-Chinese-cures-battle-for-acceptance-in-COVID-19-fight

74. Cui HT, Li YT, Guo LY, et al. Traditional Chinese medicine for treatment of coronavirus disease 2019: A review. Tradit Med Res. 2020; 5(2): 65-73 [Feb 24, 2020] doi:10.12032/TMR20200222165

75. Mateso M. [Madagascar: Covid-Organics, President Rajoelina's "remedy" against the coronavirus]. Franceinfo: Afrique, Apr 20, 2020. [cited 2021 Dec 30]. Available from: https://www.francetvinfo.fr/ monde/afrique/societe-africaine/madagascar-covid-organics-le-emede -du-president-rajoelina-contre-le-coronavirus-voit-le-jour_3925621. html [French]

76. TSU scientists suggest using a plant to protect against viruses. - Seldon News. March 24, 2020. [cited 2021 Dec 30]. Available from: https://news.myseldon.com/ru/news/index/226298305 [Russian].

77. Heise G. Germany: Scientists test artemisia plant against coronavirus. - DW, Jun 25, 2020. [cited 2021 Dec 30]. Available from: https://www.dw.com/en/germany-scientists-test-artemisia-plant-against -coronavirus/a-53944514

78. Mhatre S, Srivastava T, Naik S, Patravale V. Antiviral activity of green tea and black tea polyphenols in prophylaxis and treatment of COVID-19: A review. Phytomedicine. 2021;85:153286. doi: 10.1016/j.phymed.2020.153286 [received on May 5, 2020]

79. Litvinova D, Isachenkov V. Russia's low virus death toll still raises questions in West. - ABC News, June 14, 2020. [cited 2021 Dec 30]. Available from: https://abcnews.go.com/Health/wireStory/ russias-low-virus-death-toll-raises-questions-west-71242185

80. WHO Representative Downplays Doubts About Russian Coronavirus Figures. - Radio Free Europe, May 14, 2020. [cited 2021 Dec 30]. Available from: https://www.rferl.org/a/who-representativedownplays-doubts-about-russian-coronavirus-figures/30611973.html

81. Dobrokhotova A. A Gout drug was used against COVID: How patients were treated in a hospital, which showed the best results in Moscow. - KP, June 26, 2020. [Russian] [cited 2021 Dec 30]. Available from: https://www.kp.ru/daily/27147/4242427/

82. Covid-19 Treatment Protocol of the Moscow State University Medical Center. - RUSHIV.RU, June 29, 2020. [Russian] [cited 2021 Dec 30]. Available from: http://rushiv.ru/protokol-lecheniya-covid19-meditsinskogo-tsentra-mgu/

83. Doctor: Treatment of COVID-19 patients must be as much personalized as possible. - Vesti.ru, May 14, 2020. [Russian] [cited 2021 Dec 30]. Available from: https://www.vesti.ru/article/2409591

84. Mehra MR, Desai SS, Ruschitzka F, Patel AN. Hydroxychloroquine or chloroquine with or without a macrolide for treatment of COVID-19: a multinational registry analysis. Lancet 2020; published online May 22. https://doi.org/10.1016/S0140-6736 (20)31180-6. Available from: https://web.archive.org/web/20200523234238/https:// www.thelancet.com/journals/lancet/article/PIIS0140-6736(20)311806/fulltext [Retracted, on June 4, 2020, https://doi.org /10.1016/S01406736(20)31324-6].

85. McCullough PA, Kelly RJ, Ruocco G, et al. Pathophysiological Basis and Rationale for Early Outpatient Treatment of SARS-CoV-2 (COVID-19) Infection. Am J Med. 2021; Jan, 134(1): 16-22. doi: 10.1016/j.amjmed.2020.07.003.

86. Marcu C. [A Romanian doctor is working wonders, healing her COVID patients 100\%]. - National, Mar 17, 2021. [Romanian] [cited 2021 Dec 30]. Available from: https://www.national.ro/coronavirus /un-medic-roman-face-minuni-100-vindecati-de-covid-715258.html

87. Assessment of Evidence for COVID-19-Related Treatments. Northeast Physician Hospital Organization. Aug 19, 2021. [cited 2021 Dec 30]. Available from: https://www.nepho.org/assessmentof-evidence-for-covid-19-related-treatments-updated-4-22-2020/
88. McCullough PA. The Reply: a Letter. Am J Med, 2021, Jul 1, 134(7): e440-e441, DOI: https://doi.org/10.1016/j.amjmed.2021.02.024

89. Virchow RL. [The Scientific Method and Viewpoints in Therapy]. Virchows Arch Pathol Anat Physiol Klin Med (Berlin), 1849; Bd. 2(1): 3-37. [German]

90. Hua J, Qian CC, Luo ZB, Li Q, Wang FL. Invasive mechanical ventilation in COVID-19 patient management: the experience with 469 patients in Wuhan. Crit Care. 2020; Jun 16, 24: 348. doi: 10.1186 /s13054-020-03044-9

91. Richardson S, Hirsch JS, Narasimhan M, et al. Presenting Characteristics, Comorbidities, and Outcomes Among 5700 Patients Hospitalized With COVID-19 in the New York City Area. JAMA, 2020; Apr 22, 323(20): 2052-2059. https://doi.org/10.1001/jama.2020.6775

92. Yang X, Yu Y, Xu J, et al. Clinical course and outcomes of critically ill patients with SARSCoV-2 pneumonia in Wuhan, China: a single-centered, retrospective, observational study. - Lancet Respir Med 2020; https://doi.org/10.1016/S2213-2600(20) 30079-5. published online Feb 21.

93. Zhou F, Yu T, Du RH, et al. Clinical course and risk factors for mortality of adult inpatients with COVID-19 in Wuhan, China: a retrospective cohort study. - Lancet, 2020; Mar 28, 395(10229): 1054-1062. DOI:https://doi.org/10.1016/S0140-6736(20)30566-3

94. Bellani G, Laffey JG, Pham T, et. al. Epidemiology, Patterns of Care, and Mortality for Patients with Acute Respiratory Distress Syndrome in Intensive Care Units in 50 Countries. JAMA. 2016; Feb 23; 315(8):788-800. DOI: 10.1001/jama.2016.0291

95. Ackermann M, Verleden SE, Kuehnel M, et al. Pulmonary vascular endothelialitis, thrombosis, and angiogenesis in Covid-19. N Engl J Med 2020;383:120-8, doi:http://dx.doi.org/10.1056/NEJMoa 2015432.

96. Boosting Your Immune System in Times of Viral Respiratory Outbreaks. - Thailand Medical News, Feb 2, 2020. [cited 2021 Dec 30]. Available from: https://www.thailandmedical.news/news/boostingyour-immune-system-in-times-of-viral-respiratory-outbreaks

97. Cuvelier P, Roux H, Couëdel-Courteille A, et al. Protective reactive thymus hyperplasia in COVID-19 acute respiratory distress syndrome. Crit Care. 2021; Jan 4;25(1):4. doi: 10.1186/s13054-02003440-1.

98. Smolyakov YN, Tereshkov PK, Shapovalov YK, Konnov VA, Magen E. Immunomodulation with Thymalin in the COVID-19 Related Cytokine Storm: Case Reports. Am J Biomed Sci \& Res, 2020; 10(6): 557-564. MS.ID.001574. DOI: 10.34297/AJBSR.2020.10.001574.

99. Wooldridge LC. [Chemical vaccination trials] Arch Anat Phys Wissen Med (Leipzig), 1888, Bd. 2: 527-536. [German]

100. Roberts M. Coronavirus: Dexamethasone proves first lifesaving drug. BBC News online. June 16, 2020. [cited 2021 Dec 30]. Available from: https://www.bbc.com/news/health-53061281;

101. Horby P, Lim WS, Emberson J, et al. Effect of Dexamethasone in Hospitalized Patients with COVID-19: Preliminary Report. - medRxiv 2020.06.22.20137273; doi: https://doi.org/10.1101/2020.06.22. 2013 7273 [published in N Engl J Med 2021; 384:693-704; new DOI: 10.1056/NEJMoa2021436]

102. Yousefifard M, Mohamed Ali K, Aghaei A, et al. Corticosteroids on the Management of Coronavirus Disease 2019 (COVID-19): A Systemic Review and Meta-Analysis. Iran J Public Health. 2020; Aug, 49(8):1411-1421. doi: 10.18502/ijph.v49i8.3863.

103. Estimating mortality from COVID-19: Scientific brief, 4 August 2020. [cited 2021 Dec 30]. Available from: https://www.who.int/ publications/i/item/WHO-2019-nCoV-Sci-Brief-Mortality-2020.1

104. Liu A, Wang W, Zhao X, et al. Disappearance of antibodies to SARS-CoV-2 in a COVID-19 patient after recovery. Clin Microbiol Infect 2020; 26(12):1703-1705. doi:10.1016/j.cmi.2020.07.009

105. Haveri A, Ekström N, Solastie A, et al. Persistence of neutralizing antibodies a year after SARS-CoV-2 infection. - medRxiv 2021.07.13.21260426; doi: https://doi.org/10.1101/2021.07.13. 21260426. 
106. Ioannidis JPA. Global perspective of COVID-19 epidemiology for a full-cycle pandemic. Eur J Clin Invest. 2020 Dec;50(12):e13423. doi: 10.1111/eci.13423. Epub 2020 Oct 25.

107. Noh J, Danuser G. Estimation of the fraction of COVID-19 infected people in U.S. states and countries worldwide. 2021, PLoS ONE 16(2): e0246772. https://doi.org/10.1371/journal.pone.0246772

108. Irons NJ, Raftery AE. Estimating SARS-CoV-2 infections from deaths, confirmed cases, tests, and random surveys. Proc. Natl. Acad. Sci. USA, Aug 2021, 118 (31) e2103272118; DOI: 10.1073/pnas. 2103272118

109. Tanno S. Half of Moscow's 12 million residents have had Covid-19 - six times official figures - mayor reveals as photos show huge numbers of patients being treated in city's temporary hospitals. - DailyMail.co.uk, Feb 1, 2021. [cited 2021 Dec 30]. Available from: https://www.dailymail.co.uk/news/article-9211297/Half-Moscows12million-residents-Covid-19-mayor-reveals.html

110. Sobyanin said that more than half of Moscow residents have already had coronavirus - BFM.ru, Jan 30, 2021. [Russian] [cited 2021 Dec 30]. Available from: https://www.bfm.ru/news/463852

111. Gittelman RM, Lavezzo E, Snyder TM, et al. Diagnosis and Tracking of Past SARS-CoV-2 Infection in a Large Study of Vo', Italy Through T-Cell Receptor Sequencing. - medRxiv 2020.11.09.20228023; doi: https://doi.org/10.1101/2020.11.09.20228023

112. Swadling L, Diniz MO, Schmidt NM. et al. Pre-existing polymerase-specific $\mathrm{T}$ cells expand in abortive seronegative SARSCoV-2. Nature, 2021. https://doi.org/10.1038/s41586-021-04186-8

113. Le Bert N, Tan AT, Kunasegaran K. et al. SARS-CoV-2specific $\mathrm{T}$ cell immunity in cases of COVID-19 and SARS, and uninfected controls. Nature, 2020; 584: 457-462. https://doi.org/10.1038 /s41586-020-2550-z

114. Corman VM, Landt O, Kaiser M, et al. Detection of 2019 novel coronavirus (2019-nCoV) by real-time RT-PCR. Euro Surveill. 2020;25(3):pii=2000045. https://doi.org/10.2807/1560-7917.ES. 2020 .25.3.2000045

115. Wuhan Coronavirus. Speakers: Farrar J, Chan J, Bancel S, Hatchett R. Davos: WEForum, Jan 23, 2020. [cited 2021 Dec 30]. Available from: https://www.weforum.org/events/world-economicforum-annual-meeting-2020/sessions/update-wuhan-coronavirus

116. Joseph A. WHO Declines to Declare Coronavirus Outbreak a Global Health Emergency. - Scientific American, STAT, January 23, 2020. [cited 2021 Dec 30]. Available from: https://www.scientificamerican. com/article/who-declines-to-declare-coronavirus-outbreak-a-globalhealth-emergency/

117. WHO announces death of Peter Salama, former Ebola response leader. - Africa Times, Jan 25, 2020. [cited 2021 Dec 30]. Available from: https://africatimes.com/2020/01/25/who-announces-death-ofpeter-salama-former-ebola-response-leader/

118. No evidence that 501.V2 Variant is more dangerous than UK variant. - NICD, 24 December, 2020. [cited 2021 Dec 30]. Available from: https://www.nicd.ac.za/no-evidence-that-501-v2-variant-is-more -dangerous-than-uk-variant/

119. Frampton D, Rampling T, Cross A, et al. Genomic characteristics and clinical effect of the emergent SARS-CoV-2 B.1.1.7 lineage in London, UK: a whole-genome sequencing and hospital-based cohort study. Lancet Infect Dis. 2021 Sep;21(9):1246-1256. doi: 10.1016/S 1473-3099(21)00170-5. Epub 2021 Apr 12.

120. Ferguson NM, Laydon D, Nedjati-Gilani G. et al. Report $9-$ Impact of non-pharmaceutical interventions (NPIs) to reduce COVID19 mortality and healthcare demand. Imperial College London, March 16, 2020. [cited 2021 Dec 30]. Available from: https://www.imperial. ac.uk/mrc-global-infectious-disease-analysis/covid-19/report-9-impact -of-npis-on-covid-19/

121. Eubank S, Eckstrand I, Lewis B, et al. Commentary on Ferguson, et al., "Impact of Non-pharmaceutical Interventions (NPIs) to Reduce COVID-19 Mortality and Healthcare Demand". Bull Math Biol. 2020; 82(4):52. Published 2020 Apr 8. doi:10.1007/s11538-020-00726-X.
122. Status of COVID-19: As of 19 March 2020, COVID-19 is no longer considered to be a high consequence infectious disease (HCID) in the UK. [cited 2021 Dec 30]. Available from: https://www.gov.uk/guidance /high-consequence-infectious-diseases-hcid\#status-of-covid-19

123. Making Influenza History: The Quest for a Universal Vaccine. - Future of Health Summit 2019, Milken Institute, Washington, D.C., Oct 29, 2019; 11:15 AM-12:15 PM; [cited 2021 Dec 30]. Available from: https://www.c-span.org/video/?465845-1/universal-flu-vaccine

124. Lansiaux E, Tchagaspanian N, Arnaud J, et al. Side-Effects of Public Health Policies Against Covid-19: The Story of an OverReaction. Front Public Health. 2021 Sep 13;9:696818. doi: 10.3389/ fpubh.2021.696818.

125. Riedel-Heller S, Richter D. [COVID-19 Pandemic and Mental Health of the General Public: Is there a Tsunami of Mental Disorders?] Psychiatr Prax. 2020 Nov;47(8):452-456. [German]. doi: 10.1055/a1290-3469. Epub 2020 Nov 2.

126. Huremović D. Mental Health of Quarantine and Isolation. In: Huremović D. (eds) Psychiatry of Pandemics. - Springer, Cham, 2019, May 16, https://doi.org/10.1007/978-3-030-15346-5_9

127. Napoli PE, Nioi M, Fossarello M. The "Quarantine Dry Eye": The Lockdown for Coronavirus Disease 2019 and Its Implications for Ocular Surface Health. Risk Manag Healthc Policy. 2021;14:16291636. Published 2021 Apr 19. doi:10.2147/RMHP.S277067

128. Di Renzo L, Gualtieri P, Pivari F, et al. Eating habits and lifestyle changes during COVID-19 lockdown: an Italian survey. J Transl Med. 2020; Jun 8; 18(1): 229. doi: 10.1186/s12967-020-02399-5.

129. Gayoso M, Lim WY, Mulekar MS. et al. Effect of Covid-19 quarantine on diabetes Care in Children. Clin Diabetes Endocrinol 7, 9 (2021). https://doi.org/10.1186/s40842-021-00122-x

130. Saita Y. Risk/Caution of vitamin D insufficiency for quarantined athletes returning to play after COVID-19.BMJ Open Sport \& Exercise Medicine, 2020; 6:e000882. doi: 10.1136/bmjsem-2020-000882

131. Social isolation during COVID-19 pandemic linked with high blood pressure. Peer-Reviewed Publication. - European Society of Cardiology, Nov 19, 2020. - [cited 2021 Dec 30]. Available from: https://www.eurekalert.org/news-releases/671405

132. Mattioli AV, Ballerini Puviani M, Nasi M, Farinetti A. COVID19 pandemic: the effects of quarantine on cardiovascular risk. Eur J Clin Nutr. 2020; Jun; 74(6): 852-855. doi: 10.1038/s41430-020-0646z. Epub 2020 May 5.

133. Dimeglio C, Miedougé M, Loubes JM, et al. Side effect of a 6 p.m curfew for preventing the spread of SARS-CoV-2: A modeling study from Toulouse, France. J Infect. 2021; May;82(5):186-230. doi: 10.1016/j.jinf.2021.01.021. Epub 2021 Jan 31.

134. Burlacu A, Crisan-Dabija R, Covic A, et al. Pandemic lockdown, healthcare policies and human rights: integrating opposed views on COVID-19 public healthq1 mitigation measures. Rev Cardiovasc Med. 2020; Dec 30;21(4):509-516. doi: 10.31083/j.rcm.2020.04.274.

135. Onyeaka H, Anumudu CK, Al-Sharify ZT, et al. COVID-19 pandemic: A review of the global lockdown and its far-reaching effects. Sci Prog. 2021; Apr-Jun;104(2):368504211019854. doi: 10.1177/0036 8504211019854.

136. Jeste DV. Coronavirus, social distancing, and global geriatric mental health crisis: opportunities for promoting wisdom and resilience amid a pandemic. Int Psychogeriatr. 2020; Oct;32(10):1097-1099. doi: 10.1017/S104161022000366X.

137. Donnelly L. 'Biggest cancer catastrophe ever' to hit NHS as up to 740,000 potential cases missed. - The Telegraph. December 1, 2021. https://www.telegraph.co.uk/news/2021/12/01/biggest-cancer-catastropheever-hit-nhs-740000-potential-cases/

138. Marques NP, Silveira DMM, Marques NCT, et al. Cancer diagnosis in Brazil in the COVID-19 era. Semin Oncol. 2021 Apr;48(2):156-159. doi: 10.1053/j.seminoncol.2020.12.002. Epub 2021 Jan 7.

139. Baig AS, Knapp C, Eagan AE, Radonovich LJ Jr. Health care workers' views about respirator use and features that should be included in the next generation of respirators. Am J Infect Control. 2010; Feb;38(1):18-25. doi: 10.1016/j.ajic.2009.09.005. Epub 2009 Dec 29. 
140. Yang P, Seale H, MacIntyre CR, et al. Mask-wearing and respiratory infection in healthcare workers in Beijing, China. Braz $\mathrm{J}$ Infect Dis. 2011; Mar-Apr;15(2):102-8. doi: 10.1016/S1413-8670(11) 70153-2.

141. Shenal BV, Radonovich LJ Jr, Cheng J, et al. Discomfort and exertion associated with prolonged wear of respiratory protection in a health care setting. J Occup Environ Hyg. 2012; 9(1):59-64. doi: 10.1080/15459624.2012.635133.

142. Roberge RJ, Kim JH, Coca A, Protective Facemask Impact on Human Thermoregulation: An Overview, The Annals of Occupational Hygiene. 2012; Jan, 56(1):102-112, https://doi.org/10.1093/annhyg/mer069

143. Neilson $\mathrm{S}$. The surgical mask is a bad fit for risk reduction [published online ahead of print, 2016, Apr 11]. CMAJ. 2016; 188(8): 606-607. doi:10.1503/cmaj.151236

144. Matuschek C, Moll F, Fangerau H. et al. Face masks: benefits and risks during the COVID-19 crisis. Eur J Med Res, 2020; 25, 32. https://doi.org/10.1186/s40001-020-00430-5

145. Szepietowski JC, Matusiak $Ł$, Szepietowska M, et al. Face Mask-induced Itch: A Self-questionnaire Study of 2,315 Responders During the COVID-19 Pandemic. Acta Derm Venereol. 2020 May 28;100(10):adv00152. doi: 10.2340/00015555-3536.

146. Chughtai AA, Stelzer-Braid S, Rawlinson W. et al. Contamination by respiratory viruses on outer surface of medical masks used by hospital healthcare workers. BMC Infect Dis. 2019; 19, 491. https:// doi.org/10.1186/s12879-019-4109-x

147. Rosner E. Adverse Effects of Prolonged Mask Use among Healthcare Professionals during COVID-19. J Infect Dis Epidemiol, 2020; 6:130. doi.org/10.23937/2474-3658/1510130

148. Lazzarino AI, Steptoe A, Hamer M, Michie S. Covid-19: Important potential side effects of wearing face masks that we should bear in mind. BMJ. 2020; May 21;369:m2003. doi: 10.1136/bmj.m2003.

149. Scarano A, Inchingolo F, Lorusso F. Facial Skin Temperature and Discomfort When Wearing Protective Face Masks: Thermal Infrared Imaging Evaluation and Hands Moving the Mask. Int J Environ Res Public Health. 2020; Jun 27;17(13):4624. doi: 10.3390/ijerph17134624.

150. Walach H, Weikl R, Prentice J, et al. Experimental Assessment of Carbon Dioxide Content in Inhaled Air With or Without Face Masks in Healthy Children: A Randomized Clinical Trial. JAMA Pediatr. 2021 Jun 30:e212659. doi: 10.1001/jamapediatrics.2021.2659. Epub ahead of print. Retraction in: JAMA Pediatr. 2021 Jul 16;:e213252.

151. Schwarz S, Jenetzky E, Krafft H, et al. [Corona child studies "Co-Ki": first results of a Germany-wide register on mouth and nose covering (mask) in children]. Monatsschr Kinderheilkd. 2021 Feb 22: 1-10. [German]. doi: 10.1007/s00112-021-01133-9. Epub ahead of print.

152. Kisielinski K, Giboni P, Prescher A, et al. Is a Mask That Covers the Mouth and Nose Free from Undesirable Side Effects in Everyday Use and Free of Potential Hazards? Int J Environ Res Public Health. 2021 Apr 20;18(8):4344. doi: 10.3390/ijerph18084344.

153. Vainshelboim B. Facemasks in the COVID-19 era: A health hypothesis. Med Hypotheses. 2021; 146: 110411. Published on line 2020, Nov 22; PMCID: PMC7680614 PMID: 33303303; doi:10.1016 /j.mehy.2020. 110411https://www.ncbi.nlm.nih.gov/pmc/articles/ PMC7680614/ [Retracted]

154. Huisman W, Martina BE, Rimmelzwaan GF, et al. Vaccineinduced enhancement of viral infections. Vaccine. 2009; Jan 22; 27(4): 505-12. doi: 10.1016/j.vaccine.2008.10.087. Epub 2008 Nov 18.

155. Tseng CT, Sbrana E, Iwata-Yoshikawa N, et al. Immunization with SARS coronavirus vaccines leads to pulmonary immunopathology on challenge with the SARS virus. PLoS One. 2012; 7(4): e35421. doi: 10.1371/journal.pone.0035421. Epub 2012 Apr 20. Erratum in: PLoS One. 2012;7(8). doi:10.1371/annotation/2965cfae-b77d-4014$8 \mathrm{~b} 7 \mathrm{~b}-236 \mathrm{e} 01 \mathrm{a} 35492$

156. Iwata-Yoshikawa N, Uda A, Suzuki T, et al. Effects of Tolllike receptor stimulation on eosinophilic infiltration in lungs of BALB/ c mice immunized with UV-inactivated severe acute respiratory syndrome-related coronavirus vaccine. J Virol. 2014; Aug; 88(15): 8597-614. doi: 10.1128/JVI.00983-14. Epub 2014 May 21.
157. Liu L, Wei Q, Lin Q, et al. Anti-spike IgG causes severe acute lung injury by skewing macrophage responses during acute SARS-CoV infection. JCI Insight. 2019 Feb 21;4(4):e123158. doi: 10.1172/jci. insight. 123158 .

158. Cardozo T, Veazey R. Informed consent disclosure to vaccine trial subjects of risk of COVID-19 vaccines worsening clinical disease. Int J Clin Pract. 2021 Mar;75(3):e13795. doi: 10.1111/ijcp.13795. Epub 2020 Dec 4.

159. Lei Y, Zhang J, Schiavon CR, et al. SARS-CoV-2 Spike Protein Impairs Endothelial Function via Downregulation of ACE2. bioRxiv 2020; Dec 4:2020.12.04.409144. doi: 10.1101/2020.12. 04.409144. Update in: Circ Res. 2021 Mar 31.

160. Jiang H, Mei Y-F. SARS-CoV-2 Spike Impairs DNA Damage Repair and Inhibits V(D)J Recombination In Vitro. Viruses. 2021; 13(10):2056. https://doi.org/10.3390/v13102056

161. Pharmacokinetics: Organ Distribution (2.6.5.5B.). - In: SARS-COV-2 mRNA Vaccine (BNT162, PF-07302048) 2.6.4: Overview of Pharmacokinetic Test. Pharmaceutical and Medical Devices Agency (Japan). [Confidential Report] February 12, 2021: p. 6-8. [cited 2021 Dec 30]. Available from: https://www.pmda.go.jp/

162. Liu J, Wang J, Xu J, et al. Comprehensive investigations revealed consistent pathophysiological alterations after vaccination with COVID-19 vaccines. Cell Discov, 2021; 7, 99 https://doi.org/10. 1038/s41421-021-00329-3119.

163. Föhse FK, Geckin B, Overheul GJ, et al. The BNT162b2 mRNA vaccine against SARS-CoV-2 reprograms both adaptive and innate immune responses. - medRxiv 2021.05.03.21256520; doi: https://doi.org/10.1101/2021.05.03.21256520

164. Possible Side Effects After Getting a COVID-19 Vaccine. CDC, Nov. 3, 2021. [cited 2021 Dec 30]. Available from: https://www. cdc.gov/coronavirus/2019-ncov/vaccines/expect/after.html

165. Cumulative analysis of post-authorization adverse event: Reports of PF-07302048 (BNT162B2) received through 28-Feb-2021. - FDA-CBER-2021-5683-0000054

166. Ogata AF, Cheng CA, Desjardins M, et al. Circulating SARSCoV-2 Vaccine Antigen Detected in the Plasma of mRNA-1273 Vaccine Recipients. Clin Infect Dis. 2021; May 20:ciab465. doi: 10.1093/cid/ ciab465. Epub ahead of print. - problem - that it circulates

167. Bansal S, Perincheri S, Fleming T, et al. Cutting Edge: Circulating Exosomes with COVID Spike Protein Are Induced by BNT162b2 (Pfizer-BioNTech) Vaccination prior to Development of Antibodies: A Novel Mechanism for Immune Activation by mRNA Vaccines. J Immunol. 2021; Nov 15;207(10): 2405-2410. doi: 10.40 49/jimmunol.2100637. Epub 2021 Oct 15.

168. Avolio E, Carrabba M, Milligan R, et al. The SARS-CoV-2 Spike protein disrupts human cardiac pericytes function through CD147 receptor-mediated signalling: a potential non-infective mechanism of COVID-19 microvascular disease. Clin Sci (Lond). 2021; Dec 22;135 (24): 2667-2689. doi: 10.1042/CS20210735.

169. Hansen T, Titze U, Kulamadayil-Heidenreich NSA, et al. First case of postmortem study in a patient vaccinated against SARS-CoV2. Int J Infect Dis. 2021; 107:172-175. doi:10.1016/j.ijid.2021.04.053

170. Burkhardt A, Lang W. Analysis of tissue samples from deceased persons. In: the 2nd Pathology Conference: Are deaths and adverse health effects after vaccination against COVID-19 related in a pathologically detectable way? - Berlin, Germany, December 4, 2021 , 00:08:40-01:09.40. [cited 2021 Dec 30]. Available from: https:// pathologie-konferenz.de/en/

171. Klein NP, Lewis N, Goddard K, et al. Surveillance for Adverse Events After COVID-19 mRNA Vaccination. JAMA. 2021; Oct 12; 326(14): 1390-1399. doi: 10.1001/jama.2021.15072.

172. Dagan N, Barda N, Balicer RD. Adverse Effects after BNT162b2 Vaccine and SARS-CoV-2 Infection, According to Age and Sex. N Engl J Med. 2021 Oct 27:NEJMc2115045. doi: 10.1056/ NEJMc2115045. 
173. Rybachenko VV. Complicated post-vaccination period in persons revaccinated with "Spuntik-Light." - In: The 1st Moscow Scientific and Practical Conference with international participation 'Doctors for the Truth': Clinical and Organizational Aspects of Diagnosis, Treatment and Prevention of COVID-19. - December 12, 2021, Moscow, Russia: 5:12-5:25. [Russian] [cited 2021 Dec 30]. Available from: https://www.youtube.com /watch?v=ZqHsz8z7Bzc\&t=0s

174. Gundry SR. Expression of Concern: Abstract 10712: mRNA COVID Vaccines Dramatically Increase Endothelial Inflammatory Markers and ACS Risk as Measured by the PULS Cardiac Test: a Warning. Circulation. 2021; 144:A107128 Nov 2021; https://www.aha journals.org/doi/10.1161/circ.144.suppl_1.10712; Nov 24, 2020; DOI: 10.1161/CIR.0000000000001051;

175. Bautista GJ, Peña OP, Bonilla FJA, et al. [Acute myocarditis after administration of the BNT162b2 vaccine against COVID-19]. Rev Esp Cardiol. 2021; Sep;74(9):812-814. [Spanish]. doi: 10.1016/j. recesp.2021.03.009. Epub 2021 Mar 20.

176. Ramírez-García A, Lozano JS, Darnaude XI, et al. [Pericarditis after administration of the BNT162b2 mRNA COVID-19 vaccine]. Rev Esp Cardiol. 2021; Dec;74(12):1121-1123. [Spanish]. doi: 10.1016 /j.recesp.2021.06.006. Epub 2021 Jun 12.

177. Li M, Yuan J, Lv G, et al. Myocarditis and Pericarditis following COVID-19 Vaccination: Inequalities in Age and Vaccine Types. J Pers Med. 2021; Oct 28;11(11):1106. doi: 10.3390/jpm11111106.

178. Eggebrecht H, Breitbart P, Koch A, et al. Trends in ambulatory cardiology consultations for suspected myocarditis after COVID-19 vaccination. Clin Res Cardiol. 2021; Nov 23:1-3. doi: 10.1007/s00392 021-01974-0.

179. Heymans S, Cooper LT. Myocarditis after COVID-19 mRNA vaccination: clinical observations and potential mechanisms. Nat Rev Cardiol. 2021; Dec 9. doi: 10.1038/s41569-021-00662-w.

180. Kim HW, Jenista ER, Wendell DC, et al. Patients With Acute Myocarditis Following mRNA COVID-19 Vaccination. JAMA Cardiol. 2021 Oct 1;6(10):1196-1201. doi: 10.1001/jamacardio.2021.2828

181. Høeg TB, Krug A, Stevenson J, Mandrola J. SARS-CoV-2 mRNA Vaccination-Associated Myocarditis in Children Ages 12-17: A Stratified National Database Analysis. - medRxiv 2021.08.30.2126 2866; doi: https://doi.org/10.1101/2021.08.30.21262866

182. Sharff KA, Dancoes DM, Longueil JL, et al. Risk of Myopericarditis following COVID-19 mRNA vaccination in a Large Integrated Health System: A Comparison of Completeness and Timeliness of Two Methods. - medRxiv 2021.12.21.21268209; doi https://doi.org/10.1101/2021.12.21.21268209

183. Patone, M., Mei, X.W., Handunnetthi, L. et al. Risks of myocarditis, pericarditis, and cardiac arrhythmias associated with COVID-19 vaccination or SARS-CoV-2 infection. Nature Med, 2021; Dec 14. https://doi.org/10.1038/s41591-021-01630-0

184. Choi S, Lee S, Seo JW, et al. Myocarditis-induced Sudden Death after BNT162b2 mRNA COVID-19 Vaccination in Korea: Case Report Focusing on Histopathological Findings. J Korean Med Sci. 2021 Oct 18;36(40):e286. doi: 10.3346/jkms.2021.36.e286.

185. Rose J, McCullough PA. A Report on Myocarditis Adverse Events in the U.S. Vaccine Adverse Events Reporting System (VAERS) in Association with COVID-19 Injectable Biological Products. Curr Probl Cardiol. 2021; Sep 30 :101011. doi: 10.1016/j.cpcardiol.2021. 101011. Epub ahead of print. PMID: 34601006; [Retracted]

186. Kim IC, Kim H, Lee HJ, et al. Cardiac Imaging of Acute Myocarditis Following COVID-19 mRNA Vaccination. J Korean Med Sci. 2021; Aug 16;36(32):e229. doi: 10.3346/jkms.2021.36.e229

187. Perry RJ, Tamborska A, Singh B, et al. CVT After Immunisation Against COVID-19 (CAIAC) collaborators. Cerebral venous thrombosis after vaccination against COVID-19 in the UK: a multicentre cohort study. Lancet. 2021; Sep 25;398(10306):1147-1156. doi: 10.1016/S 0140-6736(21)01608-1. Epub 2021 Aug 6.
188. Pomara C, Sessa F, Ciaccio M, et al. Post-mortem findings in vaccine-induced thrombotic thombocytopenia. Haematologica. 2021; 106(8):2291-2293. Published 2021 Aug 1. doi:10.3324/haematol. 2021.279075

189. Greinacher A, Thiele T, Warkentin TE, et al. Thrombotic thrombocytopenia after ChAdOx1 nCov- 19 vaccination. N Engl J Med. 2021; Jun 3;384(22):2092-2101. doi: 10.1056/NEJMoa2104840. Epub 2021 Apr 9.

190. Schultz NH, Sørvoll IH, Michelsen AE, et al. Thrombosis and thrombocytopenia after ChAdOx $1 \mathrm{nCoV}-19$ vaccination. N Engl J Med. 2021; Jun 3;384(22):2124-2130. doi: 10.1056/NEJMoa2104 882. Epub 2021 Apr 9.

191. Pavord S, Scully M, Hunt BJ, et al. Clinical Features of VaccineInduced Immune Thrombocytopenia and Thrombosis. N Engl J Med. 2021; Oct 28;385(18):1680-1689. doi: 10.1056/NEJMoa2109908. Epub 2021 Aug 11.

192. Alam W. COVID-19 vaccine-induced immune thrombotic thrombocytopenia: A review of the potential mechanisms and proposed management. Sci Prog. 2021; Apr-Jun;104(2):368504211025927. doi: 10.1177/00368504211025927.

193. Rela M, Jothimani D, Vij M, et al. Auto-immune hepatitis following COVID vaccination. J Autoimmun. 2021; Sep; 123:102688. doi: 10.1016/j.jaut.2021.102688. Epub 2021 Jul 3.

194. Vuille-Lessard É, Montani M, Bosch J, Semmo N. Autoimmune hepatitis triggered by SARS-CoV-2 vaccination. J Autoimmun. 2021; Sep;123:102710. doi: 10.1016/j.jaut.2021.102710. Epub 2021 Jul 28.

195. Tuschen K, Bräsen JH, Schmitz J, et al. Relapse of class V lupus nephritis after vaccination with COVID-19 mRNA vaccine. Kidney Int. 2021; Oct;100(4):941-944. doi: 10.1016/j.kint.2021.07. 019. Epub 2021 Aug 2.

196. Zavala-Miranda MF, González-Ibarra SG, Pérez-Arias AA, et al. New-onset systemic lupus erythematosus beginning as class $\mathrm{V}$ lupus nephritis after COVID-19 vaccination. Kidney Int. 2021; Dec; 100(6):1340-1341. doi: 10.1016/j.kint.2021.09.009. Epub 2021 Sep 22.

197. Patil S, Patil A. Systemic lupus erythematosus after COVID19 vaccination: A case report. J Cosmet Dermatol. 2021; Oct;20(10): 3103-3104. doi: 10.1111/jocd.14386. Epub 2021 Aug 21.

198. Abdullah L, Awada B, Kurban M, Abbas O. Letter to the editor regarding the article "Patil S, Patil A. Systemic lupus erythematosus after COVID-19 vaccination: A case report. J Cosmet Dermatol. 2021 Aug 21. 10.1111/jocd.14386". J Cosmet Dermatol. 2021; Dec;20(12): 4076-4077. doi: 10.1111/jocd.14572. Epub 2021 Oct 26.

199. Magro C, Crowson AN, Franks L, et al. The histologic and molecular correlates of COVID-19 vaccine-induced changes in the skin. Clin Dermatol. 2021; Nov-Dec; 39(6): 966-984. doi: 10.1016/j. clindermatol.2021.07.011. Epub 2021 Jul 25.

200. Larson V, Seidenberg R, Caplan A, et al. Clinical and histopathological spectrum of delayed adverse cutaneous reactions following COVID-19 vaccination. J Cutan Pathol. 2022; Jan;49(1): 34-41. doi: 10.1111/cup.14104. Epub 2021 Aug 8.

201. Sandhu S, Bhatnagar A, Kumar H, et al. Leukocytoclastic vasculitis as a cutaneous manifestation of ChAdOx $1 \mathrm{nCoV}-19$ corona virus vaccine (recombinant). Dermatol Ther. 2021; Nov;34(6):e151 41. doi: 10.1111/dth.15141. Epub 2021 Oct 5.

202. Ciccarese G, Drago F, Boldrin S, et al. Sudden onset of vitiligo after COVID-19 vaccine. Dermatol Ther. 2021; Nov 9:e15196. doi: 10.1111/dth.15196. Epub ahead of print.

203. Sotiriou E, Tsentemeidou A, Bakirtzi K, et al. Psoriasis exacerbation after COVID-19 vaccination: a report of 14 cases from a single centre. J Eur Acad Dermatol Venereol. 2021; Dec;35(12):e857 -e859. doi: 10.1111/jdv.17582. Epub 2021 Aug 20.

204. Lehmann M, Schorno P, Hunger RE, et al. New onset of mainly guttate psoriasis after COVID-19 vaccination: a case report. J Eur Acad Dermatol Venereol. 2021; Nov;35(11):e752-e755. doi: 10.1111 /jdv.17561. Epub 2021 Aug 4. 
205. İremli BG, Şendur SN, Ünlütürk U. Three Cases of Subacute Thyroiditis Following SARS-CoV-2 Vaccine: Postvaccination ASIA Syndrome. J Clin Endocrinol Metab. 2021; Aug 18;106(9):2600-2605. doi: 10.1210/clinem/dgab373.

206. Saygll1 ES, Karakilic E. Subacute thyroiditis after inactive SARS-CoV-2 vaccine. BMJ Case Rep. 2021; Oct 1;14(10):e244711. doi: 10.1136/bcr-2021-244711.

207. Robinson KA, Maimone S, Gococo-Benore DA, et al. Incidence of Axillary Adenopathy in Breast Imaging After COVID-19 Vaccination. JAMA Oncol. 2021; 7(9):1395-1397. doi:10.1001/jamaoncol.2021.3127

208. Garreffa E, York J, Turnbull A, Kendrick D. Regional lymphadenopathy following COVID-19 vaccination: considerations for primary care management. Br J Gen Pract. 2021; May 27;71(707): 284-285. doi: 10.3399/bjgp21X716117.

209. Mitchell OR, Dave R, Bekker J, Brennan PA. Supraclavicular lymphadenopathy following COVID-19 vaccination: an increasing presentation to the two-week wait neck lump clinic? Br J Oral Maxillo fac Surg. 2021; Apr;59(3):384-385. doi: 10.1016/j.bjoms.2021.02. 002. Epub 2021 Feb 15.

210. Soub HA, Ibrahim W, Maslamani MA, et al. Kikuchi-Fujimoto disease following SARS CoV2 vaccination: Case report. IDCases. 2021; 25:e01253. doi: 10.1016/j.idcr.2021.e01253. Epub 2021 Aug 10.

211. Finsterer J. Neurological side effects of SARS-CoV-2 vaccinations Acta Neurol Scand. 2021; 00:1-5. https://doi.org/10.1111/ane.13550

212. Seneff S, Nigh G. Worse Than the Disease? Reviewing Some Possible Unintended Consequences of the mRNA Vaccines Against COVID-19. - IJVTPR, 2021; May 10, 2(1): 38-79. https://ijvtpr.com/ index.php/IJVTPR/article/view/23/51?utm_placement=cflg-dtan

213. Classen JB. COVID-19 RNA Based Vaccines and the Risk of Prion Disease. Microbiol Infect Dis. 2021; 5(1): 1-3. DOI: 10.33425/ 2639-9458.1109

214. Tetz G, Tetz V. SARS-CoV-2 Prion-Like Domains in Spike Proteins Enable Higher Affinity to ACE2. Preprints 2020, 2020030422 (doi: 10.20944/preprints202003.0422.v1).

215. Ingrid HCHM, Böszörményi K, Jacqueline W, et al. SARSCoV-2 causes brain inflammation and induces Lewy body formation in macaques. - bioRxiv 2021.02.23.432474; Posted February 23, 2021; doi: https://doi.org/10.1101/2021.02.23.432474 [Retracted]

216. Waheed S, Bayas A, Hindi F, et al. Neurological Complications of COVID-19: Guillain-Barre Syndrome Following Pfizer COVID-19 Vaccine. Cureus. 2021 Feb 18;13(2):e13426. doi: 10.7759/cureus.13426.

217. Hanson KE, Goddard K, Lewis N, et al. Guillain-Barré Syndrome after COVID-19 Vaccination in the Vaccine Safety Datalink. medRxiv 2021.12.03.21266419; doi: https://doi.org/10.1101/2021.12. 03.21266419

218. Malamud E, Caress JB, Lapid DJ, Otallah SI. Guillain-Barré Syndrome After COVID-19 Vaccination in an Adolescent. Pediatr Neurol. 2021; Dec 10: S0887-8994 (21) 00246-0. doi: 10.1016/j. pediatrneurol.2021.11.001. Epub ahead of print.

219. Sato K, Mano T, Niimi Y, et al. Facial nerve palsy following the administration of COVID-19 mRNA vaccines: analysis of a selfreporting database. Int J Infect Dis. 2021 Oct;111:310-312. doi: 10.10 16/j.ijid.2021.08.071. Epub 2021 Sep 4.

220. Panou E, Nikolaou V, Kaliampou S, et al. Epi-P-04 - Cutaneous T-cell lymphoma (CTCL) exacerbation after viral vector COVID-19 vaccination. - Eur J Cancer, 2021, 156, Suppl 1:S68,https://doi.org/ 10.1016/S0959-8049(21)00755-3.

221. Weitgasser L, Mahrhofer M, Schoeller T. Potential immune response to breast implants after immunization with COVID-19 vaccines. The Breast, 2021; 59: 76-78, https://doi.org/10.1016/j.breast.2021.06.002.

222. Pantazatos S, Seligmann H. COVID vaccination and agestratified all-cause mortality risk. - Preprint.Researchgate. - 2021; October, DOI: 10.13140/RG.2.2.28257.43366

223. Covid vaccination linked to 3 deaths: Ministry releases findings in 842 fatalities. - Bangkok Post, Nov 4, 2021 [cited 2021 Dec 30]. Available from: https://www.bangkokpost.com/thailand/general/220 9643/covid-vaccination-linked-to-3-deaths
224. McLachlan S, Osman M, Dube K, et. al. Analysis of COVID19 vaccine death reports from the Vaccine Adverse Events Reporting System (VAERS) Database Interim: Results and Analysis. - Preprint June 2021; DOI: 10.13140/RG.2.2.26987.26402

225. World's First Vaccine Murder case against Bill Gates, Adar Poonawalla filed in India's High Court. - November 25, 2021. [cited 2021 Dec 30]. Available from: https://indianbarassociation.in/worldsfirst-vaccine-murder-case-against-bill-gates-adar-poonawalla-filedin-indias-high-court/

226. Xiao J, Shiu EYC, Gao H, et al. Nonpharmaceutical Measures for Pandemic Influenza in Non-healthcare Settings-Personal Protective and Environmental Measures. Emerg Infect Dis. 2020; 26(5):967-975. doi:10.3201/eid2605.190994

227. Saunders-Hastings P, Crispo JAG, Sikora L, et al. Effectiveness of personal protective measures in reducing pandemic influenza transmission: A systematic review and meta-analysis. Epidemics. 2017; Sep; 20:1-20. doi: 10.1016/j.epidem.2017.04.003

228. Kampf G. The epidemiological relevance of the COVID-19vaccinated population is increasing. Lancet Reg Health Eur. 2021; Dec; 11:100272. doi: 10.1016/j.lanepe.2021.100272. Epub 2021 Nov 20.

229. Singanayagam A, Hakki S, Dunning J, et al. ATACCC Study Investigators. Community transmission and viral load kinetics of the SARS-CoV-2 delta (B.1.617.2) variant in vaccinated and unvaccinated individuals in the UK: a prospective, longitudinal, cohort study. Lancet Infect Dis. 2021; Oct 29:S1473-3099(21)00648-4. doi: 10.1016/S1473 $-3099(21) 00648-4$. Epub ahead of print. Erratum in: Lancet Infect Dis. 2021, Dec;21(12):e363.

230. Shitrit P, Zuckerman NS, Mor O, et al. Nosocomial outbreak caused by the SARS-CoV-2 Delta variant in a highly vaccinated population, Israel, July 2021. Euro Surveill. 2021;26(39):pii=2100822. https://doi.org/10.2807/1560-7917.ES.2021.26.39.2100822

231. Corona alarm in the hospital: Boosted staff of the clinic infected eight patients] Corona-Alarm im Krankenhaus: Geboosterter Klinik-Mitarbeiter steckt acht Patienten an. - Focus, Dec 16, 2021. [cited 2021 Dec 30]. Available from: https://www.focus.de/regional/ hamburg/viele-erkrankte-groesserer-corona-ausbruch-in-hamburgerkrankenhaus_id_24993369.html [German]

232. Davies F. Study Shows Vaccine Will Enhance Delta Infectivity. - News Concerns, September 14, 2021; https://newsconcerns.com/ study-shows-vaccine-will-enhance-delta-infectivity/

233. Liu HA, Arase T, Kishikawa JI, et al. The SARS-CoV-2 Delta variant is poised to acquire complete resistance to wild-type spike vaccines. - bioRxiv 2021.08.22.457114; doi: https://doi.org/10.1101 /2021.08.22.457114

234. Wang R, Chen J, Wei GW. Mechanisms of SARS-CoV-2 Evolution Revealing Vaccine-Resistant Mutations in Europe and America. J Phys Chem Lett. 2021; Dec 7, 12, XXX, 11850-11857. doi: 10.1021/acs.jpclett.1c03380. Epub ahead of print.

235. Rella SA, Kulikova YA, Dermitzakis ET, Kondrashov FA. Rates of SARS-CoV-2 transmission and vaccination impact the fate of vaccine-resistant strains. Sci Rep. 2021; Jul 30;11(1):15729. doi: 10.1038/s41598-021-95025-3

236. Liu LH, Iketani S, Guo YC, et al. Striking Antibody Evasion Manifested by the Omicron Variant of SARS-CoV-2. bioRxiv 2021. 12.14.472719; doi: https://doi.org/10.1101/2021.12.14.472719

237. Planas D, Saunders N, Maes P, et al. Considerable escape of SARS-CoV-2 variant Omicron to antibody neutralization. - bioRxiv 2021.12.14.472630; doi: https://doi.org/10.1101/2021.12.14.472630

238. Hoffmann M, Krüger N, Schulz S, et al. The Omicron variant is highly resistant against antibody-mediated neutralization - implications for control of the COVID-19 pandemic. - bioRxiv 2021.12.12.472286; doi: https://doi.org/10.1101/2021.12.12.472286

239. Cameroni E, Saliba C, Bowen JE, et al. Broadly neutralizing antibodies overcome SARS-CoV-2 Omicron antigenic shift. bioRxiv 2021.12.12.472269; doi: https://doi.org/10.1101/2021.12.12.472269 
M. Teppone. COVID-19: Three Phases of the Pandemic

240. Cao YL, Wang J, Jian FC, et al. B.1.1.529 escapes the majority of SARS-CoV-2 neutralizing antibodies of diverse epitopes. bioRxiv 2021.12.07.470392; doi: https://doi.org/10.1101/2021.12.07.470392

241. Sheward DJ, Kim C, Ehling RA, et al. Variable loss of antibody potency against SARS-CoV-2 B.1.1.529 (Omicron). - bioRxiv 2021. 12.19.473354; doi: https://doi.org/10.1101/2021.12.19.473354

242. Grigorieva S. Ural Scientist built a mathematical model and discovered COVID-19 cases growth proportionally to growth of the vaccinated people number. - Znak, November 25, 2021. [Russian] [cited 2021 Dec 30]. Available from: https://znak-com.turbopages.org /znak.com/s/2021-11-25/chelyabinskiy_uchenyy_postroil_matema ticheskuyu_model_zavisimosti_zabolevaemosti_covid_19_ot_vakcina

243. Kozlov M. Omicron overpowers key COVID antibody treatments in early tests. Nature, 2021; Dec 21. doi: https://doi.org /10.1038/d41586-021-03829-0

244. Kostoff RN, Calina D, Kanduc D, et al. Why are we vaccinating children against COVID-19? Toxicol Rep. 2021;8: 1665-1684. doi: 10.1016/j.toxrep.2021.08.010. Epub 2021 Sep 14.

245. Salvatore PP, Lee CC, Sleweon S, et al. Transmission potential of vaccinated and unvaccinated persons infected with the SARS-CoV-2 Delta variant in a federal prison, July-August 2021. medRxiv 2021.11.12.21265796; doi: https://doi.org/10.1101/2021.11. 12.21265796

246. Subramanian SV, Kumar A. Increases in COVID-19 are unrelated to levels of vaccination across 68 countries and 2947 counties in the United States. Eur J Epidemiol. 2021; Dec;36(12): 1237-1240. doi: 10.1007/s10654-021-00808-7. Epub 2021 Sep 30.

247. Kennedy N, Guy J. We can't vaccinate the planet every six months,' says Oxford vaccine scientist. - CNN; Jan 5, 2022. [cited 2022 Jan 10]. Available from: https://amp.cnn.com/cnn/2022/01/04/ health/andrew-pollard-booster-vaccines-feasibility-intl/index.html

248. Ivanov DV. Vaccination and death: what is happening in the world. - In: The 1st Moscow Scientific and Practical Conference. - Dec 12, 2021, Moscow, Russia: 3:34-3:49. [Russian] [cited 2021 Dec 30]. Available from:https://www.youtube.com $/$ watch? $\mathrm{v}=\mathrm{ZqHsz} 8 \mathrm{z} 7 \mathrm{Bzc} \& \mathrm{t}=0 \mathrm{~s}$

249. Nebehay S, Mason J. People who are immunocompromised or received an inactivated COVID-19 vaccine should get a booster: WHO. - The Globe and Mail, Dec 9, 2021. [cited 2021 Dec 30]. Available from: https://www.theglobeandmail.com/world/article-peoplewho-are-immunocompromised-or-received-an-inactivated-covid-19/

250. Neil M, Fenton N, Smalley J. et al. Latest statistics on England mortality data suggest systematic mis-categorisation of vaccine status and uncertain effectiveness of Covid-19 vaccination. Preprint, Researchgate, Dec 2021; DOI:10.13140/RG.2.2.14176.20483

251. Riemersma KK, Grogan BE, Kita-Yarbro A, et al. Shedding of Infectious SARS-CoV-2 Despite Vaccination. - medRxiv 2021.07. 31.21261387; doi: https://doi.org/10.1101/2021.07.31.21261387

252. Nordström P, Ballin M, Nordström A. Effectiveness of Covid19 Vaccination Against Risk of Symptomatic Infection, Hospitalization, and Death Up to 9 Months: A Swedish Total-Population Cohort Study. Preprint, SSRN 2021; Oct 25. http://dx.doi.org/10.2139/ssrn.3949410.

253. Eyre DW, Taylor D, Purver M, et al. The impact of SARS-CoV2 vaccination on Alpha \& Delta variant transmission. - medRxiv 2021. 09.28.21264260; doi: https://doi.org/10.1101/2021.09.28.2126426

254. Cherry K. What Is the Impact of Prolonged Stress? - VeryWell Mind, January 18, 2021. [cited 2021 Dec 30]. Available from: https// www.verywellmind.com/prolonged-stress-symptoms-causes-impactand-coping-5092113

255. Kiecolt-Glaser JK, Glaser R. Mind and immunity. - In: D. Goleman \& J. Gurin, (Eds.) Mind/Body Medicine. - New York: Consumer Reports, 1993: 39-59.

256. Kiecolt-Glaser JK, Glaser R. Depression and immune function: central pathways to morbidity and mortality. J Psychosom Res. 2002; Oct; 53(4): 873-6. doi: 10.1016/s0022-3999(02)00309-4.

257. Yan Q. Psychoneuroimmunology: Systems Biology Approaches to Mind-Body Medicine. - Switzerland, Springer, 2016, p. 37-129.
258. Segerstrom SC, Miller GE. Psychological stress and the human immune system: a meta-analytic study of 30 years of inquiry. Psychol Bull. 2004; 130(4):601-630. doi:10.1037/0033-2909.130.4.601

259. Ibarra-Coronado EG, Pantaleón-Martínez AM, VelazquézMoctezuma J, et al. The Bidirectional Relationship between Sleep and Immunity against Infections. J. Immunol. Res. 2015;2015: 678164. doi: 10.1155/2015/678164.

260. Chiu H-H, Wei K-C, Chen A, Wang W-H, Herpes zoster following COVID-19 vaccine: a report of three cases, QJM: An International Journal of Medicine, 2021; July, 114(7): 531-532; https://doi.org/10.1093/qjmed/hcab208

261. Eid E, Abdullah L, Kurban M, Abbas O. Herpes zoster emergence following mRNA COVID-19 vaccine. J Med Virol. 2021; Sep;93(9): 5231-5232. doi: 10.1002/jmv.27036. Epub 2021 May 3.

262. Psichogiou M, Samarkos M, Mikos N, Hatzakis A. Reactivation of Varicella Zoster Virus after Vaccination for SARS-CoV-2. Vaccines (Basel). 2021; 9(6):572. Published 2021 Jun 1. doi:10.3390/vaccines 9060572

263. Iwanaga J, Fukuoka H, Fukuoka N, et al. A narrative review and clinical anatomy of herpes zoster infection following COVID-19 vaccination. Clinical Anatomy, 2022, 35(1):45-51. https://doi.org/10. 1002/ca.23790

264. Maia CMF, Marques NP, de Lucena EHG, et al Increased number of Herpes Zoster cases in Brazil related to the COVID-19 pandemic. Int J Infect Dis. 2021 Mar;104:732-733. doi: 10.1016/j. ijid.2021.02. 033. Epub 2021 Feb 11.

265. Algaadi SA. Herpes zoster and COVID-19 infection: a coincidence or a causal relationship? Infection. 2021 Nov 22:1-5. doi: 10.1007/s1 5010-021-01714-6. Epub ahead of print.

266. Diez-Domingo J, Parikh R, Bhavsar AB, et al. Can COVID-19 Increase the Risk of Herpes Zoster? A Narrative Review. Dermatol Ther (Heidelb). 2021 Aug;11(4):1119-1126. doi: 10.1007/s13555021-00549-1. Epub 2021 May 17. Erratum in: Dermatol Ther (Heidelb). 2021 Jun 15;

267. Fukuoka H, Fukuoka N, Kibe T, et al. Oral Herpes Zoster Infection Following COVID-19 Vaccination: A Report of Five Cases. Cureus. 2021 Nov 10;13(11):e19433. doi: 10.7759/cureus. 19433.

268. Maldonado MD, Romero-Aibar J. The Pfizer-BNT162b2 mRNA-based vaccine against SARS-CoV-2 may be responsible for awakening the latency of herpes varicella-zoster virus. Brain Behav Immun Health. 2021 Dec;18:100381. doi: 10.1016/j.bbih.2021.100 381. Epub 2021 Oct 30.

269. Papasavvas I, de Courten C, Herbort CP Jr. Varicella-zoster virus reactivation causing herpes zoster ophthalmicus (HZO) after SARS-CoV-2 vaccination - report of three cases. J Ophthalmic Inflamm Infect. 2021 Sep 16;11(1):28. doi: 10.1186/s12348-021-00260-4.

270. Rodríguez-Jiménez P, Chicharro P, Cabrera LM, et al. Varicellazoster virus reactivation after SARS-CoV-2 BNT162b2 mRNA vaccination: Report of 5 cases. JAAD Case Rep. 2021;12:58-59. doi:10.1016/j.jdcr.2021.04.014

271. Hope-Simpson RE. The nature of herpes zoster: a long-term study and a new hypothesis. Proc R Soc Med. 1965; 58: 9-20. PMID: 14267505; PMCID: PMC1898279.

272. Warren-Gash C, Breuer J. Herpes zoster in people who are immunocompromised: what are the options for prevention? Lancet Infect Dis. 2019; Sep;19(9): 922-924. doi: 10.1016/S1473-3099(19) 30399-8. Epub 2019 Aug 6.

273. A Study to Evaluate Efficacy, Safety, and Immunogenicity of mRNA-1273 Vaccine in Adults Aged 18 Years and Older to Prevent COVID-19. - ClinicalTrials.gov Identifier: NCT04470427; First Posted: July 14, 2020. [cited 2020 Dec 30]. Available from: https://clinicaltrials. gov/ct2/show/NCT04470427

274. Rodríguez-Martinó E, Medina-Prieto R, Santana-Bagur J, et al. Early immunologic response to mRNA COVID-19 vaccine in patients receiving biologics and/or immunomodulators. - medRxiv 2021.09. 11.21263211; doi: https://doi.org/10.1101/2021.09.11.21263211 
275. Reynolds S. Lasting immunity found after recovery from COVID-19. - NIH, January 26, 2021. [cited 2021 Dec 30]. Available from: https://www.nih.gov/news-events/nih-research-matters/lastingimmunity-found-after-recovery-covid-19

276. Abu-Raddad LJ, Chemaitelly H, Bertollini R; National Study Group for COVID-19 Epidemiology. Severity of SARS-CoV-2 Reinfections as Compared with Primary Infections. N Engl J Med. 2021; Nov 24. doi: 10.1056/NEJMc2108120.

277. Ansari A, Arya R, Sachan S, et al. Immune Memory in Mild COVID-19 Patients and Unexposed Donors Reveals Persistent T Cell Responses After SARS-CoV-2 Infection. Front Immunol. 2021; Mar 11; 12:636768. doi: 10.3389/fimmu.2021.636768.

278. Cohen KW, Linderman SL, Moodie Z, et al. Longitudinal analysis shows durable and broad immune memory after SARS-CoV2 infection with persisting antibody responses and memory B and T cells. - medRxiv 2021.04.19.21255739; doi: https://doi.org/10.1101 /2021.04.19.21255739

279. Dan JM, Mateus J, Kato Y, et al. Immunological memory to SARS-CoV-2 assessed for up to 8 months after infection. Science. 2021; Feb 5;371(6529): eabf4063. doi: 10.1126/science.abf4063.

280. Gazit S, Shlezinger R, Perez G, et al. Comparing SARS-CoV-2 natural immunity to vaccine-induced immunity: reinfections versus breakthrough infections. - medRxiv 2021.08.24.21262415; doi: https: //doi.org/10.1101/2021.08.24.21262415

281. O Murchu E, Byrne P, Carty PG, et al. Quantifying the risk of SARS-CoV-2 reinfection over time [published online ahead of print, 2021 May 27]. Rev Med Virol. 2021; e2260. doi:10.1002/rmv.2260

282. Le Bert N, Clapham HE, Tan AT, et al. Highly functional virus-specific cellular immune response in asymptomatic SARS-CoV-2 infection. - J. Exp. Med. 2021; 218(5): e20202617; https://doi.org/10. 1084/jem.20202617

283. Turner JS, Kim W, Kalaidina E. et al. SARS-CoV-2 infection induces long-lived bone marrow plasma cells in humans. Nature, 2021; 595, 421-425. https://doi.org/10.1038/s41586-021-03647-4

284. Zhang J, Lin H, Ye BW, et al. One-year sustained cellular and humoral immunities of COVID-19 convalescents, Clinical Infectious Diseases, 2021; ciab884, https://doi.org/10.1093/cid/ciab884

285. Lab Alert: Changes to CDC RT-PCR for SARS-CoV-2 Testing. July 21, 2021. - CDC, Division of Laboratory Systems. [cited 2021 Dec 30]. Available from: https://www.cdc.gov/csels/dls/locs/2021/07-212021-lab-alert-Changes_CDC_RT-PCR_SARS-CoV-2_Testing_1.html

286. COVID19 PCR Tests are Scientifically Meaningless. Bulgarian Pathology Association, July 1, 2020. [cited 2021 Dec 30]. Available from: https://bpa-pathology.com/covid19-pcrtests-are-scientificallymeaningless/

287. Borger P, Malhotra RK, Yeadon M, et al. External peer review of the RTPCR test to detect SARS-CoV-2 reveals 10 major scientific flaws at the molecular and methodological level: consequences for false positive results. - Preprint, Nov 2020; DOI: 10.5281/zenodo.4298004

288. Tanzania president questions coronavirus kits after animal test: President Magufuli says tests were found to be faulty after goat, sheep and pawpaw samples test positive for COVID-19. - Aljazeera, May 3, 2020. [cited 2021 Dec 30]. Available from: https://www.aljazeera .com/news/2020/5/3/tanzania-president-questions-coronavirus-kitsafter-animal-test

289. Stang A, Robers J, Schonert B, et al. Letter: The performance of the SARS-CoV-2 RT-PCR test as a tool for detecting SARS-CoV2 infection in the population. J Infect. 2021; 83(2):244-245. doi:10.1016 /j.jinf.2021.05.022; https://doi.org/10.1016/j.jinf.2021.05.023

290. Curran T, McCaughey C, Ellis J, et al. False-positive PCR results linked to administration of seasonal influenza vaccine. J Med Microbiol. 2012; Mar;61(Pt 3): 332-338. doi: 10.1099/jmm.0.036178-0 Epub 2011 Nov 17.

291. Fischer M, Renevey N, Thür B, Hoffmann D, Beer M, Hoffmann B. Efficacy Assessment of Nucleic Acid Decontamination Reagents Used in Molecular Diagnostic Laboratories. PLoS One. 2016; Jul 13;11(7): e0159274. doi: 10.1371/journal.pone.0159274.
292. Czurda S, Smelik S, Preuner-Stix S, et al. Occurrence of Fungal DNA Contamination in PCR Reagents: Approaches to Control and Decontamination. J Clin Microbiol. 2016; Jan;54(1): 148-52. doi: 10.1128/JCM.02112-15. Epub 2015 Nov 11.

293. Robinson-McCarthy LR, Mijalis AJ, Filsinger GT, et al. Laboratory-Generated DNA Can Cause Anomalous Pathogen Diagnostic Test Results. Microbiol Spectr. 2021; Oct 31;9(2): e0031321. doi: 10.1128/Spectrum.00313-21. Epub 2021 Sep 15.

294. Yuan XN, Meng QY, Shen N, et al. [Detection and evaluation of SARS-CoV-2 nucleic acid contamination in corona virus disease 19 ward surroundings and the surface of medical staff's protective equipment]. Beijing Da Xue Xue Bao Yi Xue Ban. 2020; Oct 18;52(5): 803-808. [Chinese]. doi: 10.19723/j.issn.1671-167X.2020.05.002.

295. Gardner B, Yorke H. Coronavirus testing effort hampered by kits contaminated with Covid-19. The Telegraph, 30 March 2020. [cited 2021 Dec 30]. Available from: https://www.telegraph.co.uk/news/2020/03 /30/uks-attempt-ramp-coronavirus-testing-hindered-key-components/

296. Willman D. Contamination at CDC lab delayed rollout of coronavirus tests. - The Washington Post, April 18, 2020. [cited 2021 Dec 30]. Available from: https://www.washingtonpost.com/investigations /contamination-at-cdc-lab-delayed-rollout-of-coronavirus-tests/2020/ 04/18/fd7d3824-7139-11ea-aa80-c2470c6b2034_story.html

297. Willman D. CDC coronavirus test kits were likely contaminated, federal review confirms. - The Washington Post, June 20, 2020. [cited 2021 Dec 30]. Available from: https://www.washingtonpost.com/ investigations/cdc-coronavirus-test-kits-were-likely-contaminated federal-review-confirms/2020/06/20/1ceb4e16-b2ef-11ea-8f56-63f38 c990077_story.html

298. Allen K. Ontario received 100,000 contaminated, unusable swabs for COVID-19 tests. - The Star, April 10, 2020. [cited 2021 Dec 30]. Available from:https://www.thestar.com/news/canada/2020/ 04/10/ontario-received-100000-contaminated-unusable-swabs-forcovid-19-tests.html

299. Steinbach N. Santé Canada confirme la contamination de 380 000 tests de dépistage. - ICI Nouveau-Brunswick, 28 avril 2020. [cited 2021 Dec 30]. Available from: https://ici.radio-canada.ca/nouvelle/ 1697967/sante-canada-contamination-covid-19-rappel-esbe-scientific

300. Des tests de coronavirus contaminés par le coronavirus. CNEWS, 2 avril 2020. [cited 2021 Dec 30]. Available from: https://www .cnews.fr/monde/2020-04-02/des-tests-de-coronavirus-contaminespar-le-coronavirus-942737

301. 700000 tests PCR contaminés par des germes en Suisse. Watson, July 9, 2021. [cited 2021 Dec 30]. Available from: https://www .watson.ch/fr/suisse/certificat\%20covid/838281749-centaines-demilliers-de-tests-pcr-contamines-par-des-germes-en-suisse

302. Limitations. - In: The CDC 2019-Novel Coronavirus (2019nCoV) Real-Time RTPCR Diagnostic Panel. Atlanta, GA: Centers for Disease Control and Prevention, 2020, July 21, p. 37-38. [cited 2021 Dec 30]. Available from: https://www.fda.gov/media/134922/download

303. Potential for False Positive Results with Abbott Molecular Inc. Alinity m SARS-CoV-2 AMP and Alinity m Resp-4-Plex AMP Kits - Letter to Clinical Laboratory Staff and Health Care Providers. October 15, 2021. [cited 2021 Dec 30]. Available from: https://www.fda. gov/medical-devices/letters-health-care-providers/potential-falsepositive-results-abbott-molecular-inc-alinity-m-sars-cov-2-amp-andalinity-m-resp-4

304. Bullard J, Dust K, Funk D, et al. Predicting Infectious Severe Acute Respiratory Syndrome Coronavirus 2 From Diagnostic Samples. Clin Infect Dis. 2020; Dec 17;71(10):2663-2666.doi: 10.1093/cid/ciaa638

305. Jaafar R, Aherfi S, Wurtz N, et al. Correlation Between 3790 Quantitative Polymerase Chain Reaction-Positives Samples and Positive Cell Cultures, Including 1941 Severe Acute Respiratory Syndrome Coronavirus 2 Isolates. Clin Infect Dis. 2021; Jun 1;72(11): e921. doi: 10.1093/cid/ciaa1491. 
306. Covid-19: l'hypersensibilité des tests PCR, entre intox et vrai débat. Peut-on vraiment dire, comme le relaient des messages en ligne, que $90 \%$ des cas confirmés de personnes infectées sont des "faux positifs"? - Le Monde, 9 septembre 2020. [cited 2021 Dec 30]. Available from: https://www.lemonde.fr/les-decodeurs/article/2020 /09/09/covid-19-1-hypersensibilite-des-tests-pcr-entre-intox-et-vraidebat_6051528_4355770.html.

307. Healy B, Khan A, Metezai H, et al. The impact of false positive COVID-19 results in an area of low prevalence. - Clinical Med, 2021; Jan 21 (1) e54-e56; DOI: 10.7861/clinmed.2020-0839

308. Gubbay J, Rilkoff H, Kristjanson H, et al. Impact of COVID19 pre-test probability on positive predictive value of high cycle threshold SARS-CoV-2 real-time reverse transcription PCR test results. Infection Control \& Hospital Epidemiology, 2021; 1-18. doi:10.1017/ice.2021.369

309. Basile K, Maddocks S, Kok J, Dwyer DE. Accuracy amidst ambiguity: false positive SARS-CoV-2 nucleic acid tests when COVID-19 prevalence is low. Pathology. 2020; Dec; 52(7): 809-811. doi: 10.1016/j.pathol.2020.09.009. Epub 2020 Sep 30.

310. Kolata G. Faith in Quick Test Leads to Epidemic That Wasn't. The New York Times, January 22, 2007. [cited 2021 Dec 30]. Available from: https://www.nytimes.com/2007/01/22/health/22whoop.html

311. WHO Director-General's opening remarks at the media briefing on COVID-19. - March 16, 2020. [cited 2021 Dec 30]. Available from: https://www.who.int/director-general/speeches/detail/who-director-generals-opening-remarks-at-the-media-briefing-on-covid-19---16-march-2020

312. Ivanov DV, Diall GCh. The possibilities of fractal analysis in the correction of the organization of medical care. J New Med Tech, 2021; 28(3): 82-88. [Russian] DOI: 10.24412/1609-2163-2021-3-82-88

313. Shah S, Singhal T, Davar N, Thakkar P. No correlation between $\mathrm{Ct}$ values and severity of disease or mortality in patients with COVID 19 disease. Indian J Med Microbiol. 2021; 39(1):116117. doi:10.1016/j.ijmmb.2020.10.021

314. Ehizuelen M. Can China-style quarantine against COVID-19 go global? - CGTN, March 17, 2020. [cited 2021 Dec 30]. Available from: https://news.cgtn.com/news/2020-03-17/Can-China-style-quarantineagainst-COVID-19-go-global--OVQH0G4LGo/index.html

315. Yusof TA. MAEPS PKRC 2.0 ready to accommodate surge in patients. New Straits Times, May 19, 2021. [cited 2021 Dec 30]. Available from: https://www.nst.com.my/news/nation/2021/05/6914 71/maeps-pkrc-20-ready-accomodate-surge-patients

316. Vu M. Vietnam lengthens quarantine to 21 days. Hanoi Times, May 6, 2021. [cited 2021 Dec 30]. Available from: http://hanoitimes. $\mathrm{vn} /$ vietnam-lengthens-quarantine-to-21-days-317234.html

317. Protsenko DN. COVID-19 and Sepsis. Nov 24, 2020. - XXII International Congresses on Antimicrobial Therapy, November 2426, 2020, Moscow, Russia. [cited 2021 Dec 30]. https://moscow2020. iacmac.ru/; https://www.youtube.com/watch?v=kuBt_J1v330

318. Read JM, Green CA, Harrison EM, et al. ISARIC4C investigators. Hospital-acquired SARS-CoV-2 infection in the UK's first COVID19 pandemic wave. Lancet. 2021 Sep 18;398(10305):1037-1038. doi: 10.1016/S0140-6736(21)01786-4. Epub 2021 Aug 13.

319. Du Q, Zhang D, Hu W, et al. Nosocomial infection of COVID19: A new challenge for healthcare professionals (Review). Int J Mol Med. 2021; 47(4):31. doi:10.3892/ijmm.2021.4864

320. Rickman HM, Rampling T, Shaw K, et al. Nosocomial Transmission of Coronavirus Disease 2019: A Retrospective Study of 66 Hospitalacquired Cases in a London Teaching Hospital. - Clin Infect Dis, 2021; Feb 15, 72(4): 690-693, https://doi.org/10.1093/cid/ciaa816

321. Grasselli G, Scaravilli V, Mangioni D, et al. Hospital-Acquired Infections in Critically Ill Patients With COVID-19. Chest. 2021; Aug; 160(2):454-465. doi: 10.1016/j.chest.2021.04.002. Epub 2021 Apr 20.
322. Marin-Corral J, Pascual-Guardia S, Muñoz-Bermúdez R, et al. Health care-associated infections in patients with COVID-19 pneumonia in COVID critical care areas [published online ahead of print, 2021 Apr 30]. Med Intensiva (Engl Ed). 2021; 10.1016/j.medin.2021.04. 003. doi:10.1016/j.medin.2021.04.003

323. Guidance: Number of coronavirus (COVID-19) cases in the UK. - Updated on 2 July 2020. [cited 2021 Dec 30]. Available from: https://web.archive.org/web/20200703055904/https://www.gov.uk/gu idance/coronavirus-covid-19-information-for-the-public

324. Briand G. COVID-19 Deaths: A Look at U.S. Data. - Washington, D.C., Nov 11, 2020. Johns Hopkins University Advanced Academic Programs lecture. - [cited 2021 Dec 30]. Available from: https://www. youtube.com/watch?v=3TKJN61aflI

325. Tribunal Administrativo de Circulo de Lisboa. - Juizo Administrativo Comum. Processo n. ${ }^{\circ}$ 525/21.4BELSB. - Lisboa, 19 de Maio de 2021. [cited 2021 Dec 30]. Available from: https://archive.org /details/2021-may-tribunal-administrativo-de-circulo-de-lisboa-n-525 -21.4-belsb

326. Recommendations for the outpatient management of COVID19 patients with the Acute Infection and Post-COVID Syndrome. Vorobiev PA. Ed. Health Care Standardization Problems. 2021; 7-8: 3-96. [Russian] https://doi.org/10.26347/1607-2502202107-08003-096

327. McCullough PA, Alexander PE, Armstrong R, et al. Multifaceted highly targeted sequential multidrug treatment of early ambulatory high-risk SARS-CoV-2 infection (COVID-19). Rev Cardiovasc Med. 2020; Dec 30;21(4):517-530. doi: 10.31083/j.rcm.2020.04.264.

328. Bhimraj A, Morgan RL, Shumaker AH, et al. IDSA Guidelines on the Treatment and Management of Patients with COVID-19. Published by IDSA on Nov 4, 2021; Last updated, Nov 18, 2021. https://www.idsociety.org/globalassets/idsa/practice-guidelines/covid19/ treatment/idsa-covid-19-gl-tx-and-mgmt-v5.6.0.pdf

329. Rochwerg B, Agoritsas T, Diaz J, Askie L. WHO COVID-19 therapeutic guidelines. Lancet. 2021; Jul 10;398(10295):117-118. doi: 10.1016/S0140-6736(21)01331-3.

330. Gönen MS, Alaylıŏlu M, Durcan E, et al. Rapid and Effective Vitamin D Supplementation May Present Better Clinical Outcomes in COVID-19 (SARS-CoV-2) Patients by Altering Serum INOS1, IL1B, IFNg, Cathelicidin-LL37, and ICAM1. Nutrients. 2021; Nov 12;13 (11):4047. doi: 10.3390/nu13114047.

331. DeLuccia R, Clegg D, Sukumar D. The implications of vitamin D deficiency on COVID-19 for at-risk populations. Nutr Rev. 2021; 79(2):227-234. doi:10.1093/nutrit/nuaa092

332. Benskin LL. A Basic Review of the Preliminary Evidence That COVID-19 Risk and Severity Is Increased in Vitamin D Deficiency. Front Public Health. 2020; Sep 10;8:513. doi: 10.3389/fpubh.2020.00513.

333. Chopra A, Sivaraman K, Radhakrishnan R, et al. Can povidone iodine gargle/mouthrinse inactivate SARS-CoV-2 and decrease the risk of nosocomial and community transmission during the COVID19 pandemic? An evidence-based update. Jpn Dent Sci Rev. 2021; Nov;57:39-45. doi: 10.1016/j.jdsr.2021.03.001. Epub 2021 Mar 15.

334. Finzi E. Treatment of SARS-CoV-2 with high dose oral zinc salts: A report on four patients. Int J Infect Dis. 2020; Oct;99:307309. doi: 10.1016/j.ijid.2020.06.006. Epub 2020 Jun 6.

335. Liu CY, Zhao JC, China's first COVID-19 antibody drug cuts hospitalizations, deaths 80\%. - Global Times, Dec 9, 2021. [cited 2021 Dec 30]. Available from: https://www.globaltimes.cn/page/202112 /1241115.shtml

336. Önal H, Arslan B, Üçüncï Ergun N, et al. Treatment of COVID19 patients with quercetin: a prospective, single center, randomized, controlled trial. Turk J Biol. 2021; Aug 30;45(4): 518-529. doi: 10.3906/biy-2104-16.

337. Khavinson VK, Linkova NS, Chalisova NI, Ivko OM. The Use of Thymalin for Immunocorrection and Molecular Aspects of Biological Activity. Biology Bulletin Reviews. 2021; 11(4):377-382. doi:10.1134/S2079086421040046 
338. Domingo MA, Farrales MS, Loya RM, et al. The effect of $1 \%$ povidone iodine as a pre-procedural mouthrinse in 20 patients with varying degrees of oral hygiene. J Philipp Dent Assoc. 1996; Sep-Nov; 48(2):31-8. PMID: 9462082.

339. Naqvi SHS, Citardi MJ, Cattano D. et al. Povidone-iodine solution as SARS-CoV-2 prophylaxis for procedures of the upper aerodigestive tract a theoretical framework. J of Otolaryngol - Head \& Neck Surg. 2020; 49, 77. https://doi.org/10.1186/s40463-020-00474-x

340. Wichniak A, Kania A, Siemiński M, Cubała WJ. Melatonin as a Potential Adjuvant Treatment for COVID-19 beyond Sleep Disorders. Int J Mol Sci. 2021;22(16):8623. Published 2021 Aug 11. doi: 10.3390/ijms22168623

341. Thota SM, Balan V, Sivaramakrishnan V. Natural products as home-based prophylactic and symptom management agents in the setting of COVID-19. Phytother Res. 2020; Dec;34(12):3148-3167. doi: 10.1002/ptr.6794. Epub 2020 Aug 17.

342. Silveira D, Prieto-Garcia JM, Boylan F, et al. COVID-19: Is There Evidence for the Use of Herbal Medicines as Adjuvant Symptomatic Therapy? Front Pharmacol. 2020; 11:581840. Published 2020 Sep 23. doi:10.3389/fphar.2020.581840

343. Rafiqul Islam ATM, Ferdousi J, Shahinozzaman M. Previously published ethno-pharmacological reports reveal the potentiality of plants and plant-derived products used as traditional home remedies by Bangladeshi COVID-19 patients to combat SARS-CoV-2. Saudi J Biol Sci. 2021; Nov;28(11): 6653-6673. doi: 10.1016/j.sjbs.2021.07. 036. Epub 2021 Jul 17.
344. Nugraha RV, Ridwansyah H, Ghozali M, et al. Traditional Herbal Medicine Candidates as Complementary Treatments for COVID-19: A Review of Their Mechanisms, Pros and Cons. Evid Based Complement Alternat Med. 2020; Oct 10;2020:2560645. doi: 10.1155/2020/2560645.

345. Garcia S. Pandemics and Traditional Plant-Based Remedies. A Historical-Botanical Review in the Era of COVID19. Front Plant Sci. 2020; Aug 28;11:571042. doi: 10.3389/fpls.2020.571042.

346. Huang J, Tao G, Liu J, et al. Current Prevention of COVID19: Natural Products and Herbal Medicine. Front Pharmacol. 2020; 11:588508. Published 2020 Oct 16. doi:10.3389/fphar.2020.588508

347. Nile SH, Kai G. Recent Clinical Trials on Natural Products and Traditional Chinese Medicine Combating the COVID-19. Indian J Microbiol. 2020; Dec 30;61(1):1-6. doi: 10.1007/s12088-020-00919-x.

348. Prigogine I, et al. A Degumonized World. - In: Prigogine I; Stengers I. Order out of chaos: man's new dialogue with nature. Toronto; New York: Bantam Books, 1984: 30-36.

349. Beattie K. Worldwide Bayesian Causal Impact Analysis of Vaccine Administration on Deaths and Cases Associated with COVID19: A BigData Analysis of 145 Countries. - ResearchGate.Preprint. November 2021, DOI: 10.13140/RG.2.2.34214.65605

PS. Some web addresses were interrupted while the manuscript was being formatted. When looking for a source, restore an interrupted address. // If one tries to open a webpage with a certain article and gets a note [Error 403 access forbidden] - ignore it, go ahead and click a web address again. 


\section{Appendix - Illustrations}

\section{Dynamics of the number of deaths during 22 months of the pandemic in various countries}

Twenty three sets of databases, which dated the 22nd of each month from January 2020 to November 2021, were collected. The databases related to each month for every country were calculated by subtracting the previous month's data from the analyzed month's data. CFR, IFR, number of cases per 1 million $(\mathrm{C} / \mathrm{M})$ and death per 1 million $(\mathrm{D} / \mathrm{M})$ were counted.

Cumulative and Monthly number of cases, deaths, tests, $\mathrm{CFR}, \mathrm{C} / \mathrm{M}, \mathrm{D} / \mathrm{M}$ and population were presented in the form of a table (see an example for Australia). Graph illustrations for various countries included (a) Dynamics of cumulative number of deaths during 22 months of the COVID-19 pandemic; and (b) Monthly number of deaths due to COVID-19 during the pandemic.

These illustrations could help doctors of the respective countries to understand their errors that have led to an increase in the number of new cases and deaths, and to correct them.

\section{Australia}

a) Cumulative number of cases, deaths, tests, population, CFR, IFR, C/M, D/M

\begin{tabular}{|r|r|r|r|r|r|r|r|r|r|}
\hline$\#$ & Date & Cases & Deaths & Tests & Population & CFR & IFR & C/M & D/M \\
\hline 0 & 22.01 .20 & - & - & - & - & - & - & - & - \\
\hline 1 & 22.02 .20 & 21 & 0 & 0 & 0 & 0 & - & - & - \\
\hline 2 & 22.03 .20 & 1353 & 7 & 0 & 0 & 0.517 & - & - & - \\
\hline 3 & 22.04 .20 & 6649 & 74 & 452441 & 0 & 1.113 & - & - & - \\
\hline 4 & 22.05 .20 & 7095 & 101 & 1170682 & 25466640 & 1.424 & 0.036 & 278.60 & 3.97 \\
\hline 5 & 22.06 .20 & 7474 & 102 & 2105974 & 25491691 & 1.365 & 0.063 & 293.19 & 4.00 \\
\hline 6 & 22.07 .20 & 12894 & 128 & 3641780 & 25515934 & 0.993 & 0.079 & 505.33 & 5.02 \\
\hline 7 & 22.08 .20 & 24602 & 485 & 5646546 & 25540986 & 1.971 & 0.242 & 963.24 & 18.99 \\
\hline 8 & 22.09 .20 & 26942 & 854 & 7351283 & 25566037 & 3.170 & 0.506 & 1053.82 & 33.40 \\
\hline 9 & 22.10 .20 & 27466 & 905 & 8420326 & 25590280 & 3.295 & 0.602 & 1073.30 & 35.37 \\
\hline 10 & 22.11 .20 & 27821 & 907 & 9713327 & 25615331 & 3.260 & 0.687 & 1086.11 & 35.41 \\
\hline 11 & 22.12 .20 & 28219 & 908 & 10720719 & 25639574 & 3.218 & 0.747 & 1100.60 & 35.41 \\
\hline 12 & 22.01 .21 & 28755 & 909 & 12642312 & 25664626 & 3.161 & 0.865 & 1120.41 & 35.42 \\
\hline 13 & 22.02 .21 & 28930 & 909 & 14089305 & 25689677 & 3.142 & 0.957 & 1126.13 & 35.38 \\
\hline 14 & 22.03 .21 & 29205 & 909 & 15209275 & 25712304 & 3.112 & 1.023 & 1135.84 & 35.35 \\
\hline 15 & 22.04 .21 & 29588 & 910 & 16481110 & 25737355 & 3.076 & 1.094 & 1149.61 & 35.36 \\
\hline 16 & 22.05 .21 & 30003 & 910 & 17797116 & 25762406 & 3.033 & 1.164 & 1164.60 & 35.32 \\
\hline 17 & 22.06 .21 & 30366 & 910 & 19821498 & 25786649 & 2.997 & 1.280 & 1177.59 & 35.29 \\
\hline 18 & 22.07 .21 & 32426 & 915 & 23457810 & 25810892 & 2.822 & 1.425 & 1256.29 & 35.45 \\
\hline 19 & 22.08 .21 & 44034 & 981 & 29437845 & 25836752 & 2.228 & 1.410 & 1704.32 & 37.97 \\
\hline 20 & 22.09 .21 & 90391 & 1186 & 36219104 & 25860995 & 1.312 & 1.021 & 3495.26 & 45.86 \\
\hline 21 & 22.10 .21 & 154489 & 1611 & 41907968 & 25885238 & 1.043 & 0.938 & 5968.23 & 62.24 \\
\hline 22 & 22.11 .21 & 199659 & 1948 & 46696043 & 25910289 & 0.976 & 0.977 & 7705.78 & 75.18 \\
\hline
\end{tabular}

b) Monthly number of cases, deaths, tests, CFR, C/M, D/M

\begin{tabular}{|r|r|r|r|r|r|r|r|}
\hline$\#$ & Date & Cases & Deaths & Tests & CFR & C/M & D/M \\
\hline 0 & before 22.01.20 & 0 & 0 & 0 & 0 & 0 & 0 \\
\hline 1 & $23.01 .20-22.02 .20$ & 21 & 0 & 0 & 0 & - & 0 \\
\hline 2 & $23.02 .20-22.03 .20$ & 1332 & 7 & 0 & 0.526 & - & - \\
\hline 3 & $23.03 .20-22.04 .20$ & 5296 & 67 & 452441 & 1.265 & - & - \\
\hline 4 & $23.04 .20-22.05 .20$ & 446 & 27 & 718241 & 6.054 & 17.51 & 1.06 \\
\hline 5 & $23.05 .20-22.06 .20$ & 379 & 1 & 935292 & 0.264 & 14.87 & 0.04 \\
\hline 6 & $23.06 .20-22.07 .20$ & 5420 & 26 & 1535806 & 0.480 & 212.42 & 1.02 \\
\hline 7 & $23.07 .20-22.08 .20$ & 11708 & 357 & 2004766 & 3.049 & 458.40 & 14.00 \\
\hline 8 & $23.08 .20-22.09 .20$ & 2340 & 369 & 1704737 & 15.769 & 91.53 & 14.43 \\
\hline 9 & $23.09 .20-22.10 .20$ & 524 & 51 & 1069043 & 9.733 & 20.48 & 2.00 \\
\hline 10 & $23.10 .20-22.11 .20$ & 355 & 2 & 1293001 & 0.563 & 13.86 & 0.08 \\
\hline 11 & $23.11 .20-22.12 .20$ & 398 & 1 & 1007392 & 0.251 & 15.52 & 0.04 \\
\hline 12 & $23.12 .20-22.01 .21$ & 536 & 1 & 1921593 & 0.187 & 20.88 & 0.04 \\
\hline 13 & $23.01 .21-22.02 .21$ & 175 & 0 & 1446993 & 0 & 6.81 & 0.00 \\
\hline 14 & $23.02 .21-22.03 .21$ & 275 & 0 & 1119970 & 0 & 10.70 & 0.00 \\
\hline 15 & $23.03 .21-22.04 .21$ & 383 & 1 & 1271835 & 0.261 & 14.88 & 0.04 \\
\hline 16 & $23.04 .21-22.05 .21$ & 415 & 0 & 1316006 & 0 & 16.11 & 0.00 \\
\hline 17 & $23.05 .21-22.06 .21$ & 363 & 0 & 2024382 & 0 & 14.08 & 0.00 \\
\hline 18 & $23.06 .21-22.07 .21$ & 2060 & 5 & 3636312 & 0.243 & 79.81 & 0.19 \\
\hline 19 & $23.07 .21-22.08 .21$ & 11608 & 66 & 5980035 & 0.569 & 449.28 & 2.55 \\
\hline 20 & $23.08 .21-22.09 .21$ & 46357 & 205 & 6781259 & 0.442 & 1792.55 & 7.93 \\
\hline 21 & $23.09 .21-22.10 .21$ & 64098 & 425 & 5688864 & 0.663 & 2476.24 & 16.42 \\
\hline 22 & $23.10 .21-22.11 .21$ & 45170 & 337 & 4788075 & 0.746 & 1743.32 & 13.01 \\
\hline
\end{tabular}

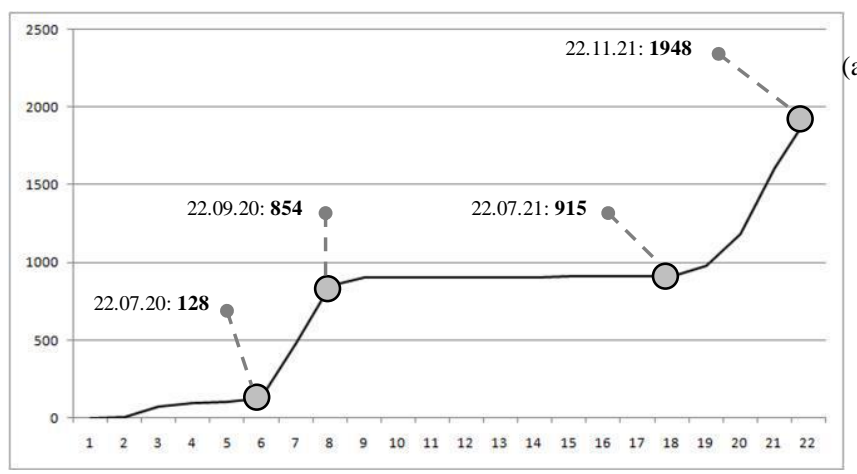

(a)

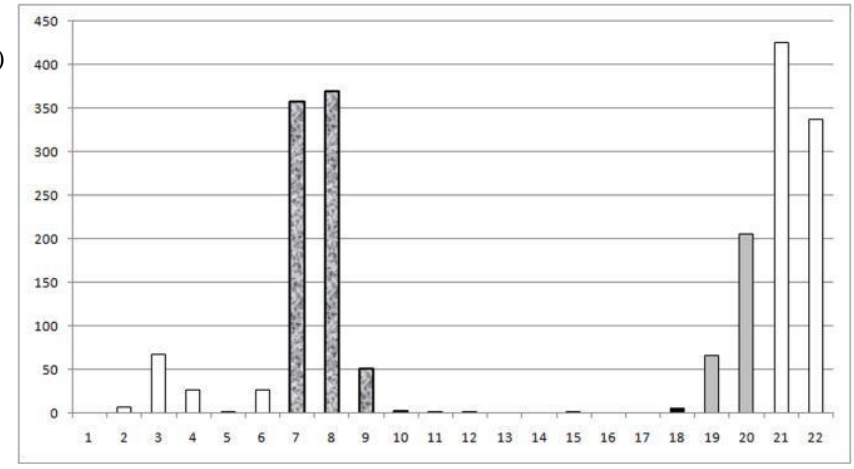

a) Dynamics of cumulative number of deaths in Australia during 22 months of the COVID-19 pandemic b) Monthly number of deaths due to COVID-19 during the pandemic in Australia.

The 1st phase includes months \# 1-6 (white columns); the 2nd phase includes months \# 7-12 (grey-white columns);

the 3rd phase includes months \# 13-18 (black columns); months \# 19-20th (grey columns); months \# 21-22nd (white columns);

The vertical axis shows number of cases (a) or deaths (b); the horizontal axis shows number of a week. 


\section{Azerbaijan}

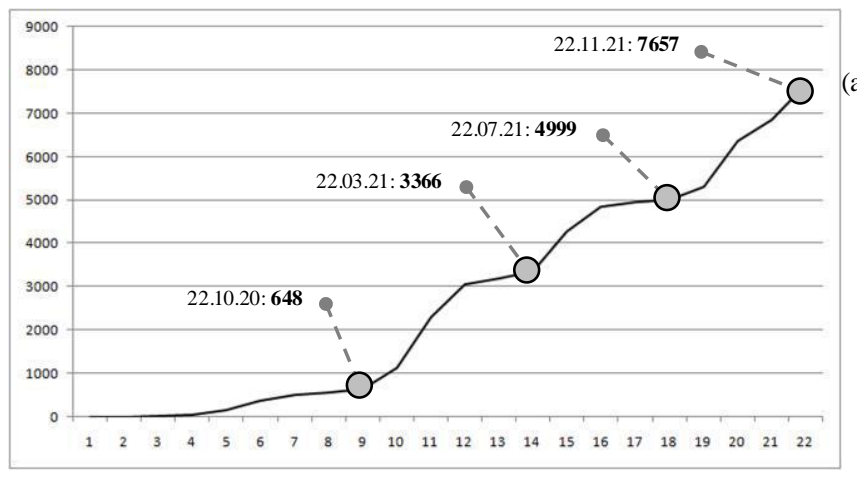

(a) (b)

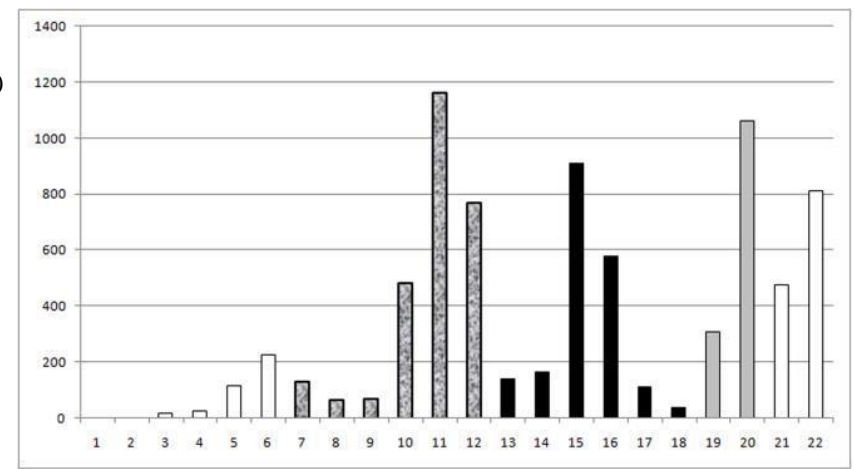

a) Dynamics of cumulative number of deaths in Azerbaijan during 22 months of the COVID-19 pandemic

b) Monthly number of deaths due to COVID-19 during the pandemic in Azerbaijan .

\section{Belarus}

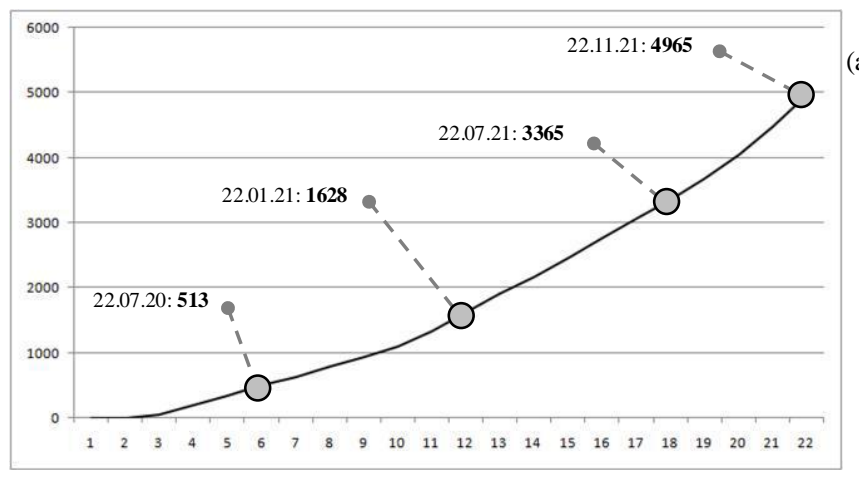

(a) (b)

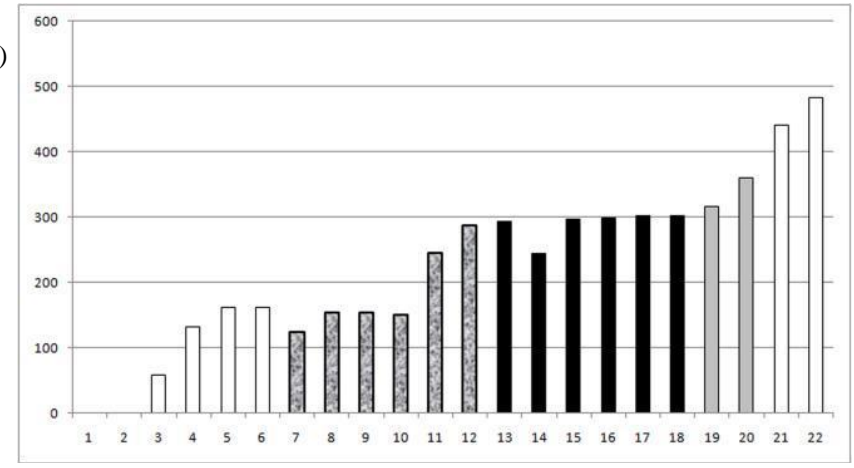

a) Dynamics of cumulative number of deaths in Belarus during 22 months of the COVID-19 pandemic

b) Monthly number of deaths due to COVID-19 during the pandemic in Belarus.

\section{Cambodia}

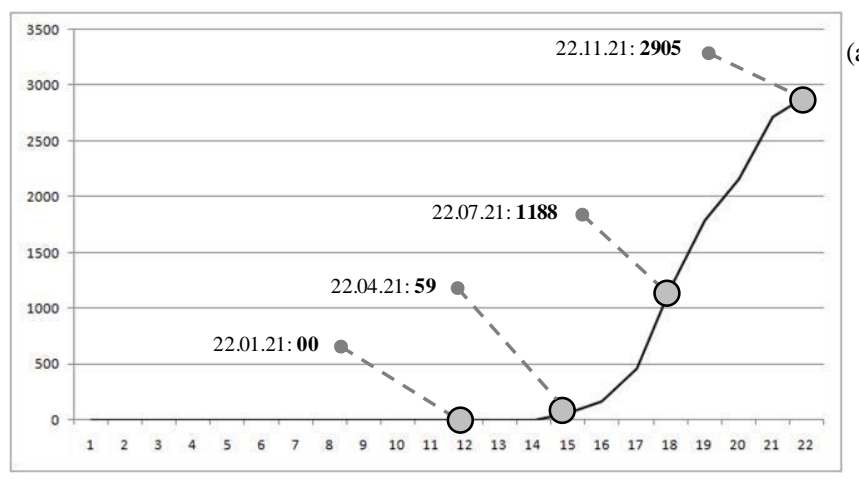

(a) (b)

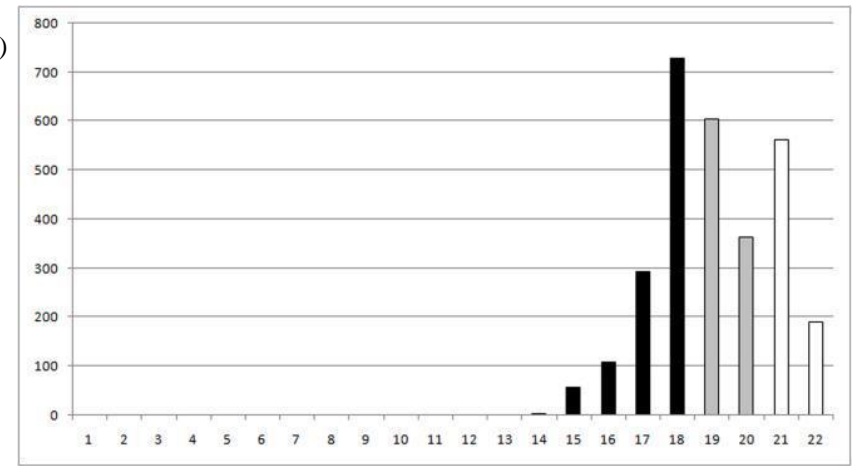

a) Dynamics of cumulative number of deaths in Cambodia during 22 months of the COVID-19 pandemic

b) Monthly number of deaths due to COVID-19 during the pandemic in Cambodia. 


\section{Cuba}

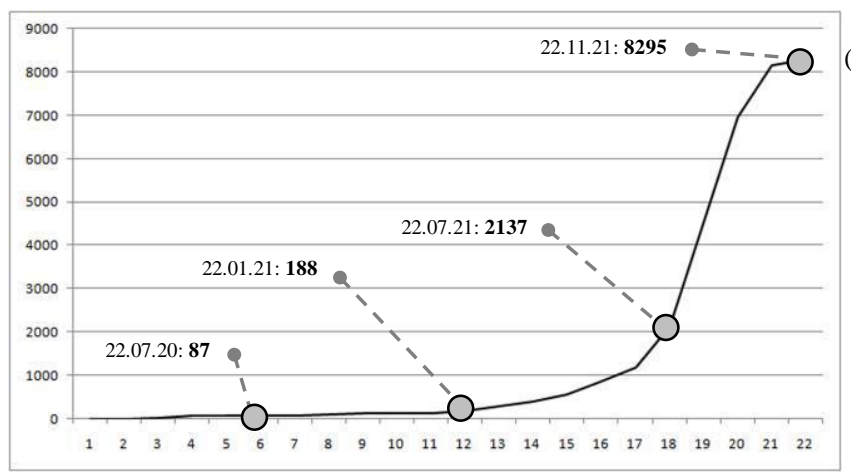

(a) (b)

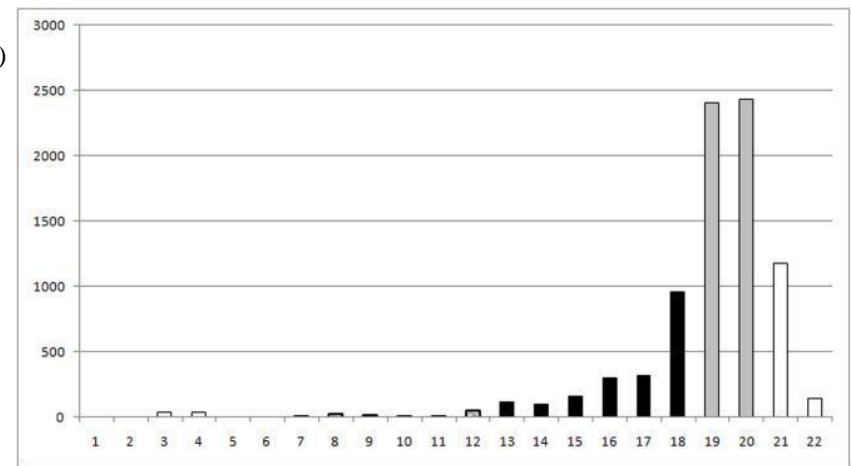

a) Dynamics of cumulative number of deaths in Cuba a during 22 months of the COVID-19 pandemic b) Monthly number of deaths due to COVID-19 during the pandemic in Cuba.

\section{Czechia}

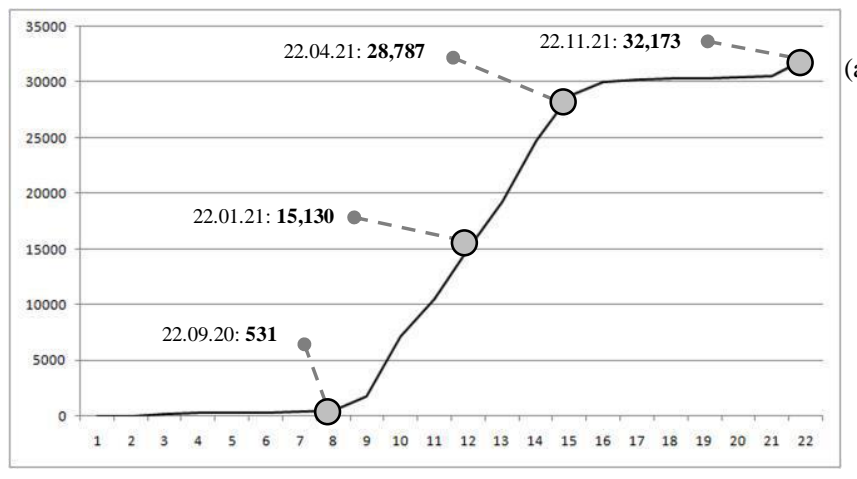

(a) (b)

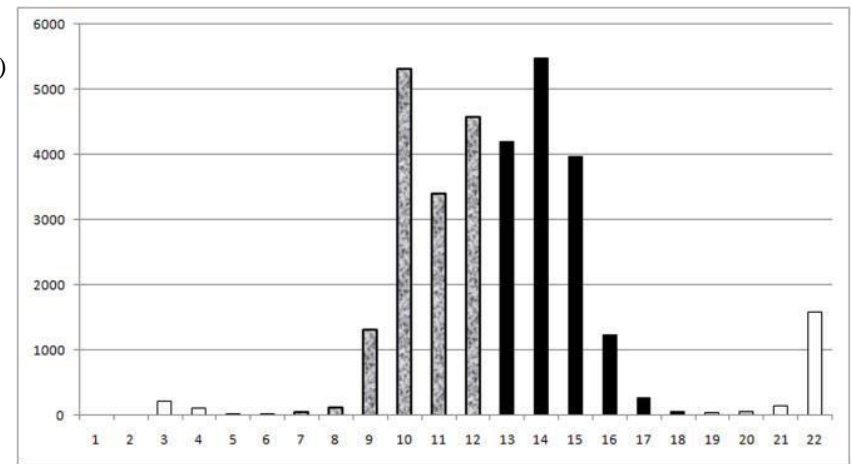

a) Dynamics of cumulative number of deaths in Czechia during 22 months of the COVID-19 pandemic b) Monthly number of deaths due to COVID-19 during the pandemic in Czechia.

\section{Denmark}

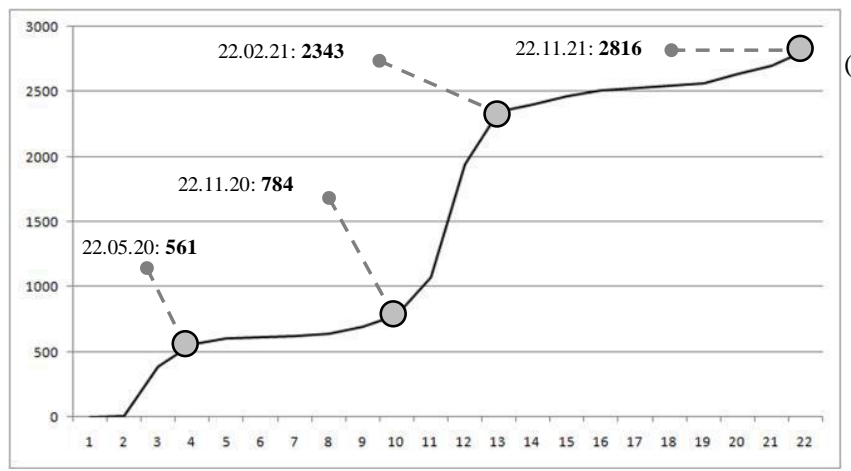

(a) (b)

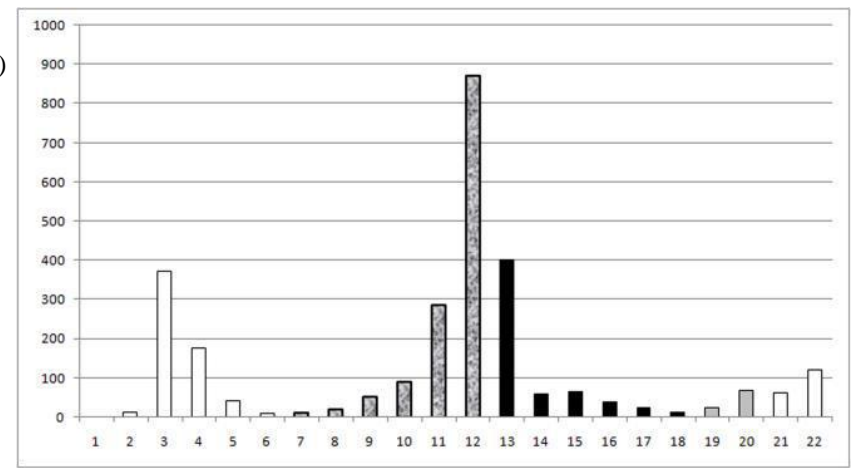

a) Dynamics of cumulative number of deaths in Denmark during 22 months of the COVID-19 pandemic b) Monthly number of deaths due to COVID-19 during the pandemic in Denmark. 


\section{Finland}

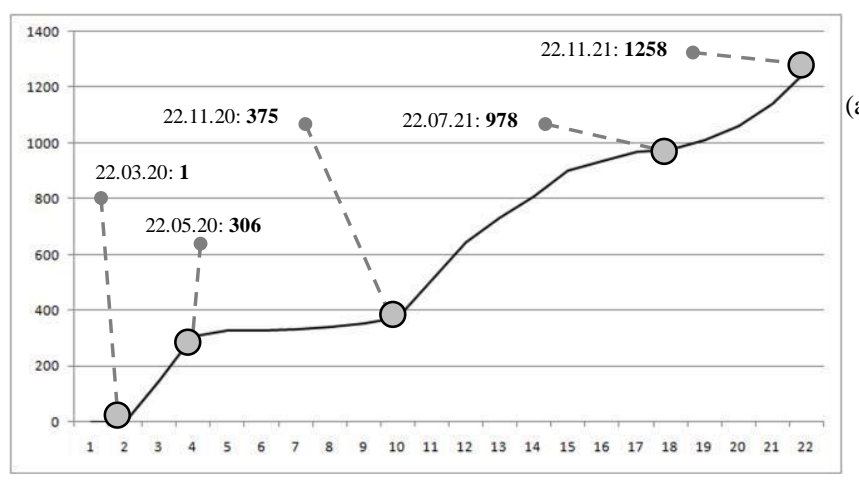

(a) (b)

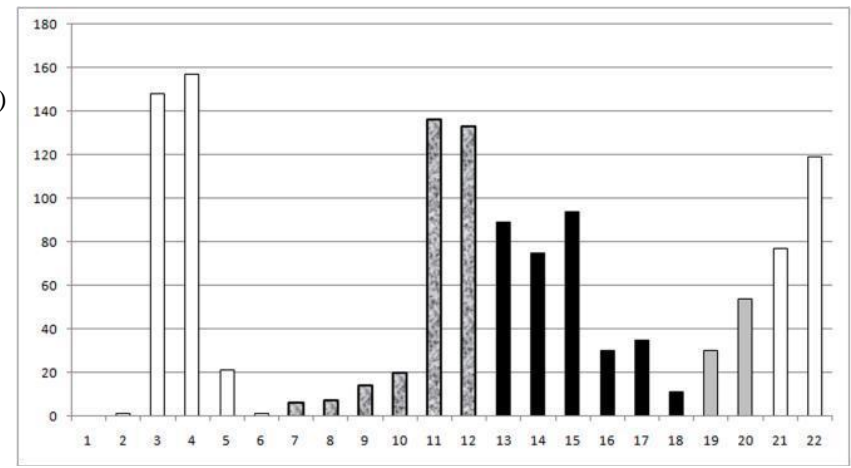

a) Dynamics of cumulative number of deaths in Finland a during 22 months of the COVID-19 pandemic

b) Monthly number of deaths due to COVID-19 during the pandemic in Finland.

\section{Germany}

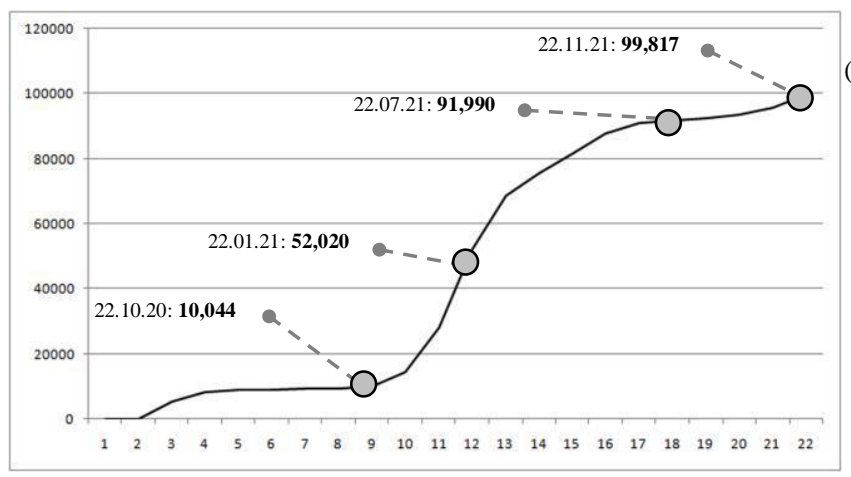

(a) (b)

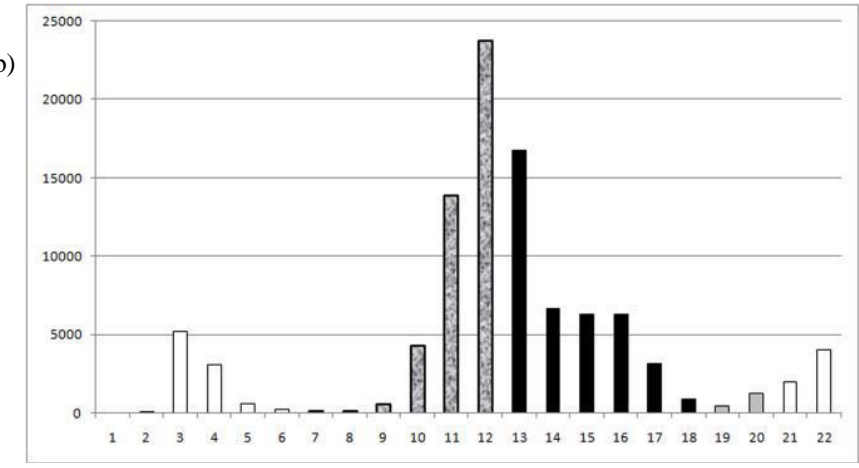

a) Dynamics of cumulative number of deaths in Germany during 22 months of the COVID-19 pandemic

b) Monthly number of deaths due to COVID-19 during the pandemic in Germany.

\section{Hungary}

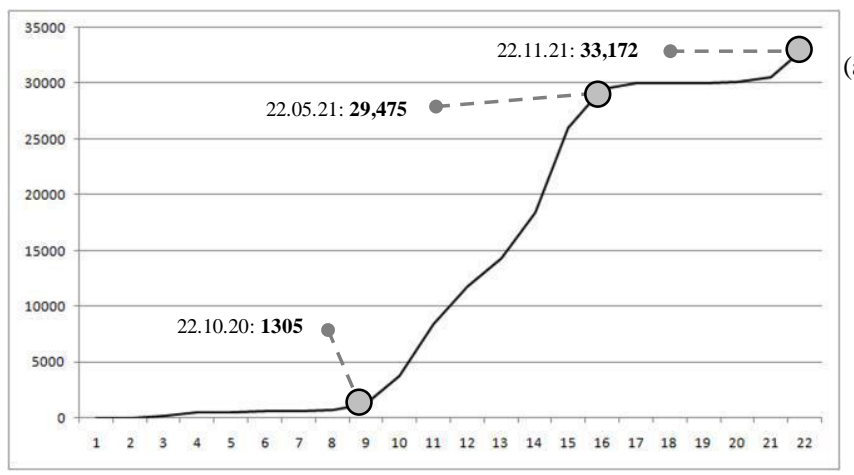

(a) (b)

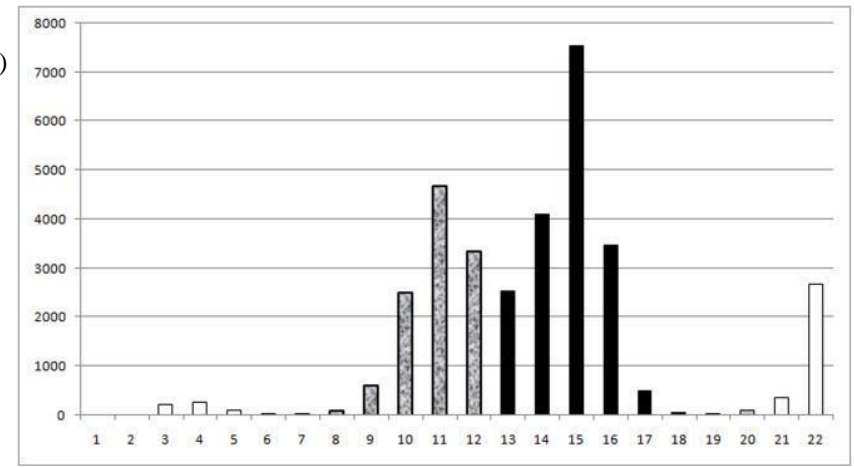

a) Dynamics of cumulative number of deaths in Hungary during 22 months of the COVID-19 pandemic

b) Monthly number of deaths due to COVID-19 during the pandemic in Hungary. 
India

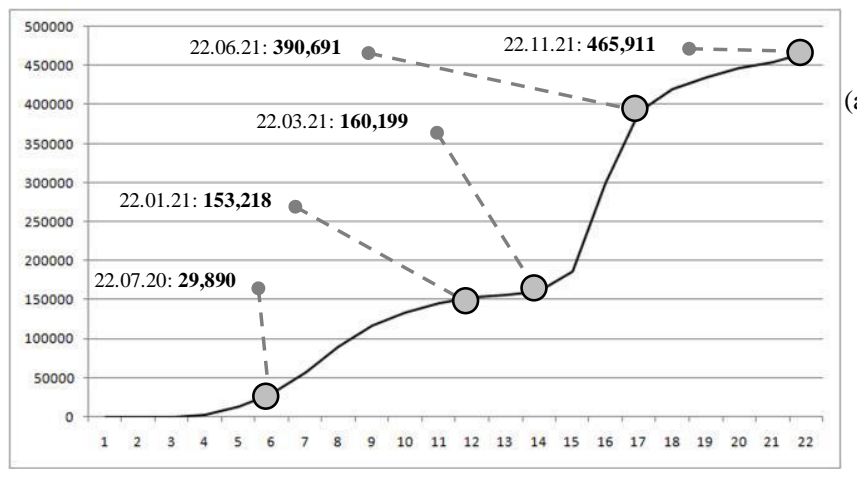

(a) (b)

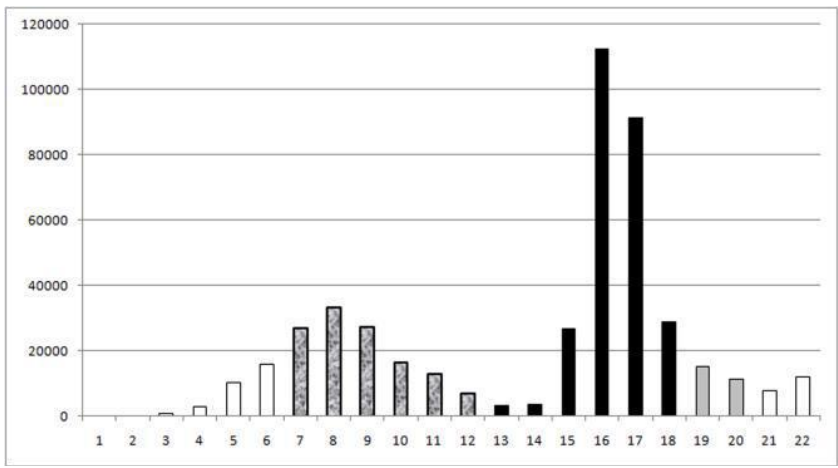

a) Dynamics of cumulative number of deaths in India during 22 months of the COVID-19 pandemic

b) Monthly number of deaths due to COVID-19 during the pandemic in India.

\section{Indonesia}

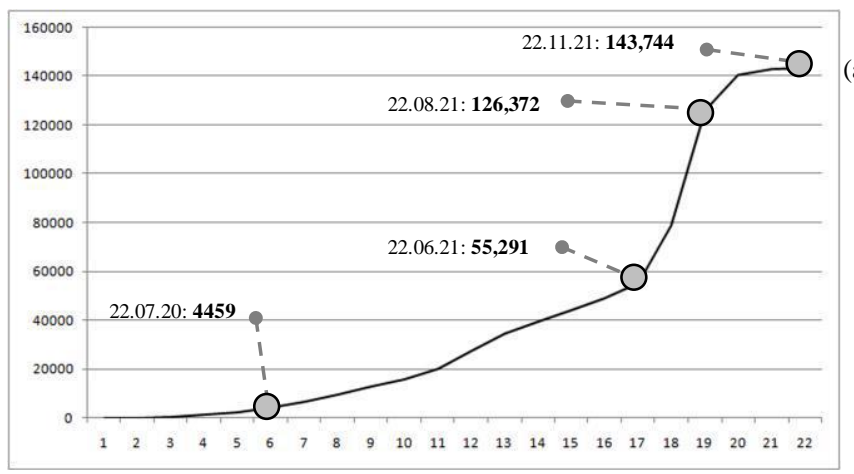

(a) (b)

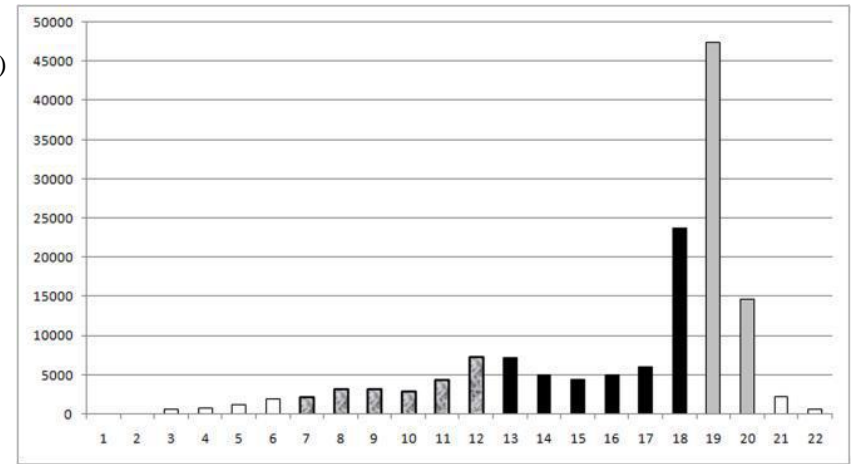

a) Dynamics of cumulative number of deaths in Indonesia during 22 months of the COVID-19 pandemic

b) Monthly number of deaths due to COVID-19 during the pandemic in Indonesia.

Israel

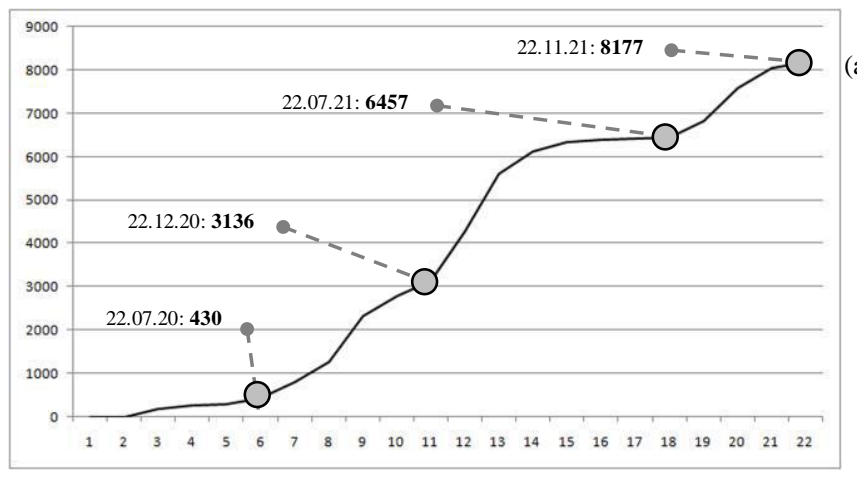

(a) (b)

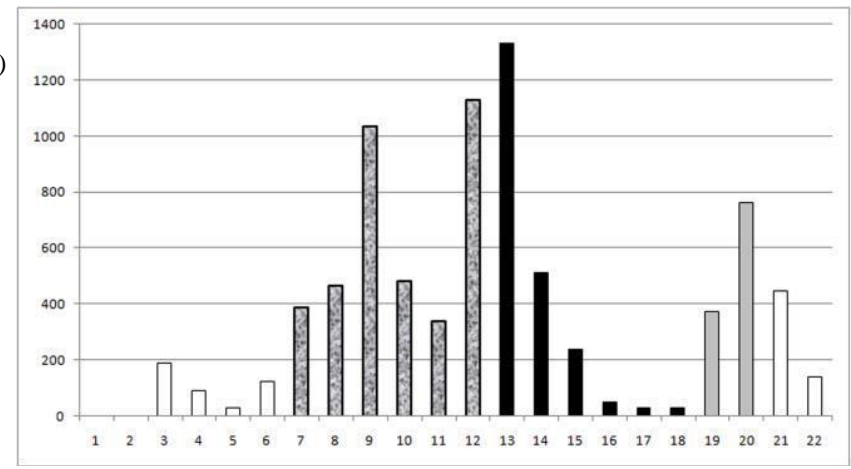

a) Dynamics of cumulative number of deaths in Israel during 22 months of the COVID-19 pandemic

b) Monthly number of deaths due to COVID-19 during the pandemic in Israel. 
Italy

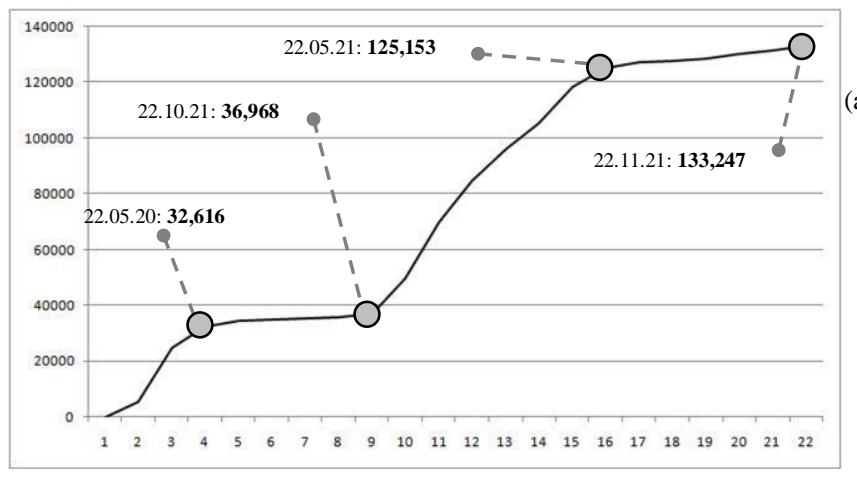

(a) (b)

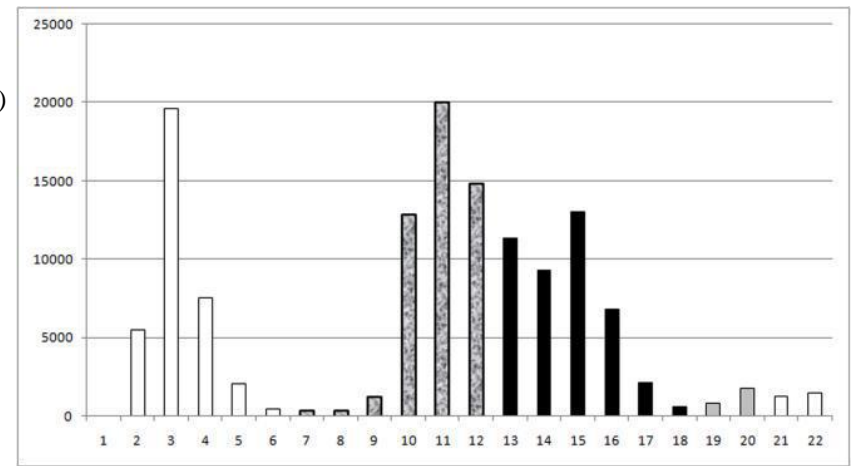

a) Dynamics of cumulative number of deaths in Italy during 22 months of the COVID-19 pandemic

b) Monthly number of deaths due to COVID-19 during the pandemic in Italy.

Japan

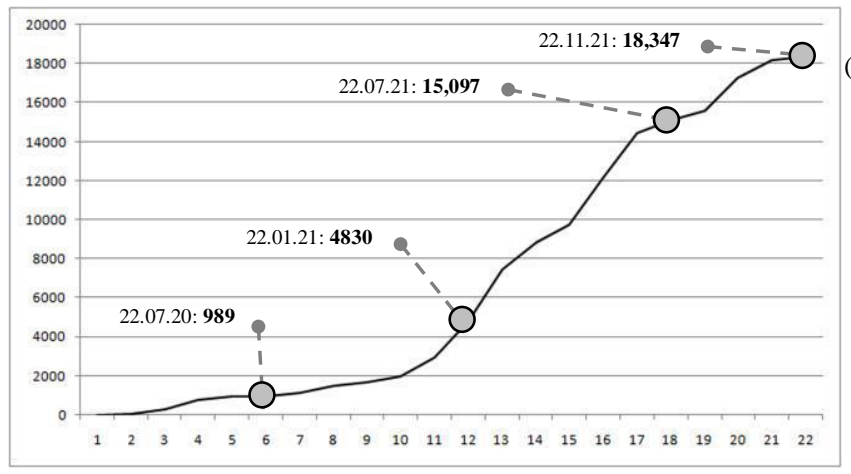

(a) (b)

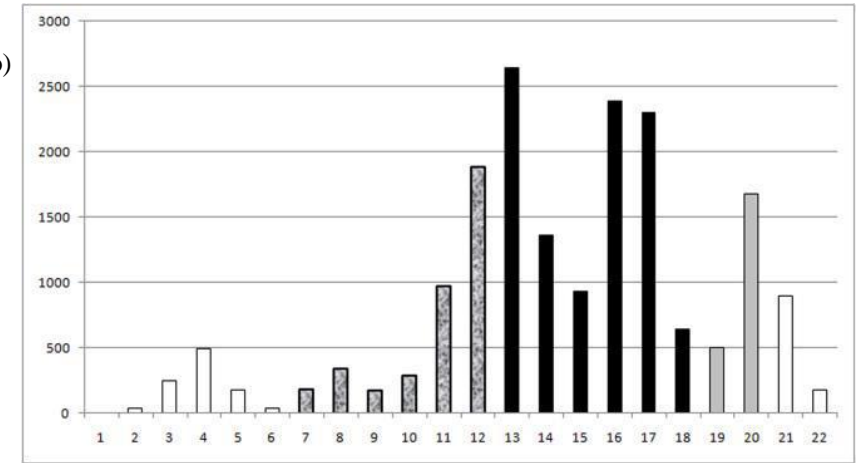

a) Dynamics of cumulative number of deaths in Japan during 22 months of the COVID-19 pandemic

b) Monthly number of deaths due to COVID-19 during the pandemic in Japan.

\section{Kazakhstan}

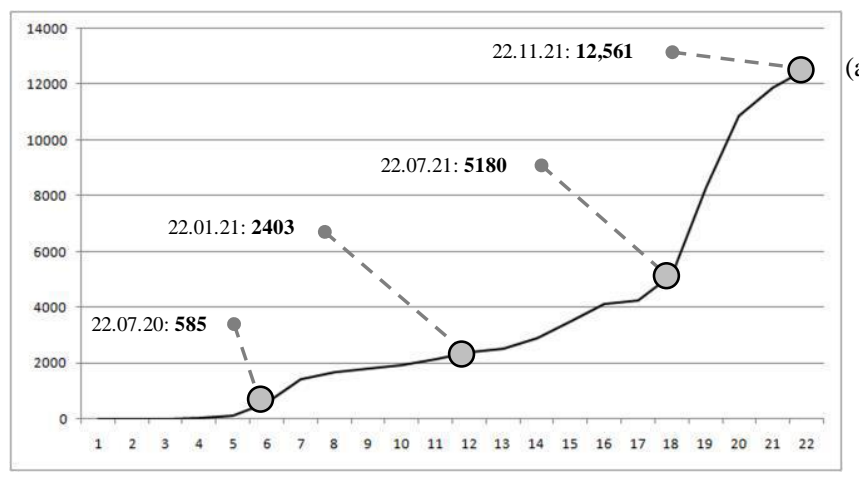

(a) (b)

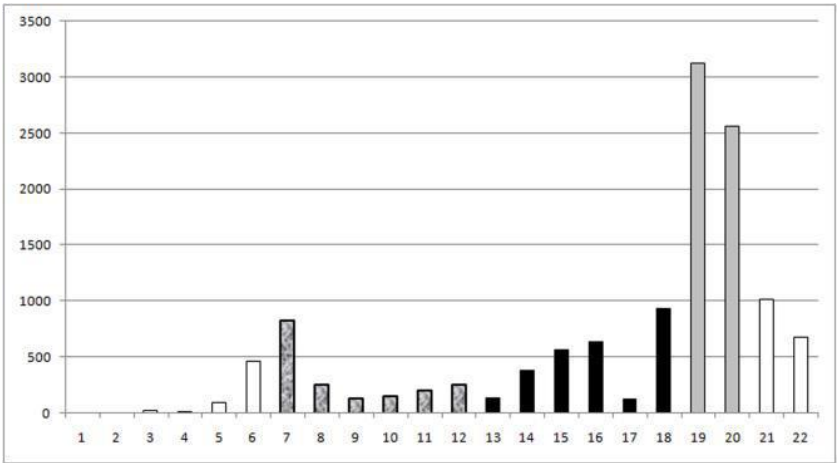

a) Dynamics of cumulative number of deaths in Kazakhstan during 22 months of the COVID-19 pandemic

b) Monthly number of deaths due to COVID-19 during the pandemic in Kazakhstan. 
Laos

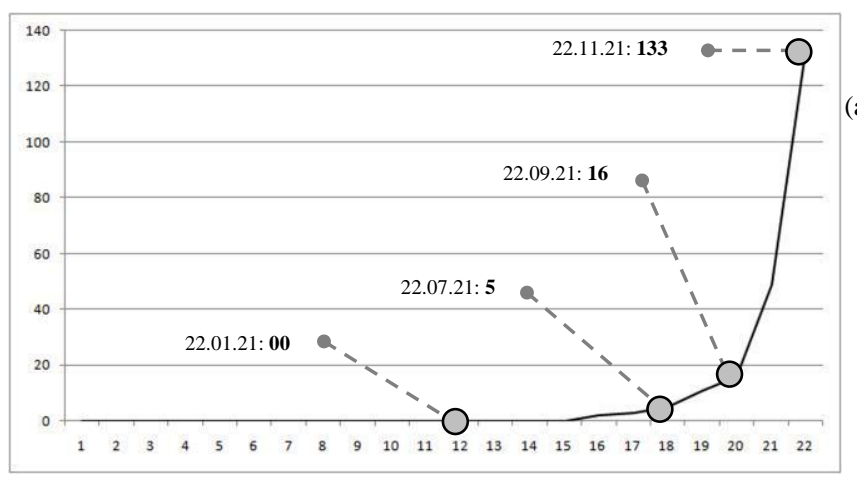

(a) (b)

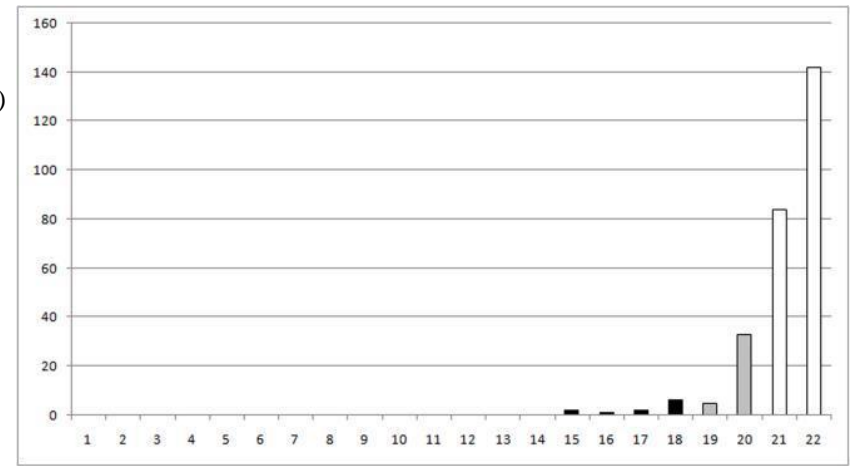

a) Dynamics of cumulative number of deaths in Laos during 22 months of the COVID-19 pandemic

b) Monthly number of deaths due to COVID-19 during the pandemic in Laos.

\section{Malaysia}

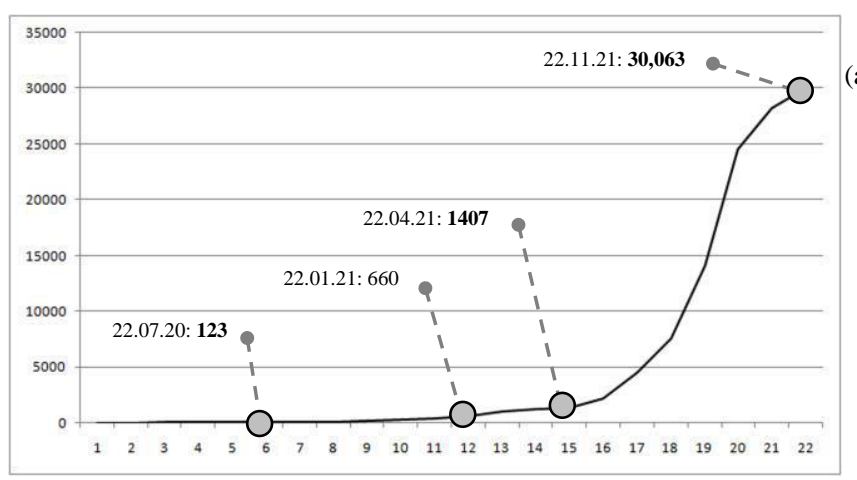

(a) (b)

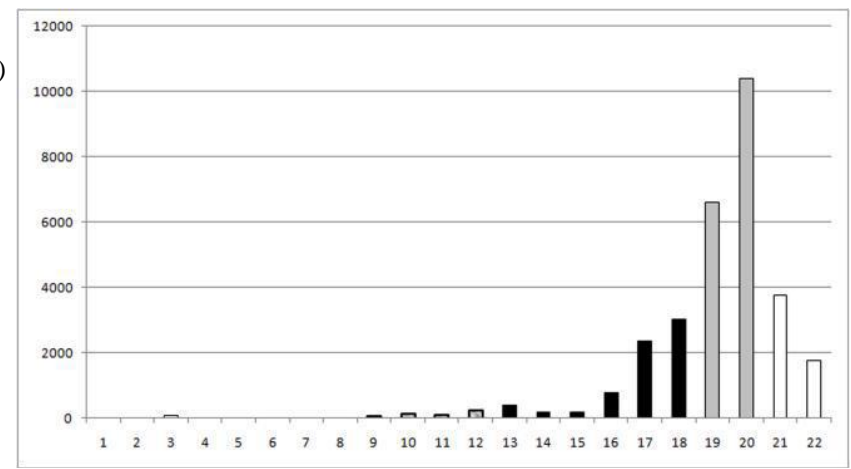

a) Dynamics of cumulative number of deaths in Malaysia during 22 months of the COVID-19 pandemic

b) Monthly number of deaths due to COVID-19 during the pandemic in Malaysia.

\section{Mongolia}

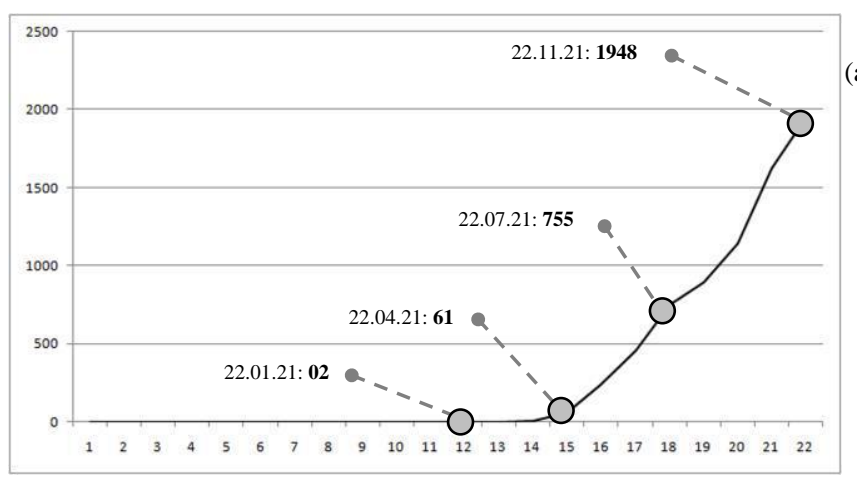

(a) (b)

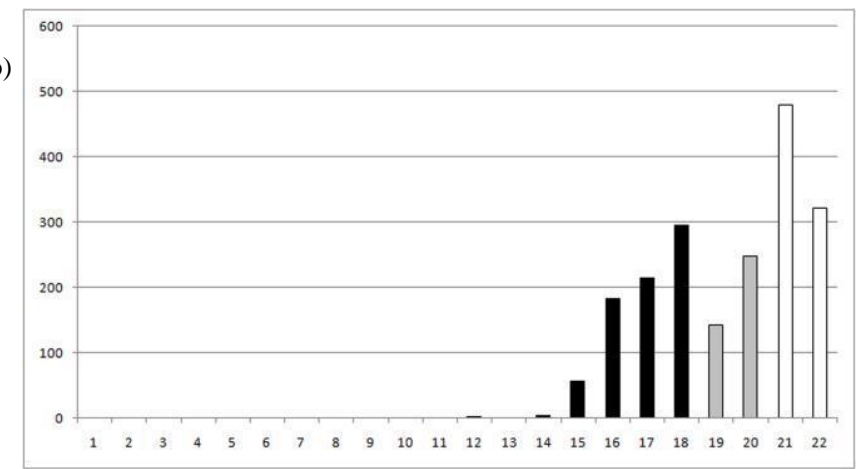

a) Dynamics of cumulative number of deaths in Mongolia during 22 months of the COVID-19 pandemic

b) Monthly number of deaths due to COVID-19 during the pandemic in Mongolia. 


\section{Morocco}

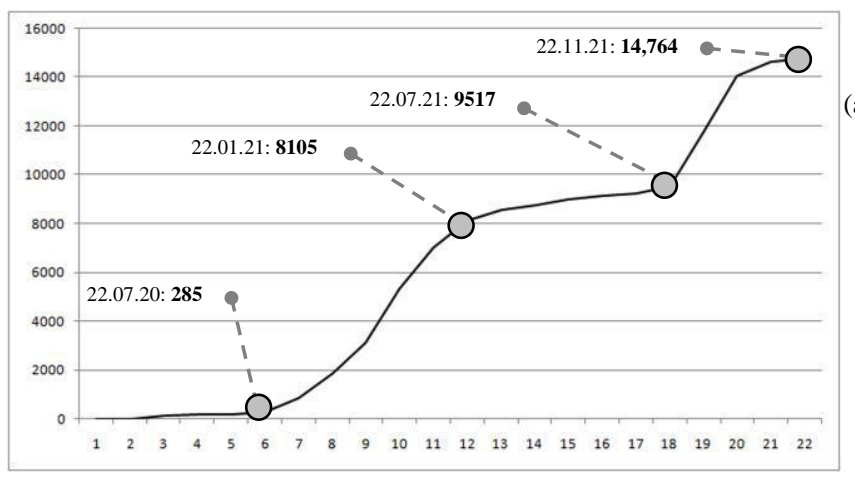

(a) (b)

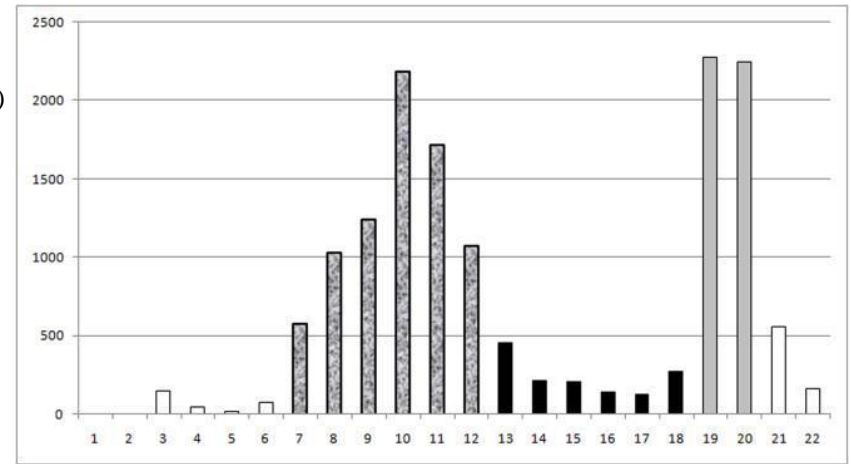

a) Dynamics of cumulative number of deaths in Morocco during 22 months of the COVID-19 pandemic

b) Monthly number of deaths due to COVID-19 during the pandemic in Morocco.

\section{Namibia}

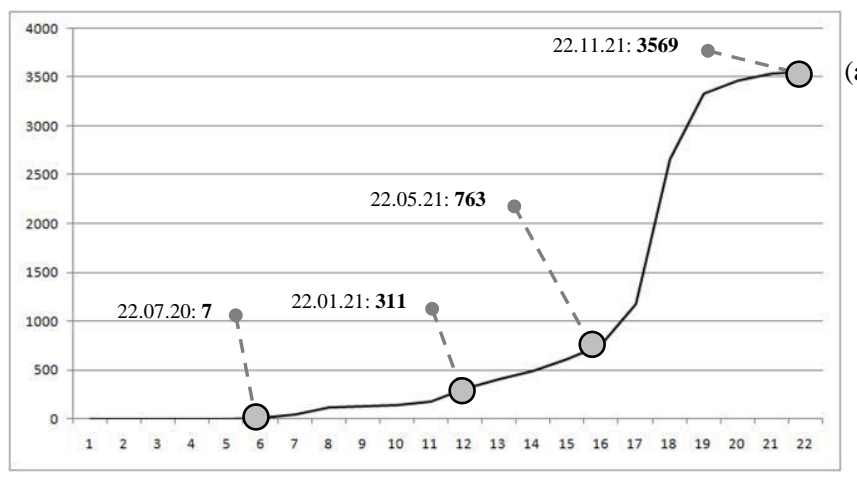

(a)

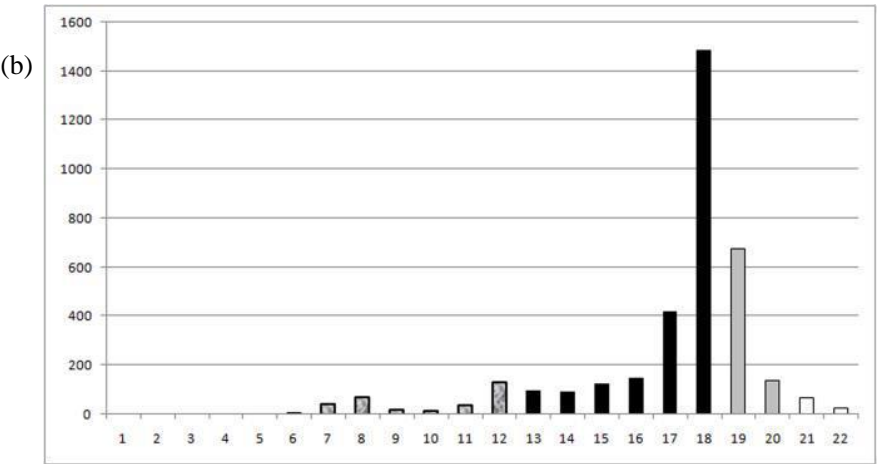

a) Dynamics of cumulative number of deaths in Namibia during 22 months of the COVID-19 pandemic

b) Monthly number of deaths due to COVID-19 during the pandemic in Namibia.

\section{Norway}

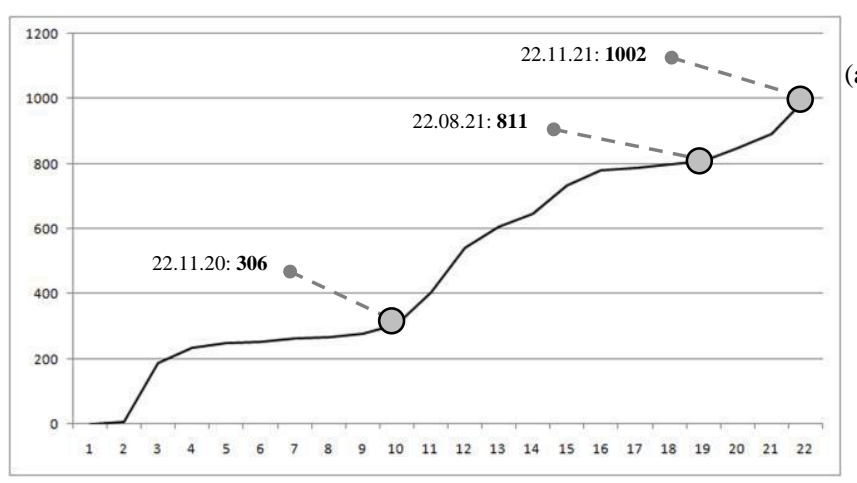

(a) (b)

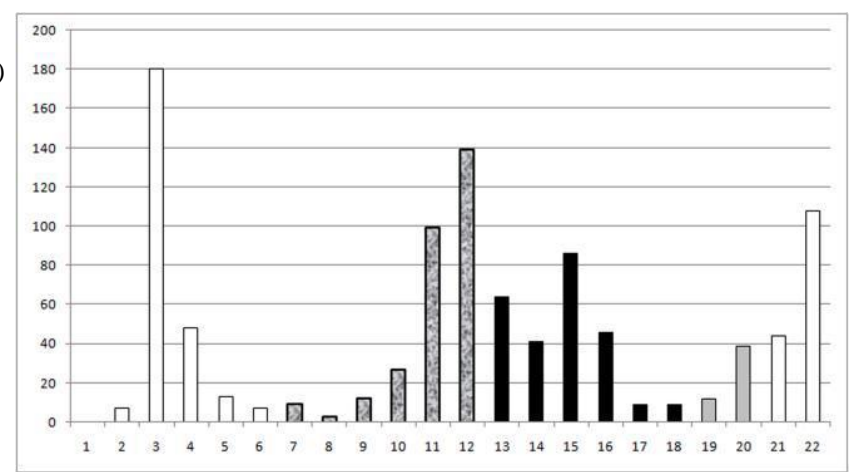

a) Dynamics of cumulative number of deaths in Norway during 22 months of the COVID-19 pandemic

b) Monthly number of deaths due to COVID-19 during the pandemic in Norway. 


\section{Paraguay}

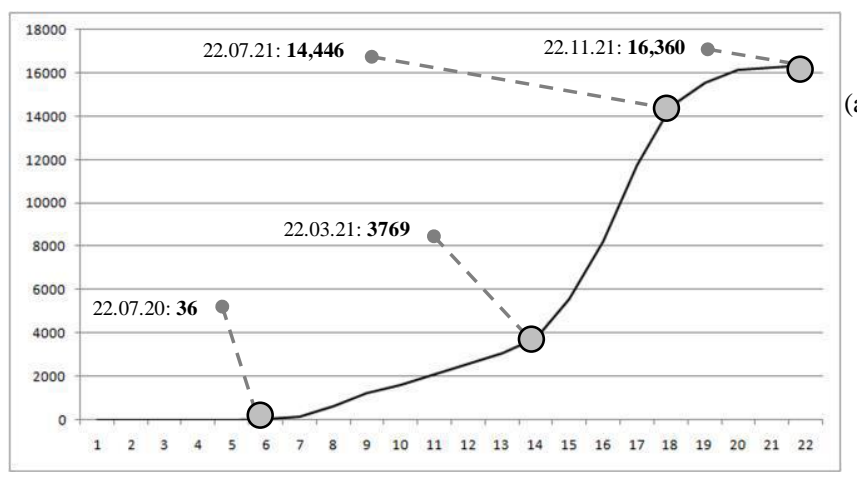

(a) (b)

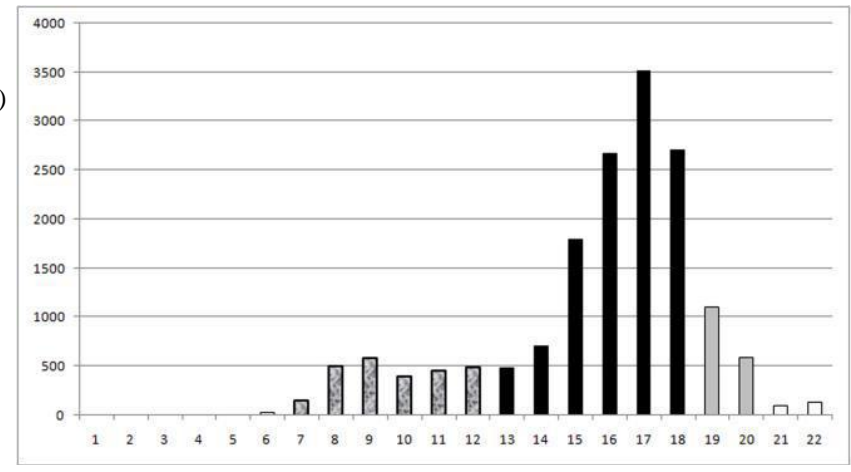

a) Dynamics of cumulative number of deaths in Paraguay during 22 months of the COVID-19 pandemic

b) Monthly number of deaths due to COVID-19 during the pandemic in Paraguay.

\section{Russia}

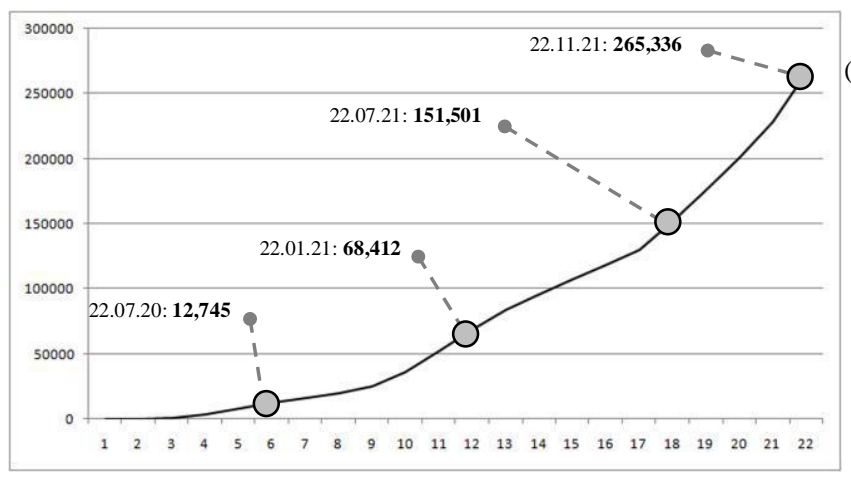

(a) (b)

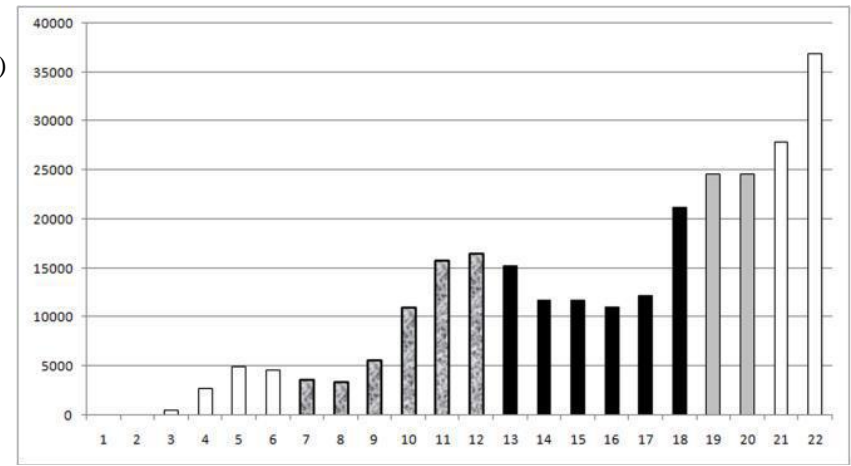

a) Dynamics of cumulative number of deaths in Russia during 22 months of the COVID-19 pandemic

b) Monthly number of deaths due to COVID-19 during the pandemic in Russia.

\section{Poland}

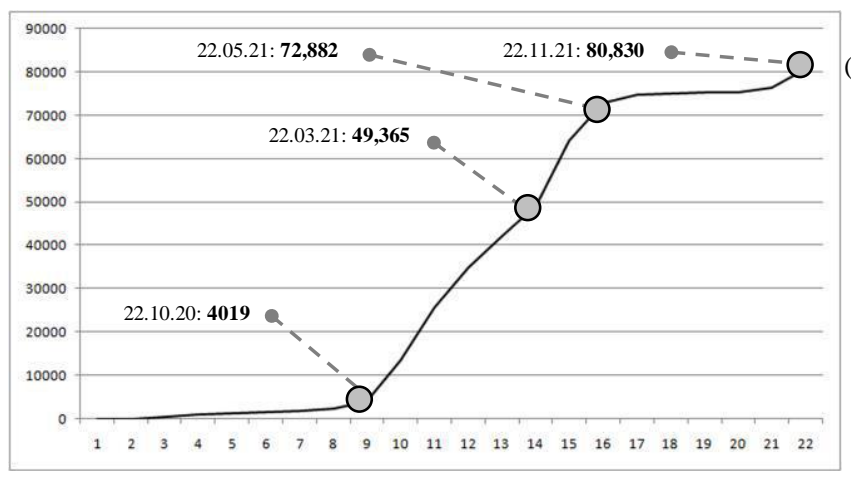

(a) (b)

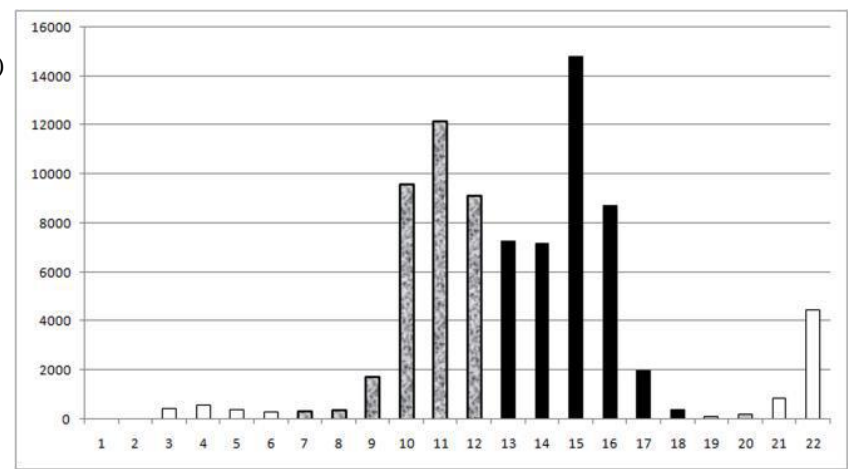

a) Dynamics of cumulative number of deaths in Poland during 22 months of the COVID-19 pandemic b) Monthly number of deaths due to COVID-19 during the pandemic in Poland. 
The Seychelles

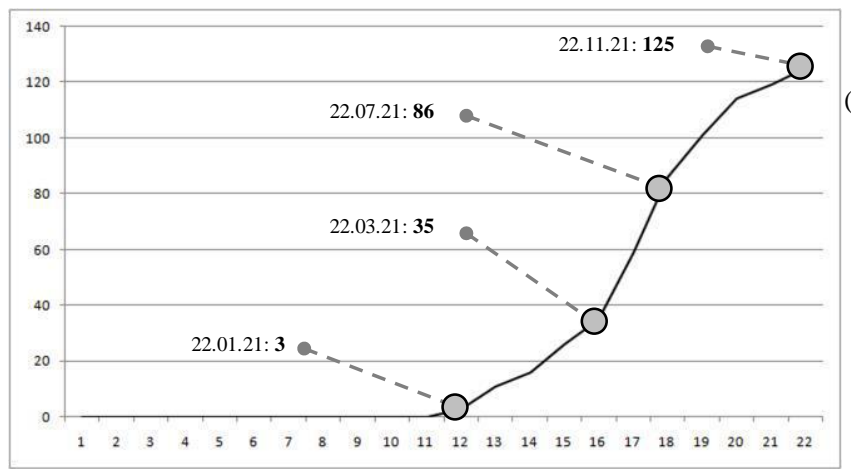

(a) (b)

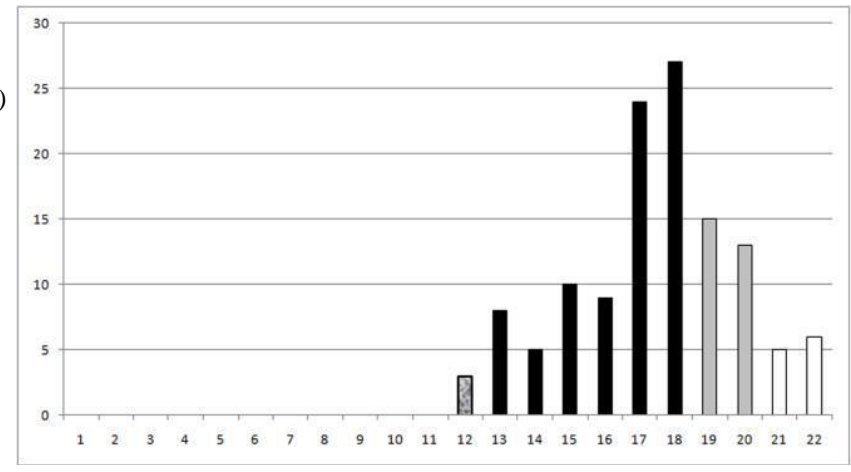

a) Dynamics of cumulative number of deaths in The Seychelles during 22 months of the COVID-19 pandemic

b) Monthly number of deaths due to COVID-19 during the pandemic in The Seychelles.

\section{Singapore}

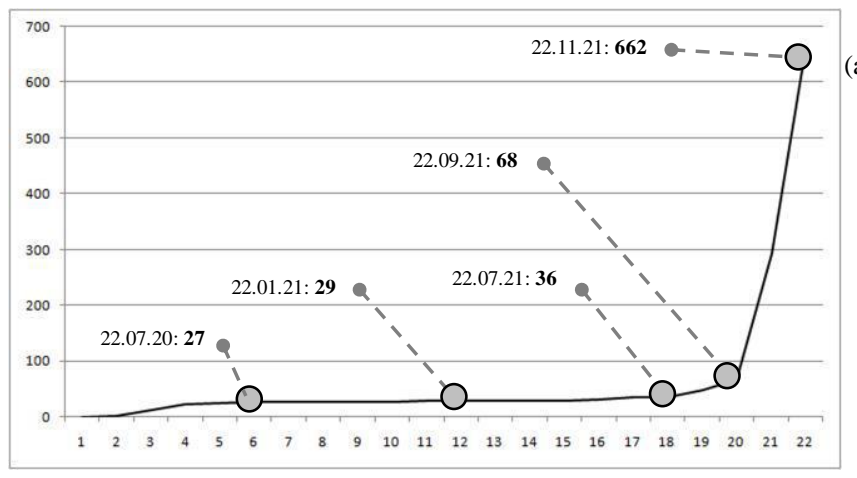

(a) (b)

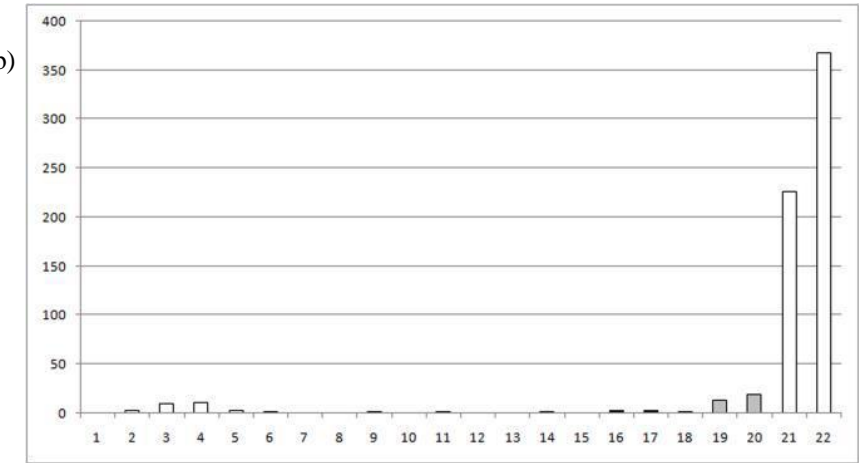

a) Dynamics of cumulative number of deaths in Singapore during 22 months of the COVID-19 pandemic

b) Monthly number of deaths due to COVID-19 during the pandemic in Singapore.

\section{South Korea}

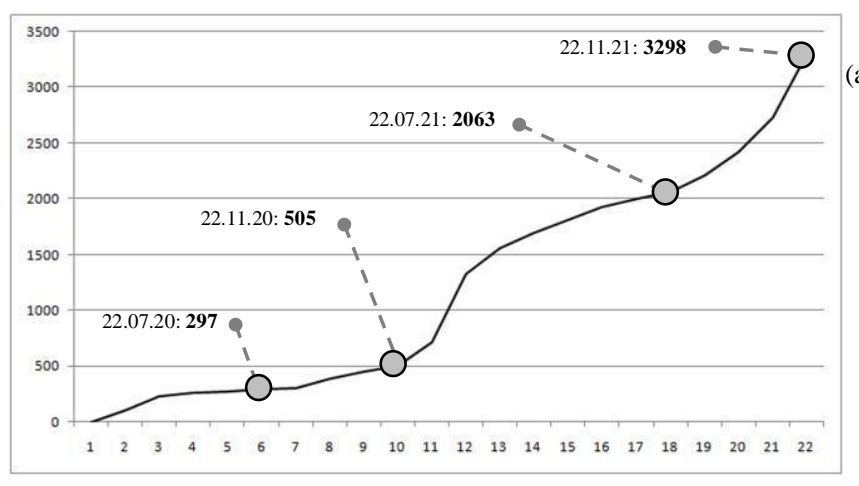

(a) (b)

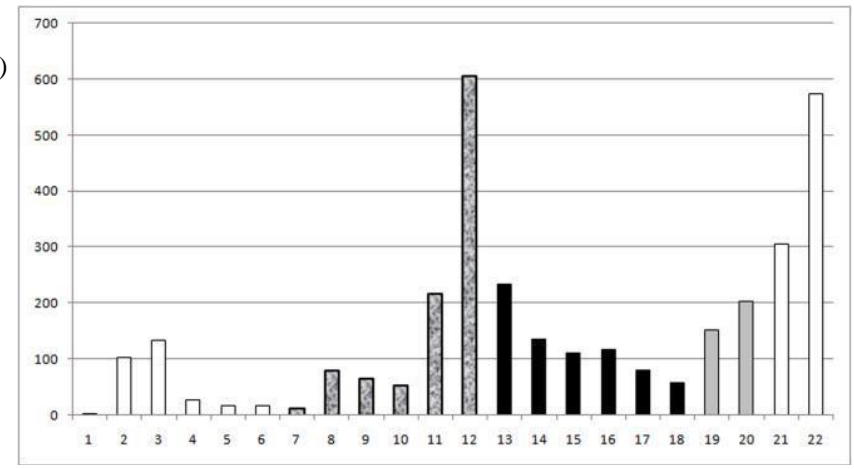

a) Dynamics of cumulative number of deaths in S. Korea during 22 months of the COVID-19 pandemic b) Monthly number of deaths due to COVID-19 during the pandemic in S. Korea. 


\section{Spain}

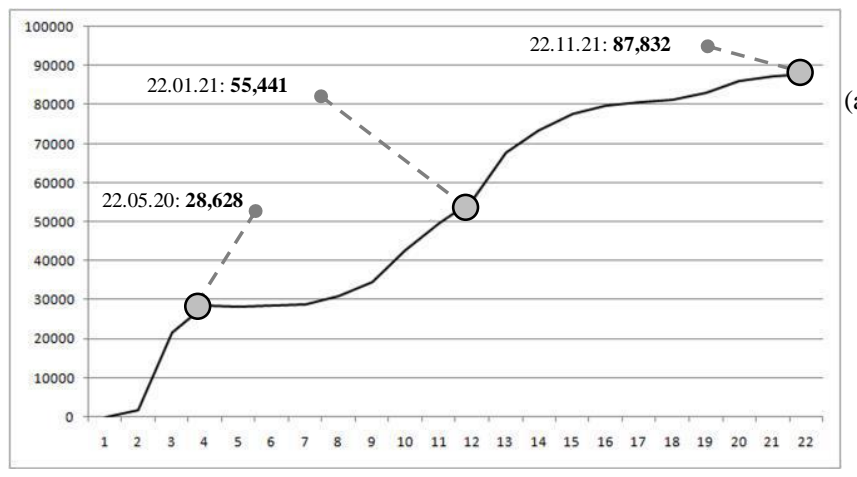

(a) (b)

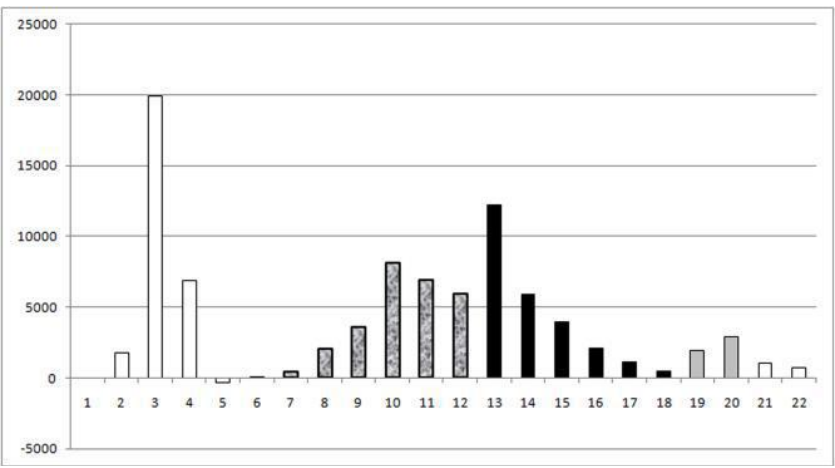

a) Dynamics of cumulative number of deaths in Spain during 22 months of the COVID-19 pandemic

b) Monthly number of deaths due to COVID-19 during the pandemic in Spain.

\section{Sri Lanka}

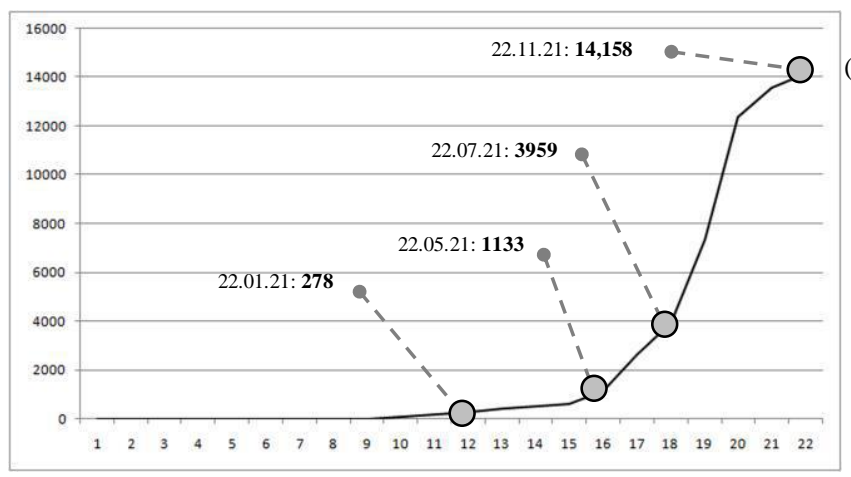

(a) (b)

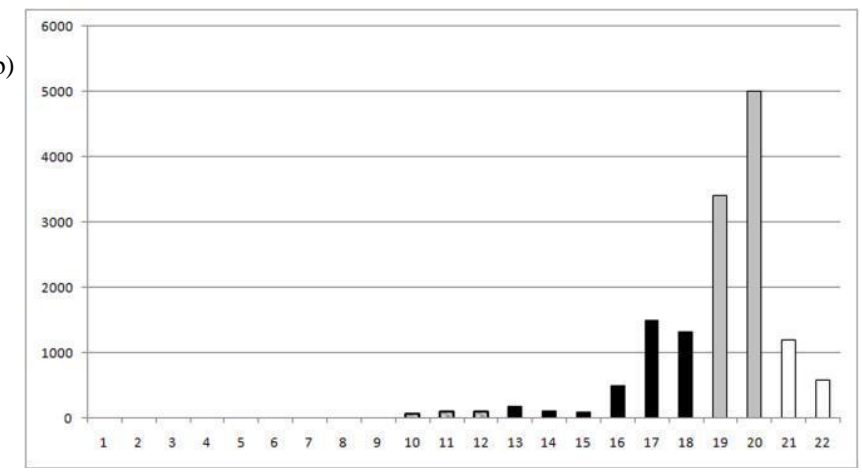

a) Dynamics of cumulative number of deaths in Sri Lanka during 22 months of the COVID-19 pandemic

b) Monthly number of deaths due to COVID-19 during the pandemic in Sri Lanka.

\section{Sweden}

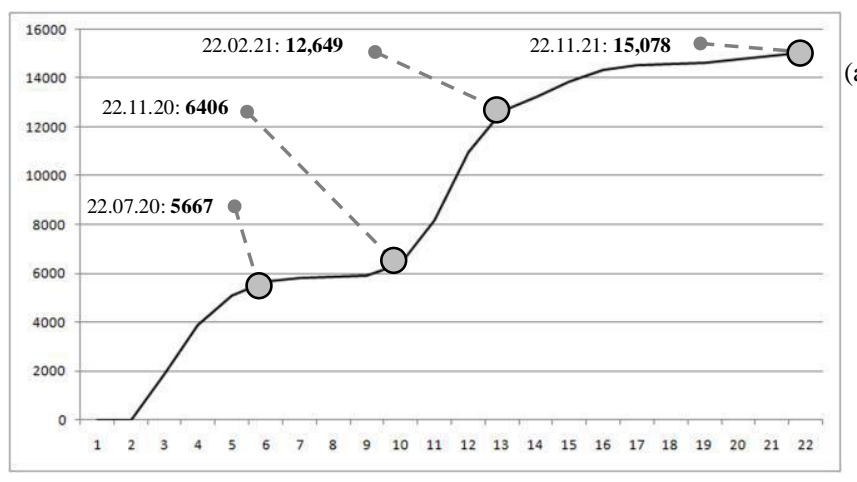

(a) (b)

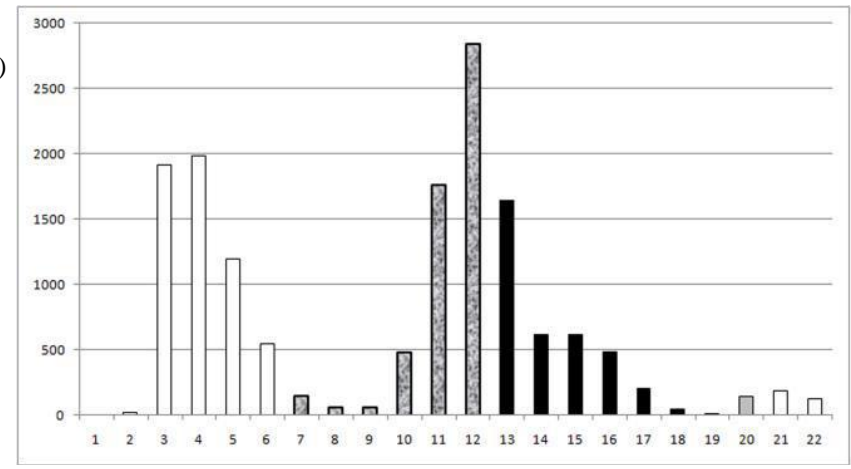

a) Dynamics of cumulative number of deaths in Sweden during 22 months of the COVID-19 pandemic b) Monthly number of deaths due to COVID-19 during the pandemic in Sweden. 


\section{Taiwan}

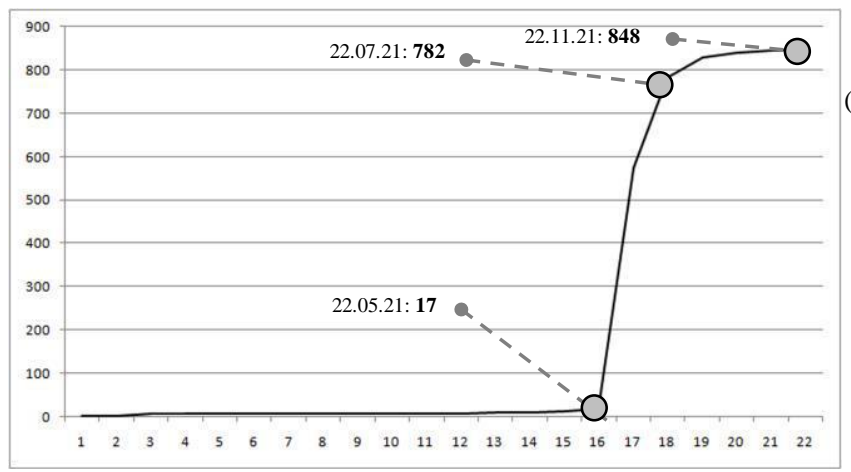

(a) (b)

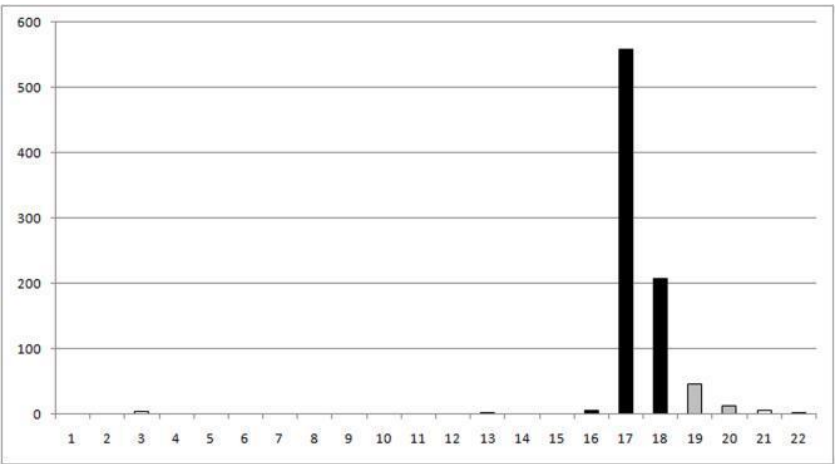

a) Dynamics of cumulative number of deaths in Taiwan during 22 months of the COVID-19 pandemic

b) Monthly number of deaths due to COVID-19 during the pandemic in Taiwan.

\section{Tanzania}

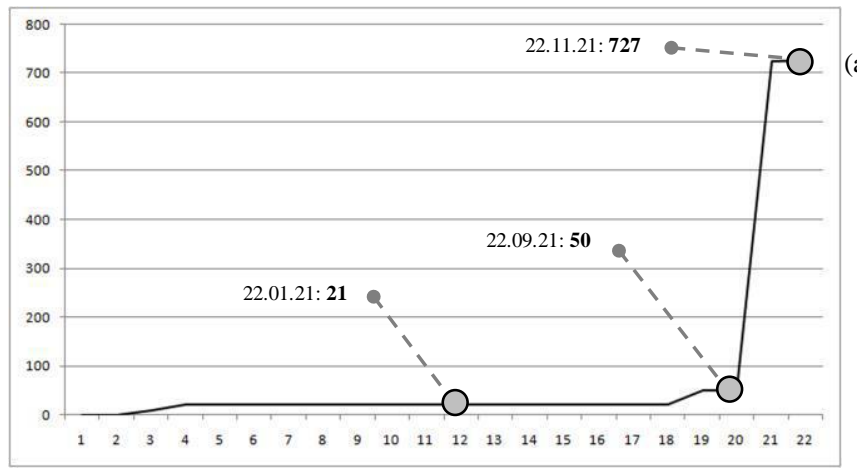

(a) (b)

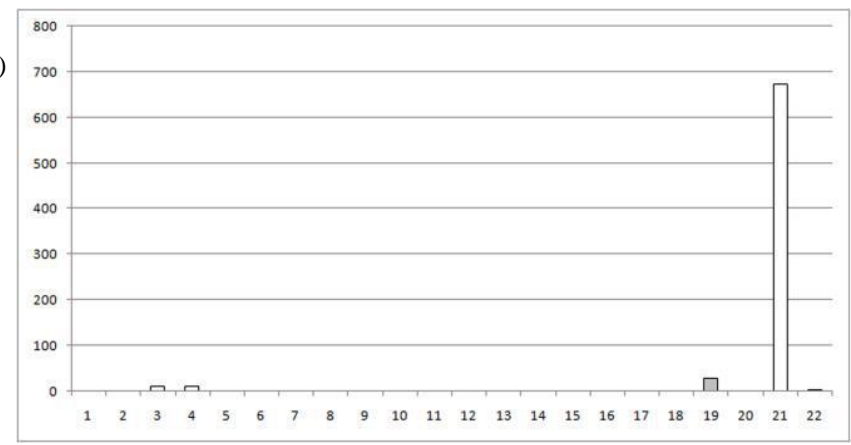

a) Dynamics of cumulative number of deaths in Tanzania during 22 months of the COVID-19 pandemic

b) Monthly number of deaths due to COVID-19 during the pandemic in Tanzania.

\section{Thailand}

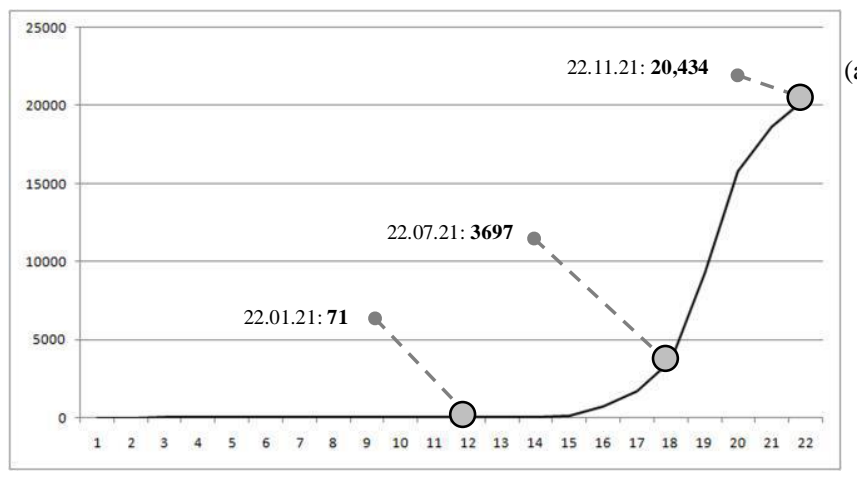

(a)

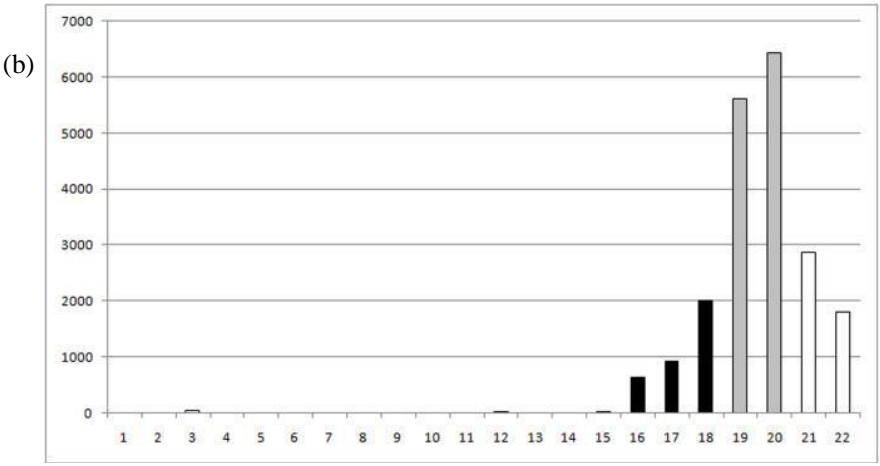

a) Dynamics of cumulative number of deaths in Thailand during 22 months of the COVID-19 pandemic b) Monthly number of deaths due to COVID-19 during the pandemic in Thailand. 


\section{Ukraine}

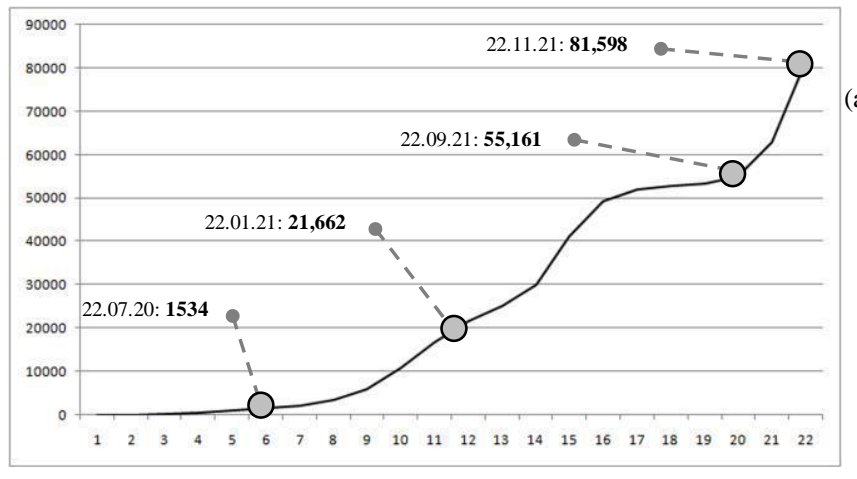

(a) (b)

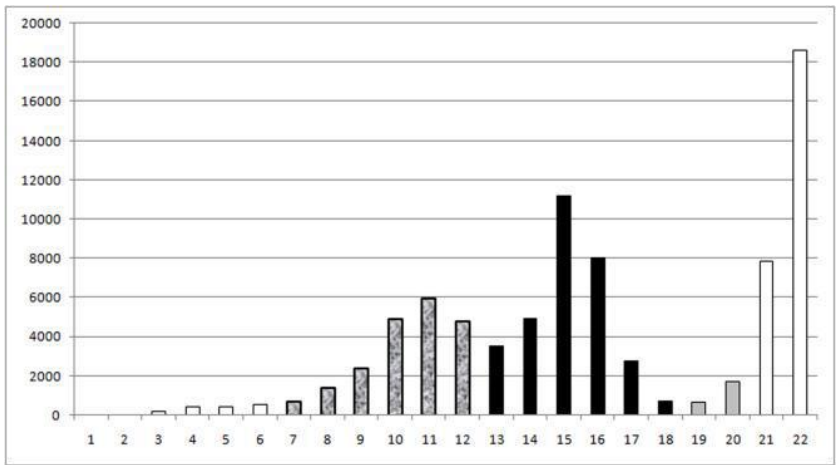

a) Dynamics of cumulative number of deaths in Ukraine during 22 months of the COVID-19 pandemic

b) Monthly number of deaths due to COVID-19 during the pandemic in Ukraine.

\section{The United Kingdom}

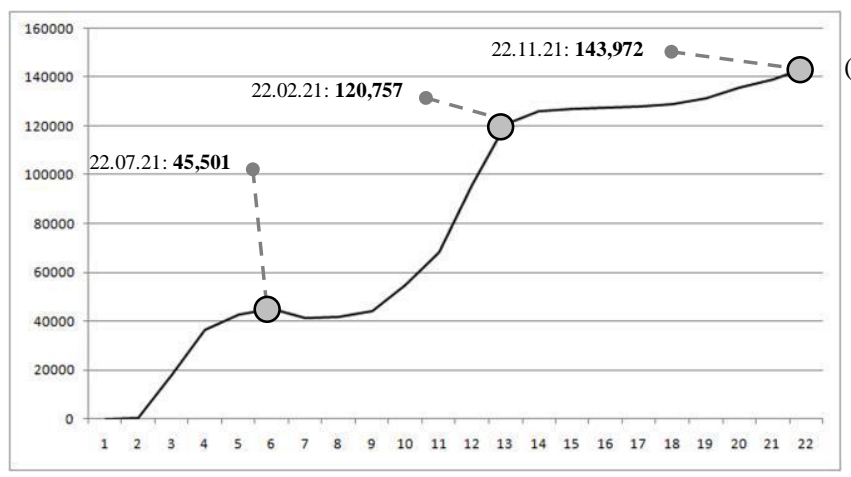

(a) (b)

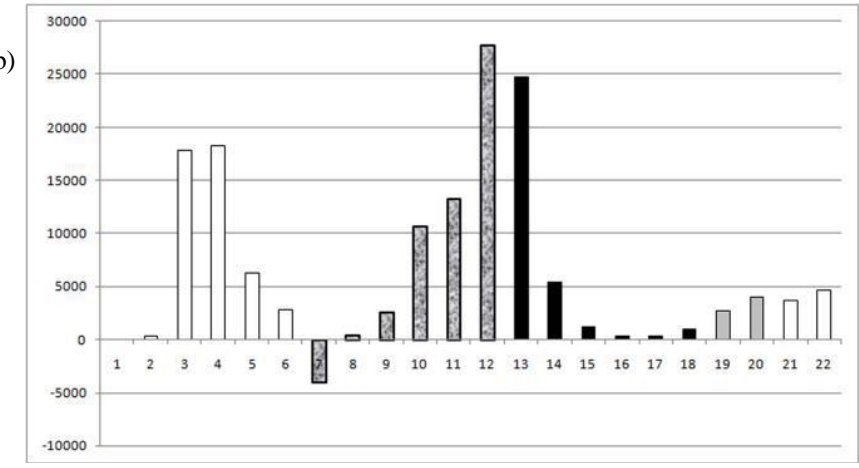

a) Dynamics of cumulative number of deaths in The United Kingdom during 22 months of the COVID-19 pandemic

b) Monthly number of deaths due to COVID-19 during the pandemic in The United Kingdom.

\section{The United States}

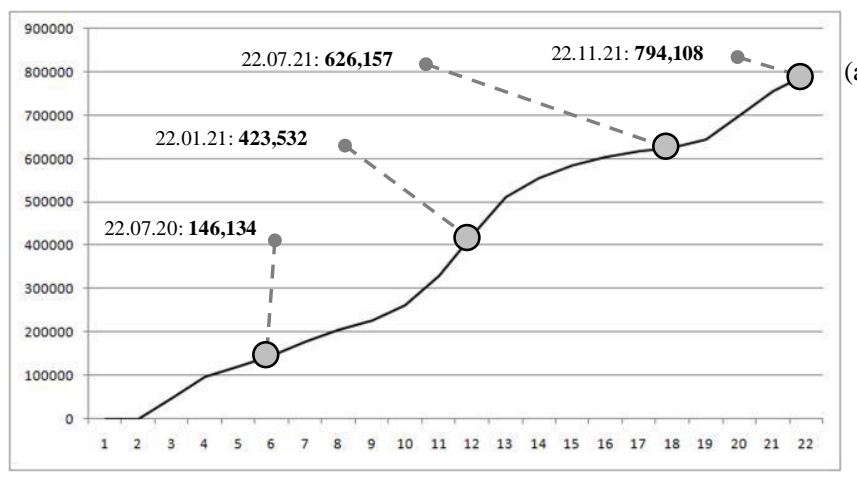

(a) (b)

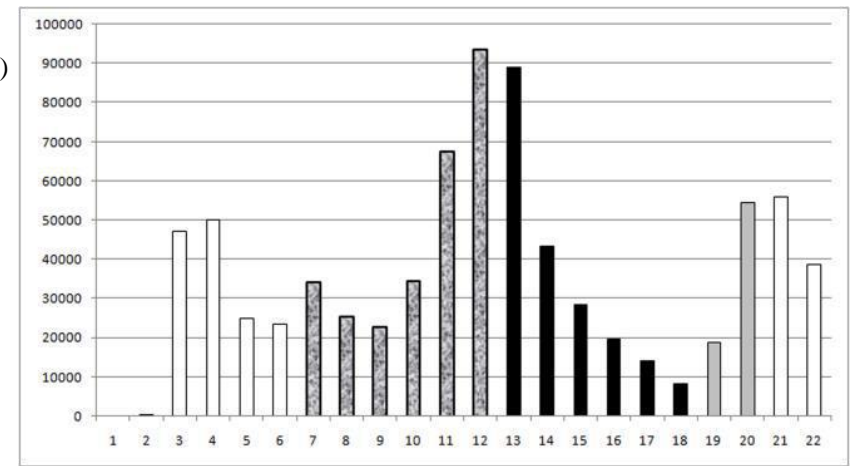

a) Dynamics of cumulative number of deaths in The United States during 22 months of the COVID-19 pandemic b) Monthly number of deaths due to COVID-19 during the pandemic in The United States. 


\section{Uruguay}

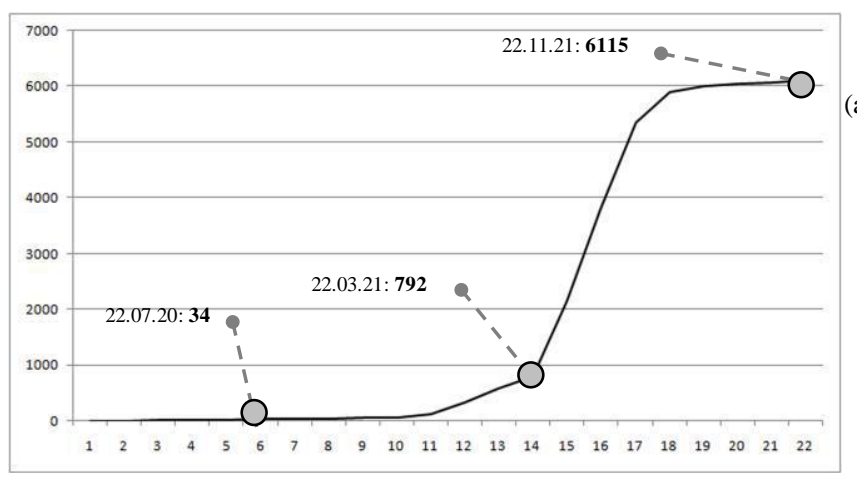

(a) (b)

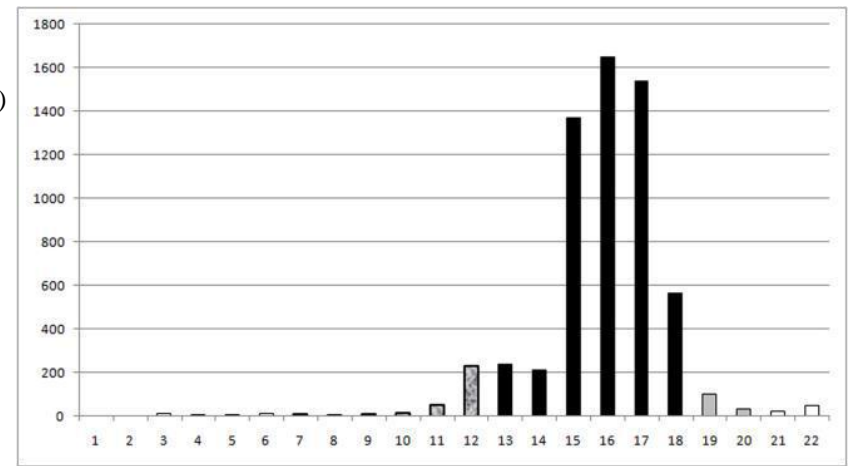

a) Dynamics of cumulative number of deaths in Uruguay during 22 months of the COVID-19 pandemic

b) Monthly number of deaths due to COVID-19 during the pandemic in Uruguay.

\section{Vietnam}

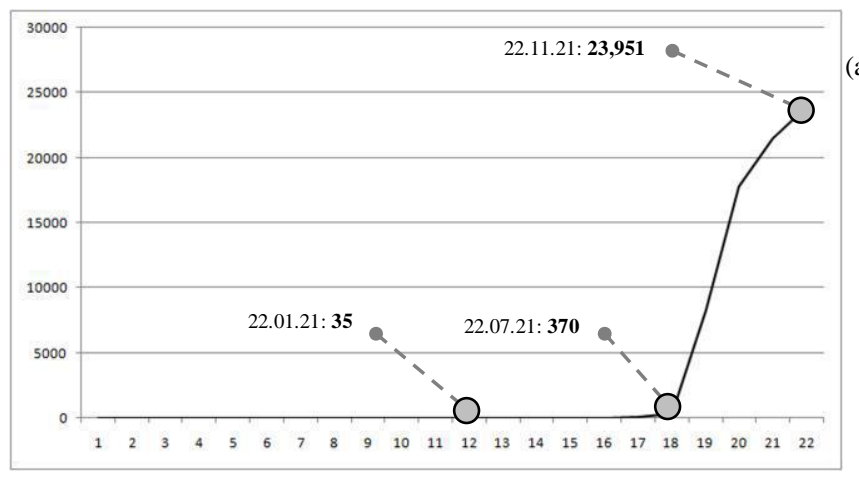

(a) (b)

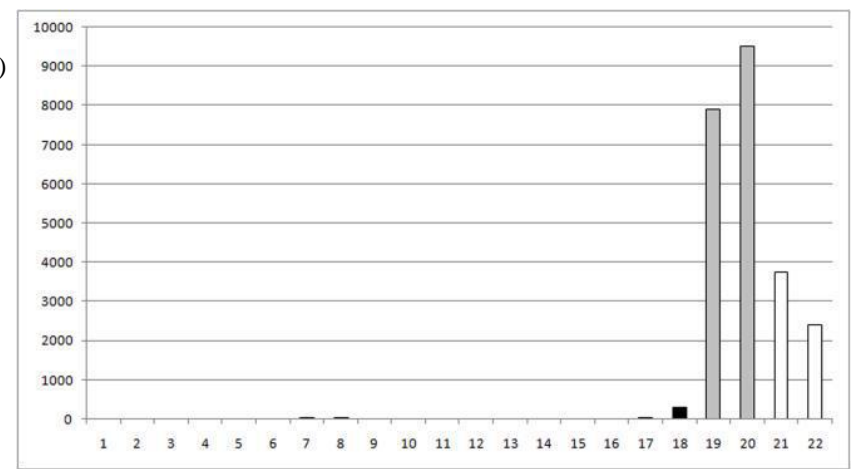

a) Dynamics of cumulative number of deaths in Vietnam during 22 months of the COVID-19 pandemic

b) Monthly number of deaths due to COVID-19 during the pandemic in Vietnam.

\section{Zimbabwe}

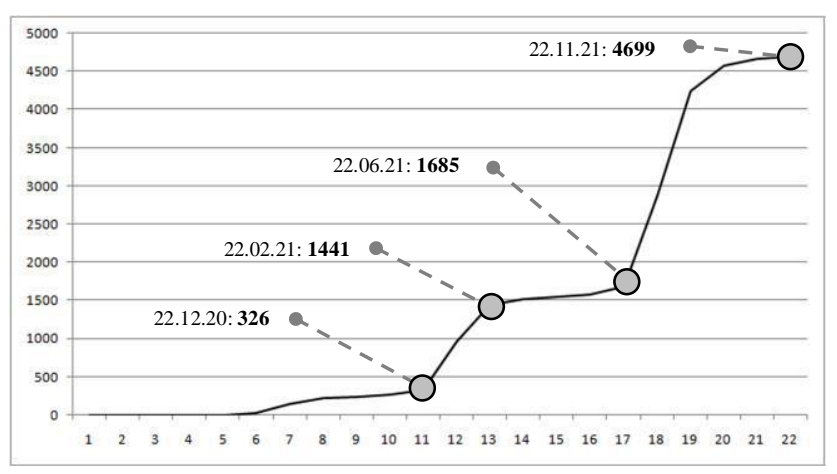

(a)

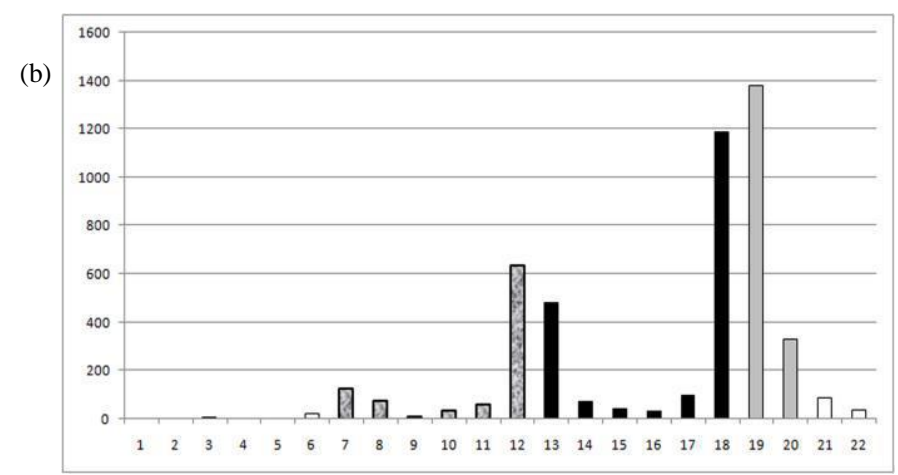

a) Dynamics of cumulative number of deaths in Zimbabwe during 22 months of the COVID-19 pandemic

b) Monthly number of deaths due to COVID-19 during the pandemic in Zimbabwe. 